\title{
Taxonomic utility of Early Cretaceous Australian plesiosaurian vertebrae
}

\author{
Vikram Vakil, Gregory Webb, and Alex Cook
}

\begin{abstract}
Despite their broad occurrence in Australian basins, lower-level taxonomy of Australian Early Cretaceous plesiosaurs is hindered by the scarcity of skulls and other diagnostic elements. This paper presents a morphological and morphometric analysis of the vertebrae of Australian plesiosaurs and a comparison with selected non-Australian elasmosaurids (basal elasmosaurs, styxosaurines, aristonectines). Biometric analysis involved measurements that include centrum height $(\mathrm{CH})$, centrum width $(\mathrm{CW})$, centrum length $(\mathrm{CL})$, width of zygapophyses, and others. Principal component analysis (PCA) and multivariate analysis of variance (MANOVA) were carried out on $\mathrm{CH}, \mathrm{CW}$, and CL. Morphometric ratios [Vertebral Length Index (VLI), Height Index $(\mathrm{HI})$, and Breadth Index $(\mathrm{BI})$ ] were plotted along the length of the vertebral column and on bivariate graphs where the analysis is independent of vertebral position and correct sequencing. Direct comparison of homologous groups of vertebrae (especially anterior cervicals) easily distinguished an Australian polycotylid from all elasmosaurids in all plots. Most Australian elasmosaurid specimens plotted near basal 'Cimoliasaurus'grade elasmosaurs, where they clustered as a group relatively distinct from, but overlapping coeval non-Australian forms. However, one specimen plotted consistently with the non-Australian styxosaurines and Opallionectes andamookaensis plotted with the aristonectines. Although it is not possible to distinguish phylogenetic relationships from morphological convergence in the plotted positions, the analyses provide potential hypotheses to be tested with additional data. Hence, vertebrae have some taxonomic value for potential assignment of Australian plesiosaurs, even in the absence of skulls or other diagnostic material.
\end{abstract}

Vikram Vakil. School of Earth and Environmental Sciences, University of Queensland, Brisbane St. Lucia, QLD 4072 Australia. vikram.vakil@uqconnect.edu.au

Prof. Gregory Webb. School of Earth and Environmental Sciences, University of Queensland, Brisbane St. Lucia, QLD 4072 Australia. g.webb@uq.edu.au

Dr. Alex Cook. School of Earth and Environmental Sciences, University of Queensland, Brisbane St. Lucia, QLD 4072 Australia. alex.cook@y7mail.com

Keywords: Plesiosaurs; Australian; Early Cretaceous; vertebrae; morphometrics; taphonomy

Vakil, Vikram, Webb, Gregory, and Cook, Alex. 2021. Taxonomic utility of Early Cretaceous Australian plesiosaurian vertebrae. Palaeontologia Electronica, 24(3):a30. https://doi.org/10.26879/1095

palaeo-electronica.org/content/2021/3471-plesiosaur-vertebrae 


\section{INTRODUCTION}

Plesiosaurs as a distinct type of extinct marine reptiles were first recognized by De la Beche and Conybeare (1821) with the description of Plesiosaurus from the English Lias (Late Triassic-Early Jurassic) (see also Conybeare, 1822; O'Keefe, 2001a). Plesiosaurs evolved from Triassic sauropterygians (Rieppel, 1997; Rieppel, 2000; O'Keefe, 2001a) near the Triassic-Jurassic boundary (Rhaetian, Upper Triassic; Taylor and Cruickshank, 1993; Storrs, 1993, 1999, Wintrich et al., 2017a,b), and diversified through the Jurassic and Cretaceous before going extinct at the end of the Mesozoic Era (Romer, 1966; O'Keefe, 2001a, 2001b, 2002; Gasparini et al., 2003; O'Gorman et al., 2019a, b). Historically, the term 'plesiosaur' was commonly used only to refer to plesiosauromorphs (long-necked, small-headed forms) as opposed to 'pliosaurs' (pliosauromorphs: short-necked, large headed forms). However, this traditional taxonomic distinction has been challenged by recent phylogenetic analyses, which indicate multiple origins of longand short-necked morphs across Plesiosauria (Carpenter, 1997; O'Keefe, 2000, 2001a; Benson and Druckenmiller, 2014; Fischer et al., 2018, 2020). The most species-rich clade of Cretaceous plesiosaurs, Xenopsaria, includes both primarily long- (Elasmosauridae) and short-necked (Leptocleididae, Polycotylidae) families (Benson and Druckenmiller, 2014).

Plesiosaurs were cosmopolitan in distribution (Ketchum and Benson, 2010), with specimens known from every continent including Antarctica (Wiffen and Moisely, 1986; Chatterjee and Small, 1989; Cruickshank, 1997; O'Gorman et al., 2019a). In Australia, xenopsarian plesiosauromorphs occur in almost every Lower Cretaceous sedimentary basin (Figure 1) (Kear, 2016; Kear et al., 2017). However, the Early Cretaceous evolution of xenopsarians is poorly understood, owing to the small number of known taxa and the systematics of the group being in flux (Otero, 2016; O'Gorman et al., 2017; Fischer et al., 2020). This problem is exacerbated in Australia by the frequent lack of preserved skull material. Hence, the majority of specimens have been categorised as 'indeterminate' in the absence of diagnostic cranial characters. Previously, the vertebrae of plesiosauromorphs, particu-

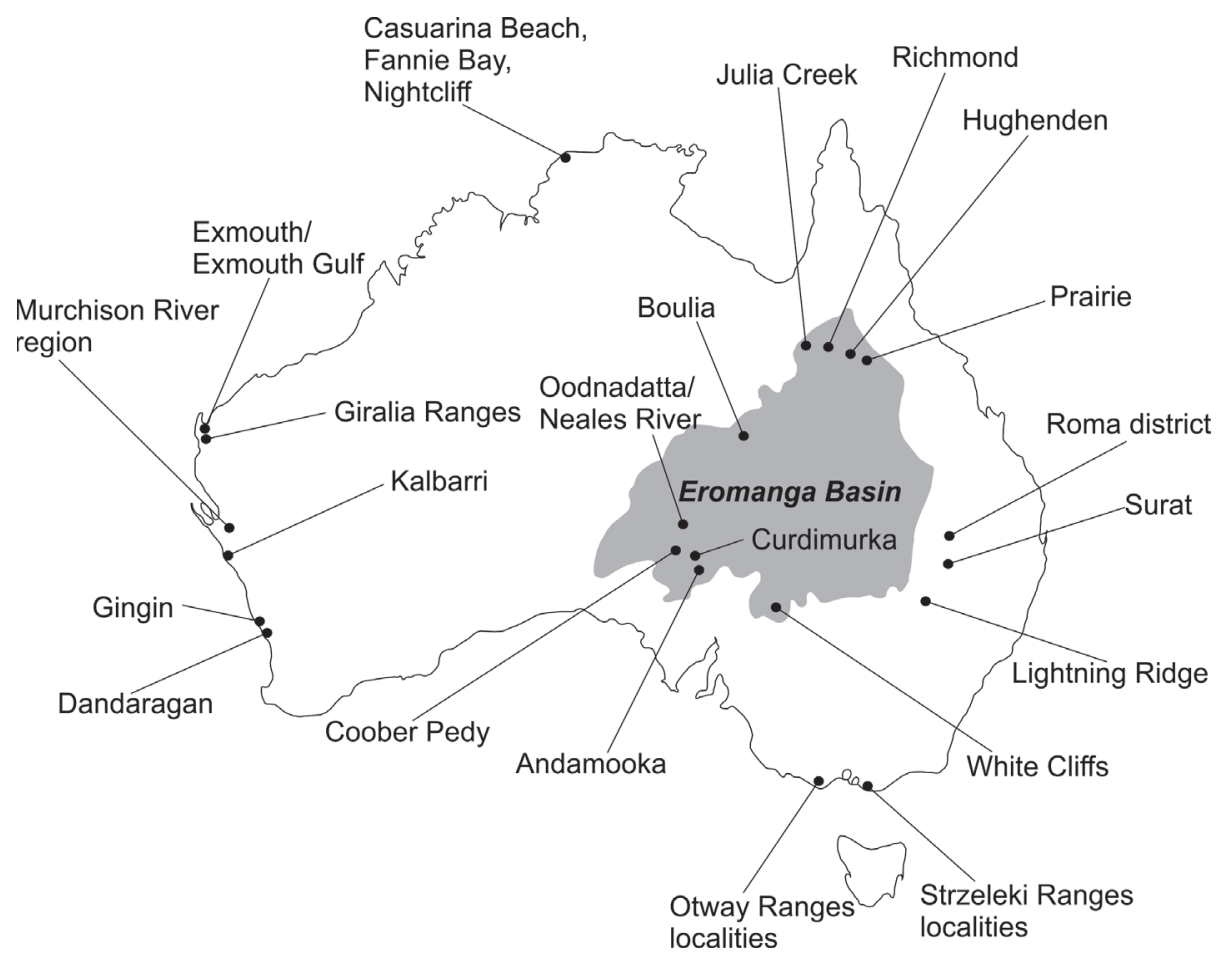

FIGURE 1. Locality map showing plesiosaur-bearing fossil localities in Australia (modified from Kear, 2003). Specimens analysed here are from the Richmond area, Queensland and Coober Pedy, South Australia. 
larly the cervical (neck) vertebrae, were commonly used to differentiate species (e.g., Welles, 1942, 1952; Brown, 1981) and for broader phylogenetic studies (e.g., O'Keefe and Hiller, 2006; O'Gorman et al., 2013; Benson and Druckenmiller, 2014; Otero, 2016). However, vertebral morphology varies not only with taxonomy, but also with position within the body, ontogeny, and taphonomy (Welles, 1952), and there can be significant variation in the measurements even of adjacent vertebrae (O'Keefe and Hiller, 2006). When taking these factors into account, vertebral biometrics have been found to have some taxonomic utility in elasmosaurids and cryptoclidids (O'Keefe and Hiller, 2006; Benson and Bowdler, 2014; Roberts et al., 2017). Vertebral remains dominate the Australian Cretaceous plesiosaur record, but despite basic morphological studies having been done on a vast collection of specimens (Cruickshank et al., 1999; Kear, 2001, 2002, 2003, 2004, 2005a, 2006a, 2006b, 2007, 2016; Kear et al., 2017; Sachs, 2004, 2005a), few biometric studies have been carried out to try and refine their taxonomic attributions.

The purpose of this paper is to compare postcranial materials of xenopsarian plesiosauromorphs (mostly elasmosaurids) from the intracontinental Eromanga Basin in Queensland to gauge the utility of vertebral analysis for differentiating and/or grouping Australian specimens. This could help inform estimates of diversity amongst these commonly headless fossils and provide additional support for possible relationships among different species of Australian and non-Australian elasmosaurids (e.g., styxosaurines, aristonectines), which also commonly lack preserved skulls. This style of morphometric analysis could also be extended to other fossil assemblages lacking diagnostic cranial remains (see Vakil et al., 2020, for the application of this technique to ichthyosaurs).

\section{Institutional Abbreviations}

AM - Australian Museum, Sydney, Australia; AMNH FARB - American Museum of Natural History (Fossil Amphibian, Reptile, and Bird collections), New York, USA; ANSP - Academy of Natural Sciences of Drexel University, Philadelphia, USA; BGR - Bundesanstalt für Geowissenschaften und Rohstoffe, Hannover, Germany; CM - Canterbury Museum, Christchurch, New Zealand; DMNH - Denver Museum of Natural History, Denver, USA; GSQ - Geological Survey of Queensland, Brisbane, Australia; KUVP - University of Kansas Museum of Paleontology (Vertebrate Paleontology collections), Lawrence, USA;
MLP - Museo de La Plata, La Plata, Argentina; NZGS CD - Nuclear and Geological Science, Lower Hutt, New Zealand; QM - Queensland Museum, Brisbane, Australia; RM/KK - Richmond Museum (Kronosaurus Korner) fossil collections, Richmond, Australia; SGO - Área Paleontología de Vertebrados, Museo Nacional de Historia Natural, Santiago, Chile; TMP - Royal Tyrrell Museum of Palaeontology, Drumheller, Alberta, Canada; UCMP - University of California Museum of Paleontology, San Francisco, USA; UPM - Undory Palaeontological Museum, Undory, Russia.

\section{GEOLOGICAL SETTING}

The extensive intracratonic Eromanga basin in northern and central Queensland (Figure 1) contains continental and marine epicontinental Lower Cretaceous (Aptian-Albian) deposits and has yielded several marine reptile fossil assemblages, including plesiosaurs, ichthyosaurs, and turtles (Kear, 2003, 2016; Kear et al., 2017), which must have thrived in high-latitude, temperate environments (Kear, 2006b; Ketchum and Benson, 2010; Kear et al., 2017). The Aptian-Albian epicontinental marine extensions of the Eromanga basin in New South Wales and South Australia also contain marine reptiles (Kear, 2003; Kear et al., 2017). Four xenopsarian families (Leptocleididae White, 1940; Polycotylidae Williston, 1908; Elasmosauridae Cope 1869; and probably Cryptoclididae Williston, 1925) have been identified from the Australian Cretaceous (e.g., Kear, 2003; see review by Kear et al., 2017). Within Australia, Aptian deposits are richest in plesiosaur fossils, whereas Albian strata show fewer plesiosaurs but contain abundant ichthyosaur remains (Kear, 2003). The Rolling Downs Group of Queensland and New South Wales includes Aptian-Cenomanian fossiliferous marine sediments (Kear, 2003). Many studies have been published on marine reptiles from these deposits (e.g., Etheridge, 1897, 1904; Longman, 1915, 1922, 1924, 1943; White, 1935; Persson, 1960, 1982; Gaffney, 1981; Murray, 1985, 1987; Wade, 1984, 1990; Molnar, 1982a, b, 1991; Thulborn and Turner, 1993; Cruickshank and Long, 1997; Long and Cruickshank, 1998; Cruickshank et al., 1999; Kear, 2001, 2002). Despite the recovery of several excellently preserved specimens (Kear, 2016; Kear et al., 2017), the type materials of most nominal Australian marine reptile taxa are fragmentary and poorly preserved, making their taxonomy problematic.

A further issue encountered when dealing with fragmentary Australian marine reptile remains is 
TABLE 1. Plesiosauromorph specimens examined for this research.

\begin{tabular}{|c|c|c|c|c|c|}
\hline Specimen & Locality & Formation & Age & Current Location & Material \\
\hline QM F12719 & $\begin{array}{l}\text { Stewart Creek, Dunraven } \\
\text { Station, Central } \\
\text { Queensland }\end{array}$ & Toolebuc & late Albian & $\begin{array}{l}\text { Queensland } \\
\text { Museum }\end{array}$ & $\begin{array}{l}27 \text { isolated vertebrae free of matrix, of } \\
\text { which some are crushed and others } \\
\text { are cojoined; disarticulated cranial } \\
\text { elements, isolated teeth. }\end{array}$ \\
\hline $\begin{array}{l}\text { QM F11050 } \\
\text { (Holotype) }\end{array}$ & $\begin{array}{l}\text { Yambore Creek, near } \\
\text { Maxwetton, Central } \\
\text { Northern Queensland }\end{array}$ & Toolebuc & $\begin{array}{l}\text { late Albian- } \\
\text { early Aptian }\end{array}$ & $\begin{array}{l}\text { Queensland } \\
\text { Museum }\end{array}$ & $\begin{array}{l}\text { A badly crushed skull, } 5 \text { vertebrae free } \\
\text { of matrix of which } 2 \text { are cojoined. }\end{array}$ \\
\hline QM F12934 & $\begin{array}{l}\text { Kentle Downs, south of } \\
\text { Hughenden }\end{array}$ & Allaru & late Albian & $\begin{array}{l}\text { Queensland } \\
\text { Museum }\end{array}$ & 36 isolated vertebrae free of matrix \\
\hline RM FR269 & Richmond & Toolebuc & late Albian & $\begin{array}{c}\text { Kronosaurus } \\
\text { Korner }\end{array}$ & $\begin{array}{l}55 \text { vertebrae free of matrix of which } \\
\text { some are cojoined, while others are } \\
\text { isolated; rib fragments, parts of the } \\
\text { right and left front paddles, propodial } \\
\text { elements }\end{array}$ \\
\hline QM F2085 & $\begin{array}{l}\text { Flinders River, about } 4.8 \\
\mathrm{~km} \text {. from Richmond. }\end{array}$ & Toolebuc & late Albian & $\begin{array}{l}\text { Queensland } \\
\text { Museum }\end{array}$ & $\begin{array}{l}22 \text { vertebrae free of matrix of which } \\
\text { some are cojoined while others are } \\
\text { isolated. }\end{array}$ \\
\hline QM L39 & $\begin{array}{l}\text { Near Bore Drain on 'Lydia } \\
\text { Downs' Station, north of } \\
\text { Nelia at Julia Creek }\end{array}$ & Toolebuc & late Albian & $\begin{array}{l}\text { Queensland } \\
\text { Museum }\end{array}$ & 6 isolated vertebrae free of matrix \\
\hline RM FR436 & Richmond & Toolebuc & late Albian & $\begin{array}{l}\text { Kronosaurus } \\
\text { Korner }\end{array}$ & 12 isolated vertebrae free of matrix. \\
\hline QM F171282 & $\begin{array}{l}\text { Flinders River, about } 4.8 \\
\mathrm{~km} \text {. from Richmond }\end{array}$ & Toolebuc & late Albian & $\begin{array}{l}\text { Queensland } \\
\text { Museum }\end{array}$ & Isolated vertebra free of matrix \\
\hline QM PL & $\begin{array}{l}\text { Unknown (Central } \\
\text { Queensland?) }\end{array}$ & & & $\begin{array}{l}\text { Queensland } \\
\text { Museum }\end{array}$ & 2 isolated vertebrae free of matrix \\
\hline
\end{tabular}

their stratigraphic origin, as many of these fossils lost their stratigraphic context during excavation and/or preservation (Kear, 2003). With this said, many of the fossils in question can confidently be considered Aptian in age based on the associated invertebrate fauna (Ludbrook, 1966; Johns, 1968; Day, 1969; Henderson et al., 2000) or associated concretions and nodules (Robertson and Scott, 1990; Sheard, 1990; Krieg and Rodgers, 1995; Burton and Mason, 1998).

\section{MATERIALS AND METHODS}

The vertebrae associated with specimen QM F11050 (holotype of Eromangasaurus australis (Sachs, 2005)) from the Queensland Museum (QM), Brisbane, Queensland and eight previously undescribed xenopsarian specimens (one polycotylid and seven elasmosaurids) from QM and the Kronosaurus Korner Museum (RM) in Richmond, Queensland, were described and measured for morphometric analysis (Table 1). All specimens are thought to be from the upper Albian Toolebuc Formation near Richmond, Queensland, except for QM F12934, which is from the overlying, Albian-
Cenomanian Allaru Mudstone, and QM F3567, which is from the Barremian-Albian Wallumbilla Formation (Gray et al., 2002).

Morphological and morphometric data were recorded from specimens where possible or compiled from the literature to obtain morphological characters and morphometric datasets of previously published species for comparison. Previous data on Australian specimens, such as Opallionectes andamookaensis Kear, 2003, were taken from papers by Kear $(2001,2003,2005 a)$ and Sachs (2004). For international specimens, papers by O'Keefe (2001), O'Keefe and Hiller (2006), Sato et al. (2000), Druckenmiller and Russell (2008), O'Gorman et al. (2013), O'Gorman et al. (2015), and Kubo et al. (2012) were utilised to include specimens with 'Cimoliasaurus'-grade vertebrae, Aristonectinae, and Styxosaurinae (sensu Otero, 2016; note that this taxon may be synonymous with Elasmosaurinae, see Serratos et al., 2017). Morphological comparisons include analyses of variation in shape and structure of vertebrae, including, where possible, the measurement of different parts of the vertebrae, such as the centrum (body), rib 


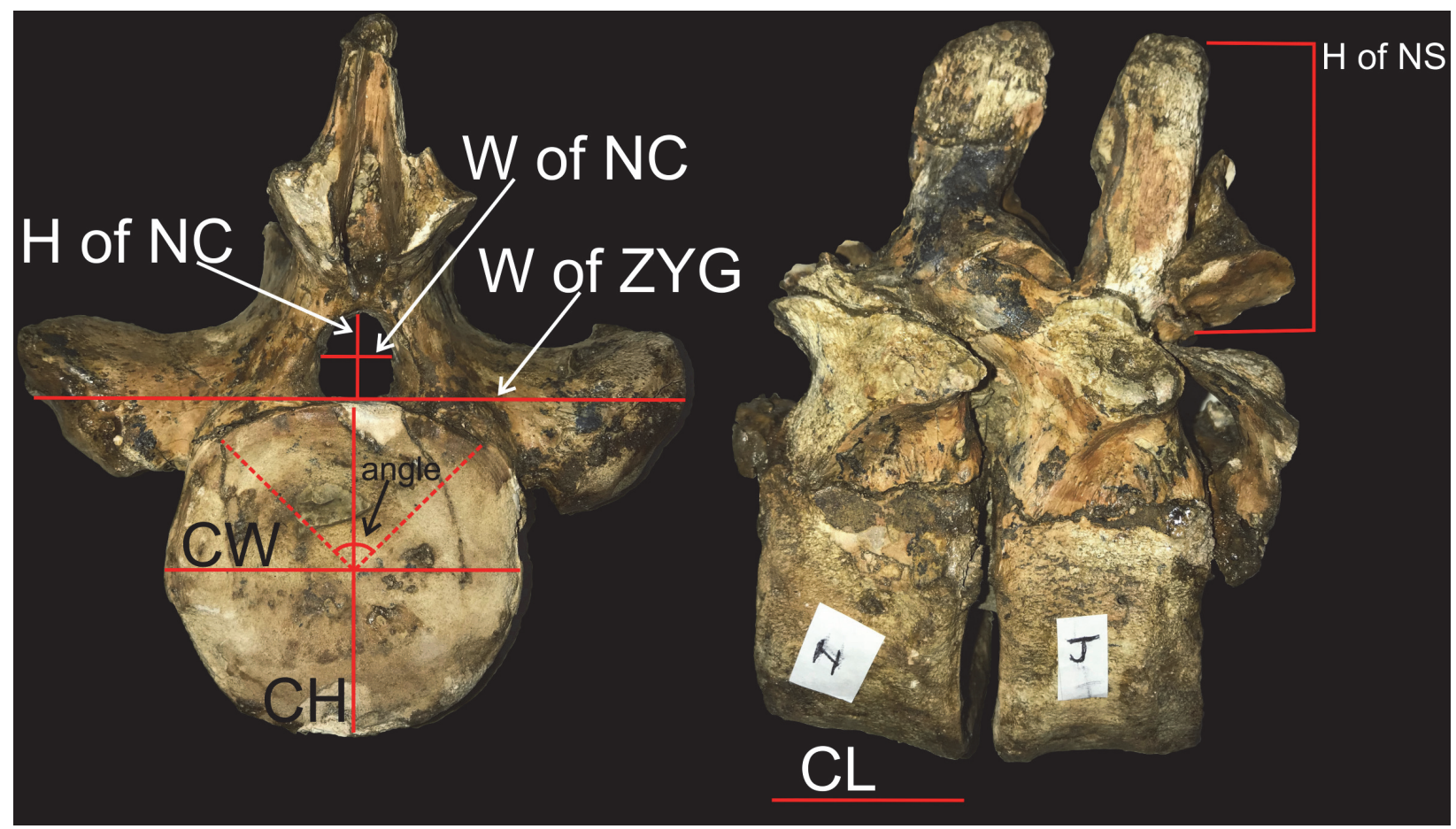

FIGURE 2. Measured morphometric parameters of vertebrae (specimen QM F12719); CW: centrum width; CH: centrum height; $\mathrm{CL}$ : centrum length; $\mathrm{H}$ of $\mathrm{NC}$ - height of neural canal; $\mathrm{W}$ of $\mathrm{NC}$ - width of neural canal; $\mathrm{W}$ of ZYG. - width of zygapophyses; H of NS - height of neural spine; angle - angle of zygapophysis with centre of centrum.

facets (pre-zygapophyses, post-zygapophyses, diapophyses), and neural spines.

The following measurements were recorded for specimens from the QM and RMF collections (see Table 1 for specimen list): centrum height $(\mathrm{CH})$, centrum width $(\mathrm{CW})$, both of which were taken on the anterior articular facet of the vertebra, centrum length (CL), width of zygapophyses, angle between transverse processes/diapophyses and centre of the centrum, height of neural spine, height and width of neural canal, and distance between cervical foramina subcentralia (Figure 2, Appendix Table 1). The $\mathrm{CH}$ for medially constricted centra was calculated as the average of three values (two on either side of the constriction and one at the constriction). Centrum dimensions were measured at pre-defined points and where unclear, the average of three values for each dimension was used. Specific mathematical parameters of Brown (1981) were plotted as bivariate graphics. While the parameters themselves are dependent on the position of the vertebrae in the vertebral sequence, their analysis on the bivariate plots is independent of position, and thus does not require the correct order to be known (O'Keefe and Hiller, 2006; O'Gorman et al., 2013) [(i.e., vertebral Length Index (VLI), Height Index (HI), and Breadth
Index $(\mathrm{BI})$ also were calculated]. Knutsen et al. (2012) pointed out that VLI did not differentiate the height and breadth contributions to the mean centrum diameter used to calculate VLI. Other measurements (e.g., height of neural spine, width of zygapophyses, etc.) were made where possible, but because of lack of sufficient data, they were not used in morphometric analyses. Centrum dimensions provided the basis for most analyses.

Statistical analysis is supported by graphing biometric relationships modified from O'Gorman et al. (2013), where VLI, HI, and BI were plotted against each other, and the resulting trends/patterns were compared with morphometric datasets from the literature. The following equations were used (after Welles, 1952; Brown, 1981):

$$
\begin{gathered}
\mathrm{VLI}=100^{*} \mathrm{CL} /\left[0.5^{*}(\mathrm{CH}+\mathrm{CW})\right] \\
\mathrm{BI}=100^{*} \mathrm{CW} / \mathrm{CL} \\
\mathrm{HI}=100^{*} \mathrm{CH} / \mathrm{CL} \\
\mathrm{BHI}=100^{*} \mathrm{CW} / \mathrm{CH}
\end{gathered}
$$

where $\mathrm{CL}=$ centrum length; $\mathrm{CH}=$ centrum height; and $\mathrm{CW}=$ centrum width.

Owing to incompleteness of specimens and differences in neck length for different taxa, normalised positions (relative to total number) of ver- 
tebrae within the key three body regions (cervical, dorsal, and caudal) (cf. Vakil et al., 2020) were plotted against VLIs for all specimens to compare any trends along the length of the vertebral column. Vertebrae were initially assigned to body region based on their morphology, with cervicals bearing rib facets wholly on the centrum, pectorals and sacrals partly on the centrum and neural arch, dorsals wholly on the neural arch, and caudals either on the neural arch or side of the centrum in addition to the presence of chevron facets on their ventral surfaces (e.g., Taylor et al., 1993; Druckenmiller, 2002; Noè et al., 2017). Distinction between anterior and posterior cervicals of elasmosaurids was based on the narrower or wider spacing of the foramina subcentralia in anterior and posterior cervicals, respectively (Bardet et al., 1999; Otero et al., 2014), and with respect to the changing position of rib facets towards the neural arch facets from anterior to posterior cervicals (Otero et al., 2014). Their exact position/sequence within the vertebral column was determined on the basis of the preserved sequence as excavated, where possible, by their gradation in morphology as mentioned above, or by increasing/decreasing size. The VLI plots then were compared to those of more complete specimens of known plesiosauromorph taxa from the literature to evaluate taxonomic similarity. Non-Australian specimens from the literature with relatively incomplete cervical vertebral sequences were omitted from VLI plots but were included in subsequent plots (see below for PCA, $\mathrm{HI}-\mathrm{BI}-\mathrm{VLI}$, and $\mathrm{H} / \mathrm{W}$ plots). As isolated vertebrae are difficult to compare meaningfully, VLI values of QM F11050, QM F171282, and QM PL were not plotted against vertebral position.

As errors are possible in the sequencing of vertebrae that were not preserved in situ, additional quantitative analyses were carried out using principal component analysis (PCA) on CL, CW, and $\mathrm{CH}$ and $\mathrm{HI}, \mathrm{BI}$, and $\mathrm{BHI}$ for vertebrae where all three could be adequately determined. Importantly, PCA analysis does not rely on the sequence of a given vertebra in the column. Two methods were used to normalise $\mathrm{CL}, \mathrm{CW}$, and $\mathrm{CH}$ data so as to address heteroscedasticity and highlight ontogenetic changes in morphology. Firstly, vertebral dimensions $(C X)$ were centred and normalised individually for $\mathrm{CW}, \mathrm{CH}$, and $\mathrm{CL}$ prior to analysis using the following formula (Vakil et al., 2020):

$$
\begin{gathered}
\mathrm{CX}_{\text {normalised }}=\{\mathrm{CX}-\text { Mean }(\mathrm{CW}, \mathrm{CH}, \mathrm{CL})\} / \\
\text { Standard Deviation }(\mathrm{CW}, \mathrm{CH}, \mathrm{CL})
\end{gathered}
$$

Raw data were transformed to natural logarithms (cf. O'Keefe and Hiller, 2006) as another means to normalise against the effects of heteroscedasticity and plotted separately.

Following PCA, Box's M test of equality of covariance matrices was used to test the null hypothesis that observed covariance matrices of the variables were equal across different sample groups (e.g., anterior versus posterior cervicals) of Australian and non-Australian specimens. Multivariate analysis of variance (MANOVA) was used to investigate differences between Australian and non-Australian plesiosauromorph specimens using centrum dimensions. Pillai's trace values were then calculated. This statistic ranges from 0 to 1 (Seber 1984, Pillai 1995) with values closer to 1 representing more statistically significant results, and consequently, the greater difference between compared groups. PAST software version 3 (v3) was utilised for statistical analyses (Hammer et al., 2001).

\section{SYSTEMATIC PALAEONTOLOGY}

Superorder SAUROPTERYGIA Owen, 1860

Order PLESIOSAURIA de Blainville, 1835

Superfamily PLESIOSAUROIDEA Gray, 1825

Clade XENOPSARIA Benson and Druckenmiller, 2014

Family POLYCOTYLIDAE Cope, 1869

Polycotylidae gen. et sp. indet. (QM F12719)

Figure 3

Referred material. Partial cranial and partial postcranial material; 27 vertebrae free of matrix - some are isolated, others articulated; several isolated teeth.

Locality. Stewart Creek, Dunraven Station, Central Queensland.

Stratigraphic horizon. Toolebuc Formation (Late Albian).

Description of vertebrae. Most centra are complete; six cervical vertebrae have distinct foramina subcentralia and some have an additional foramen on the neural arches, at the junction of the neural canal and the neural arch facets (Figure 3C-E); most dorsal vertebrae are partially to wholly complete with neural spines, prezygapophyses, postzygapophyses, and diapophyses (Figure 3, B); six cervical vertebrae with foramina subcentralia and rib facets borne wholly on centra $(\mathrm{CW}=55.1$ $66.1 \mathrm{~mm} ; \mathrm{CL}=33.9-39.4 \mathrm{~mm} ; \mathrm{CH}=56.6-65.3$ $\mathrm{mm}) ; 17$ measurable and four partly measurable dorsal vertebrae with rib facets borne wholly on the neural arches $(C W=62.5-71 \mathrm{~mm} ; C L=31.1-43$ $\mathrm{mm} ; \mathrm{CH}=57.4-70.3 \mathrm{~mm})$. Centra of cervicals and dorsals are circular in outline with a well- 


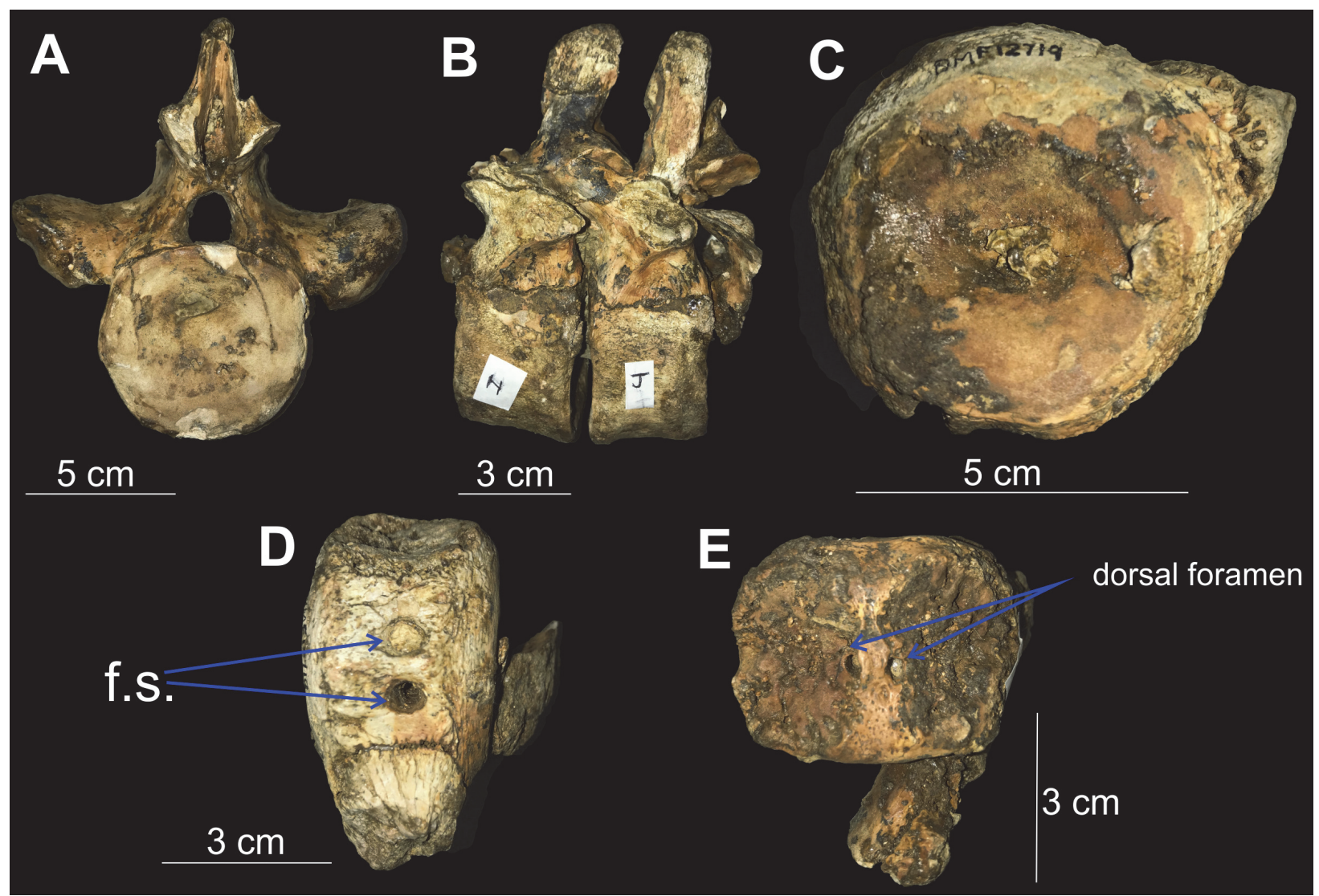

FIGURE 3. Specimen QM F12719. A. Dorsal vertebra, anterior view. B. Dorsal vertebra, lateral view. C. Cervical vertebra, anterior view. D. Cervical vertebra, ventral view showing foramina subcentralia (f.s.). E. Cervical vertebra, dorsal view showing foramen on neural arches. Scales shown on figure.

marked outer rim, amphicoelous, have a distinct notochordal pit and CL generally less than one-half of $\mathrm{CH}$ (cf. McKean, 2012). Overall length of the vertebral column is unknown and difficult to estimate.

Remarks. The specimen is considered a polycotylid based on the general morphology of the vertebrae $(\mathrm{CL}<1 / 2 \mathrm{CH}$, circular rim, distinct notochordal pit) and the presence of distinctly amphicoelous articular facets (Figure 3A, C), which are typical for the family (McKean, 2012). The original sequence of vertebrae is lost; the current sequence is arranged based on the size and shape of the centra within body regions. Based on the overall size of centra and weak fusion of neural spines and transverse processes to centra, i.e., open neurocentral sutures (osteological immatureness of the vertebrae), the specimen appears to be a juvenile. However, we cannot rule out the possibility of paedomorphism, which is common in pliosaurs (Espen Knutsen, personal communication, 2021).

Family ELASMOSAURIDAE Cope, 1869

Genus EROMANGASAURUS Kear, 2005b
Type species. Eromangasaurus australis (Sachs, 2005).

Remarks. Eromangasaurus was erected by Kear (2005b) on the basis of a badly crushed skull (QM F11050), the posterior part of which was associated with a fused atlas-axis complex and three cervical vertebrae (QM F12216, QM F12217), recovered from the upper Albian Toolebuc Formation near Maxwelton at Yambore Creek in Queensland. An additional two cervical vertebrae (QM F12219) were recovered subsequently along with the anterior portion of the skull (for a history of the material, see Persson, 1982). Persson (1982) initially referred the material with reservation to Woolungasaurus glendowerensis Persson, 1960 based only on cervical centra. However, Welles (1962) and later Kear (2003) considered W. glendowerensis to be a nomen dubium owing to its lack of diagnostic characters, and the latter considered this material to represent a new, undescribed genus and species of elasmosaurid (see also Thulborn and Turner, 1993). Sachs (2004) referred QM F11050 to Tuarangisaurus Wiffen and Moisley, 
1986, a genus previously known from New Zealand (Wiffen and Moisley, 1986; O'Gorman et al., 2017). Then in 2005, Sachs and Kear independently described new taxonomic names for the specimen, with Sachs (2005) erecting the species Tuarangisaurus australis and Kear (2005b) erecting the new genus and species Eromangasaurus carinognathus. Subsequently, Kear (2007) demonstrated that the skull of Tuarangisaurus keyesi (the type species) differed substantially from QM F11050, supporting generic distinction. Recognizing the priority of Sach's (2005) species name, the new combination Eromangasaurus australis was established for QM F11050 (Kear, 2007) and has been maintained in subsequent studies (e.g., Druckenmiller and Knutsen, 2012).

Eromangasaurus australis (Sachs, 2005) Figure 4

1982 Woolungasaurus cf. W. glendowerensis Persson, p. 648, PI. 1, figs.1, 2, Pl. 2, fig. 1.

1993 Elasmosauridae, gen. et sp. nov. Thulborn and Turner, figs. 2, 3.

2003 Elasmosauridae, gen. et sp. nov. Kear, fig. 3A.

2004 Tuarangisaurus, sp. nov. Sachs, p. 713.

2005 Tuarangisaurus australis Sachs, p. 426, figs. 2-5.

2005b Eromangasaurus carinognathus Kear, p. 793, figs. 2-7.

2007 Eromangasaurus australis (Sachs, 2005) comb. nov., Kear, p. 244, figs. 1, 2.

Holotype. QM F11050. Nearly complete, but badly crushed skull (including atlas-axis complex) plus five cervical vertebrae, including three isolated anterior cervical vertebrae (QM F12216 and QM F12219a,b) and two more posterior cervical vertebrae (QM F12217). An additional ventral impression of QM F12216 containing minor bone fragments is labelled QM F12218 (see Appendix Table 2 for vertebrae specimen numbers).

Locality. Yambore Creek, north of Julia Creek, central northern Queensland.

Stratigraphic horizon. Toolebuc Formation (early Aptian - late Albian).

Diagnosis. See Kear (2007).

Description. The skull and atlas-axis complex of this individual have been described previously (Sachs, 2005; Kear, 2005b, 2007) and are not dealt with here. Specimens QM F12216 and QM F12217 also have been described previously (Persson, 1982; Sachs 2005), and the description below is taken from them with additional observa- tions and measurements. Sachs (2005) labelled one vertebra as QM F12216-19, but illustrated only QM F12216 (his figure 5B), apparently not having had access to the last two vertebrae recovered (which make up QM F12219). Vertebrae include three anterior cervical vertebrae free of matrix (QM F12216, QM F12219a,b; mean CW = $69.5 \mathrm{~mm}$; mean $\mathrm{CL}=67.4 \mathrm{~mm}$; mean $\mathrm{CH}=50.9 \mathrm{~mm}$ ) and two mid- to posterior cervicals that are cojoined but free of matrix (QM F11217; CW = 104.15, 105.2 $\mathrm{mm} ; \mathrm{CL}=99.05,98.15 \mathrm{~mm} ; \mathrm{CH}=84.45,87.65$ $\mathrm{mm}$ ) (all measurements in Appendix Table 1). All centra are complete, with distinct foramina subcentralia. Anterior cervical vertebrae (QM F12216 and QM F12219) (Figure 4A, D-G) have dumbbellshaped articular facets, a lateral ridge, latero-ventrally placed rib facets borne wholly on the centrum, part of the neural arch facet on the dorsal surface and narrowly-spaced foramina subcentralia. The cojoined vertebrae (QM F12217) (Figure $4 \mathrm{~B}, \mathrm{C})$ have neural arches and parts of neural spines fused to centra with a faint suture, dumbbell-shaped articular facets, a prominent ridge on the lateral surface but positioned towards the rib facets, laterally positioned but widely-spaced rib facets, and relatively widely-spaced foramina subcentralia.

Remarks. The original sequence of vertebrae is lost and the current sequence is based on morphology and size with the anterior specimens most similar in size to the atlas-axis complex and the cojoined pair (QM F12217) being significantly larger (Figure 4). This specimen has a complex collection history, detailed by Persson (1982), with even the skull being collected in two parts at separate times. This has created some confusion in numbering, with the last two collected centra becoming separated from the skull and first collected centra within the QM collection (Appendix Table 2). As a result, one of the QM F12219 centra was erroneously labelled QM F12217, duplicating the number of the original cojoined specimens. However, Persson (1982) made it clear that QM F12219 represented two separate centra. Adding to the complexity is that whereas the three smaller anterior centra share similar matrix with the skull and atlas-axis complex, the cojoined specimens (QM F12217) have somewhat different matrix. Regardless, all vertebrae appear to be associated with the skull based on field notes despite the great disparity in size of QM F12217. Based on the osteological immaturity of the vertebrae and atlas-axis complex, Persson (1982) considered the specimen a subadult. 


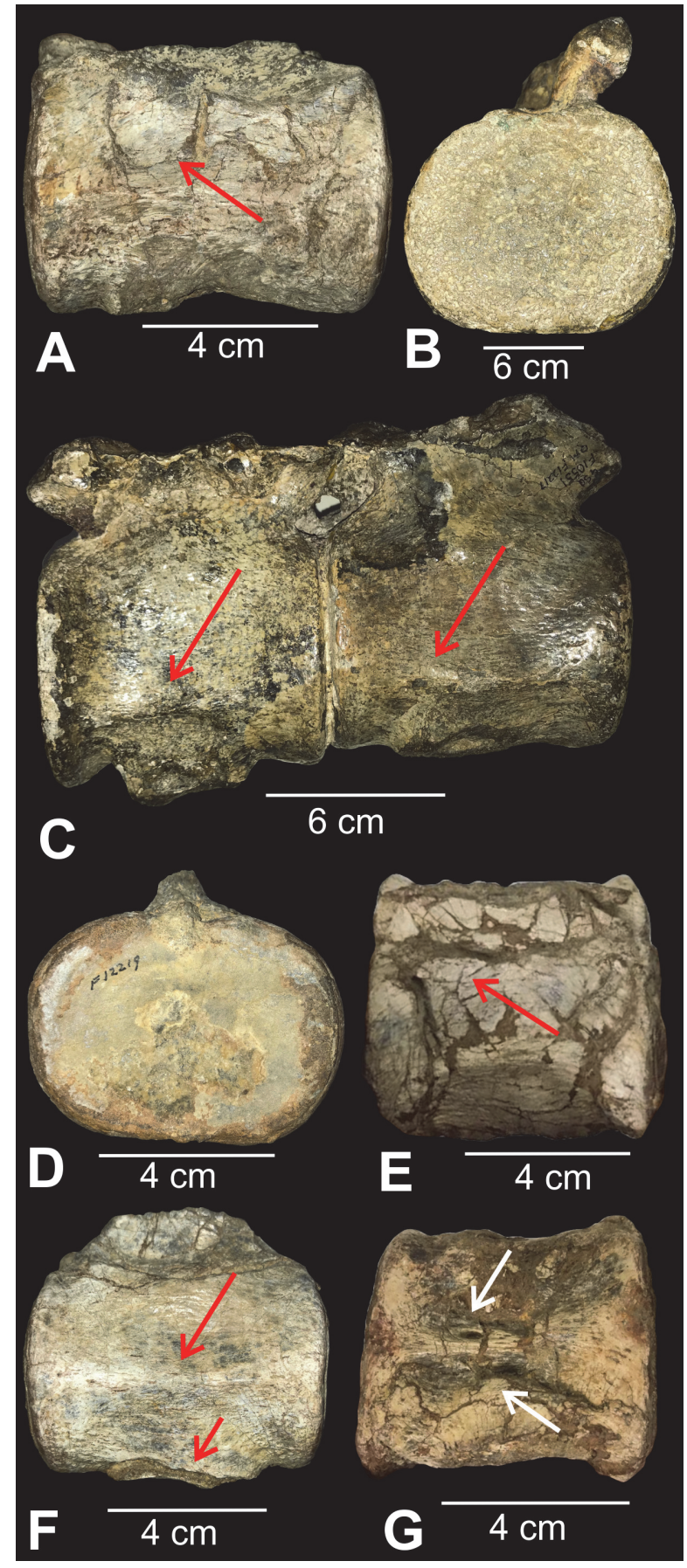

FIGURE 4. Vertebrae associated with specimen QM F11050 - Eromangasaurus australis holotype. A. QM F12216, lateral view showing lateral ridge (red arrow). B. Cojoined vertebrae QM F12217, anterior view. C. QM F12217, lateral view showing lateral ridges (red arrows). D. QM F12219a, anterior view. E. QM F12219a, lateral view showing lateral ridge (red arrow). F. QM F12219b, lateral view showing lateral ridge (long red arrow) and rib facet borne wholly on centrum (short red arrow). G. QM F12219b, ventral view showing foramina subcentralia (white arrows) separated by a mid-ventral keel. Scales shown on figure.
Elasmosauridae gen. et sp. indet. (QM F12934)

Figure 5

Material. Partial postcranial material; 36 isolated vertebrae, free of matrix; it is unclear as to whether there are any other postcranial elements associated with this specimen.

Locality. Kentle Downs, south of Hughenden.

Stratigraphic horizon. Allaru Formation (late Albian).

Description. Most centra are complete; nine anterior cervical centra have distinct foramina subcentralia (Figure 5F) and lateral ridges (Figure 5G), while two posterior cervical centra are identified on the basis of position of rib facets (Figure $5 \mathrm{E})(\mathrm{CW}=$ $70.9-123.15 \mathrm{~mm} ; \mathrm{CL}=73.55-98.6 \mathrm{~mm} ; \mathrm{CH}=$ $53.85-93.5 \mathrm{~mm}$ ); three dorsal centra lack fused parts (diapophyses and zygapophyses) and are identified on the basis of relatively circular shape in anterior view and dorso-lateral position of rib facets borne on the transverse processes of the neural arches $(\mathrm{CW}=115.2-97.6 \mathrm{~mm} ; \mathrm{CL}=91.5-61.7$ $\mathrm{mm} ; \mathrm{CH}=87.55-78.15 \mathrm{~mm}$ ) (Figure $5 \mathrm{H}$ ); 13 measurable and 9 partly measurable caudal centra lack fused neural arches and ribs and bear chevron facets (Figure $5 \mathrm{~A}$ ) in addition to rib facets (Figure 5B) $(\mathrm{CW}=50.5-104.1 \mathrm{~mm} ; \mathrm{CL}=39.6-64.6 \mathrm{~mm} ; \mathrm{CH}$ $=37.3-82.05 \mathrm{~mm}$ ). Sacral vertebrae were identified on the basis of the relatively elliptical shape of their articular facets in anterior view and the shape and position of rib facets, borne partly on the centrum and partly on the neural arches (Figure 5C, D).

Remarks. The original sequence of vertebrae is lost and the current sequence was determined based on size. Vertebrae show typical elasmosaur characteristics (lateral ridges and dumbbell-shaped articular facets) (Otero et al., 2014; Sachs and Kear, 2017). Based on the osteological immaturity of the vertebrae, the specimen appears to be a subadult. Some fragmentary postcranial material occurs with QM F12934, but it is unclear as to whether it belongs to the referred specimen, as the field notes are not clear.

Elasmosauridae gen. et sp. indet. (RM FR269) Figures 6, 7

Material. Partial postcranial material; 55 vertebrae of which 36 are measurable; most are isolated and free of matrix whereas some dorsals and caudals are cojoined and partially obscured in matrix.

Locality. Near Richmond, Queensland.

Stratigraphic horizon. Toolebuc Formation (upper Albian). 


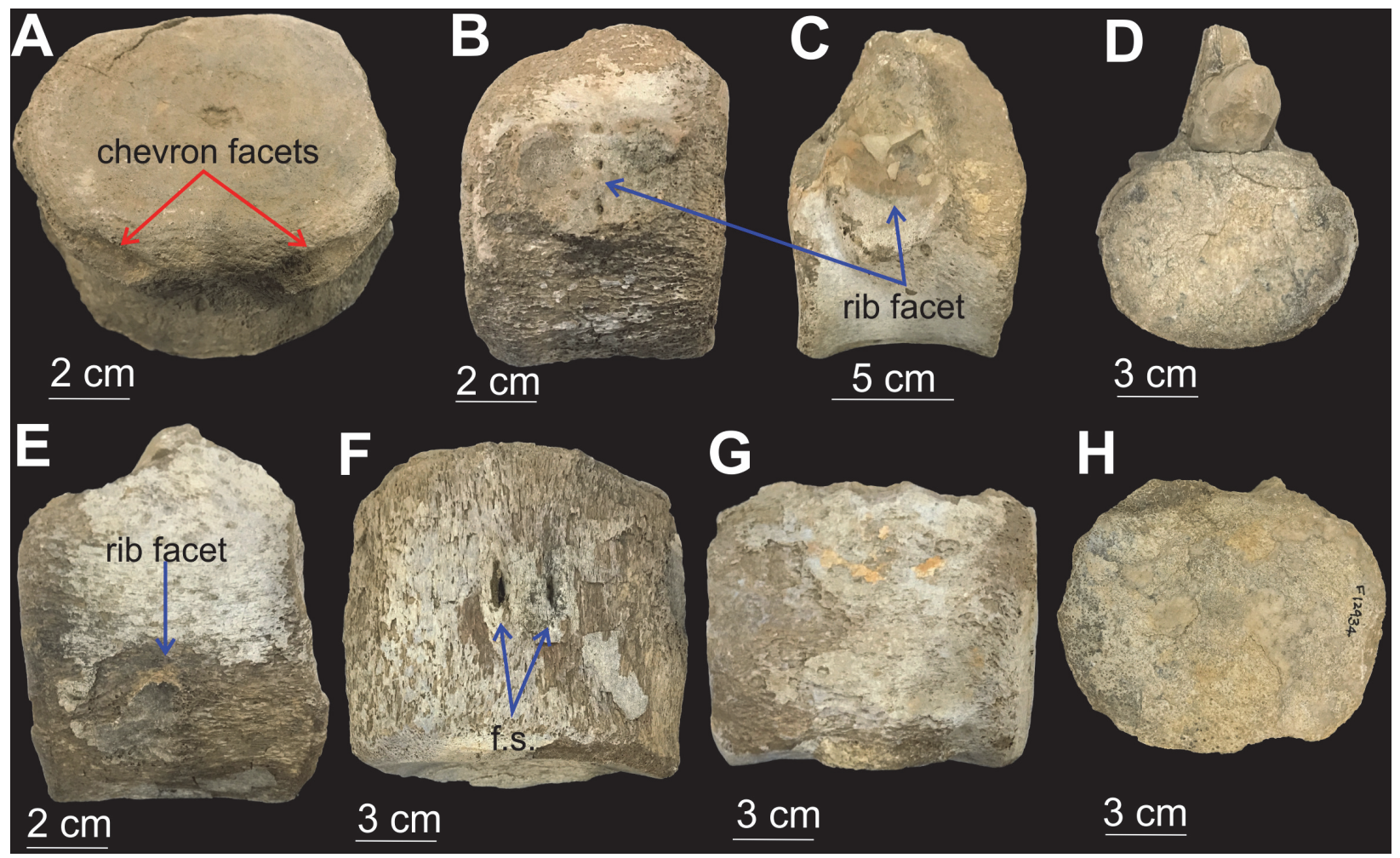

FIGURE 5. Specimen QM F12934. A. Caudal vertebra showing chevron facets; B. Caudal vertebra showing rib facet, lateral view. C. Sacral vertebra showing rib facets borne partly on centrum and partly on neural arch, lateral view; D. Sacral vertebra, anterior view. E. Posterior cervical showing rib facet, lateral view. F. Anterior cervical showing foramina subcentralia (f.s.), ventral view. G. Anterior cervical, lateral view. H. Dorsal vertebra, anterior view. Scales shown on figure.

Description. Most centra are complete, but because some centra are partially obscured in matrix, their dimensions were extrapolated by doubling the measurements taken from exposed portions where at least one-half of the centrum was visible. Eleven cervicals have distinct foramina subcentralia (Figure 6C) and distinct lateral ridges; some have neural arch bases fused to them with faint suture lines visible, while others show fusion of the zygapophyses (pre- and postzygapophyses) with faint suture lines (Figure $6 \mathrm{~A}, \mathrm{~B})(\mathrm{CW}=64.4-$ $119.5 \mathrm{~mm} ; \mathrm{CL}=50.6-93.4 \mathrm{~mm} ; \mathrm{CH}=57.2-76.9$ $\mathrm{mm}$ ); 10 dorsals (4 pectorals, 5 dorsals, 2 sacrals) are mostly obscured in matrix but are identifiable on the basis of the position of rib facets; some have neural arches attached to the centra with faint suture lines (Figure $6 \mathrm{D})(\mathrm{CW}=109.55-86.6 \mathrm{~mm}$; $\mathrm{CL}=51.5-91.55 \mathrm{~mm} ; \mathrm{CH}=59.25-78.55 \mathrm{~mm}$ ); pectorals are distinguishable from dorsals on the basis of their position relative to the cervicals and the position of rib facets borne partly on the centrum and partly on the neural arches; their transition into dorsals is apparent where the rib facets are borne wholly on the neural arches (Figure 7B)
$(\mathrm{CW}=112.35-110.9 \mathrm{~mm} ; \mathrm{CL}=80.65-81.75$ $\mathrm{mm} ; \mathrm{CH}=86.45-87.1 \mathrm{~mm}$ ); two sacral vertebrae are distinguishable from the dorsals and caudals on the basis of the position of rib facets, borne partly on the centrum and partly on the neural arches; the transition from dorsals is apparent since the last six dorsals and the sacral vertebrae are articulated (Figure $7 \mathrm{~A})(\mathrm{CW}=94 \mathrm{~mm} ; \mathrm{CL}=$ $60.95 \mathrm{~mm}$; $\mathrm{CH}=65.2 \mathrm{~mm}$ ); one measurable caudal is identified on the basis of its size and the latero-ventral position of chevron facets, but the remaining 14 identifiable caudals were only partly measured because most are either obscured in matrix or distorted $(\mathrm{CW}=84.25 \mathrm{~mm} ; \mathrm{CL}=51.65$ $\mathrm{mm} ; \mathrm{CH}=68.2 \mathrm{~mm}$ ).

Remarks. The original sequence of most vertebrae is lost, but some vertebral sets (especially in the dorsal region) are preserved in articulation. The current sequence is based on the size of vertebrae and gradual change in position of rib facets and is thought to be the original sequence as excavated. Vertebrae have elasmosaurid characteristics (e.g., lateral ridges) (Otero et al., 2017; Sachs and Kear, 2017). Based on the osteological immaturity of the 


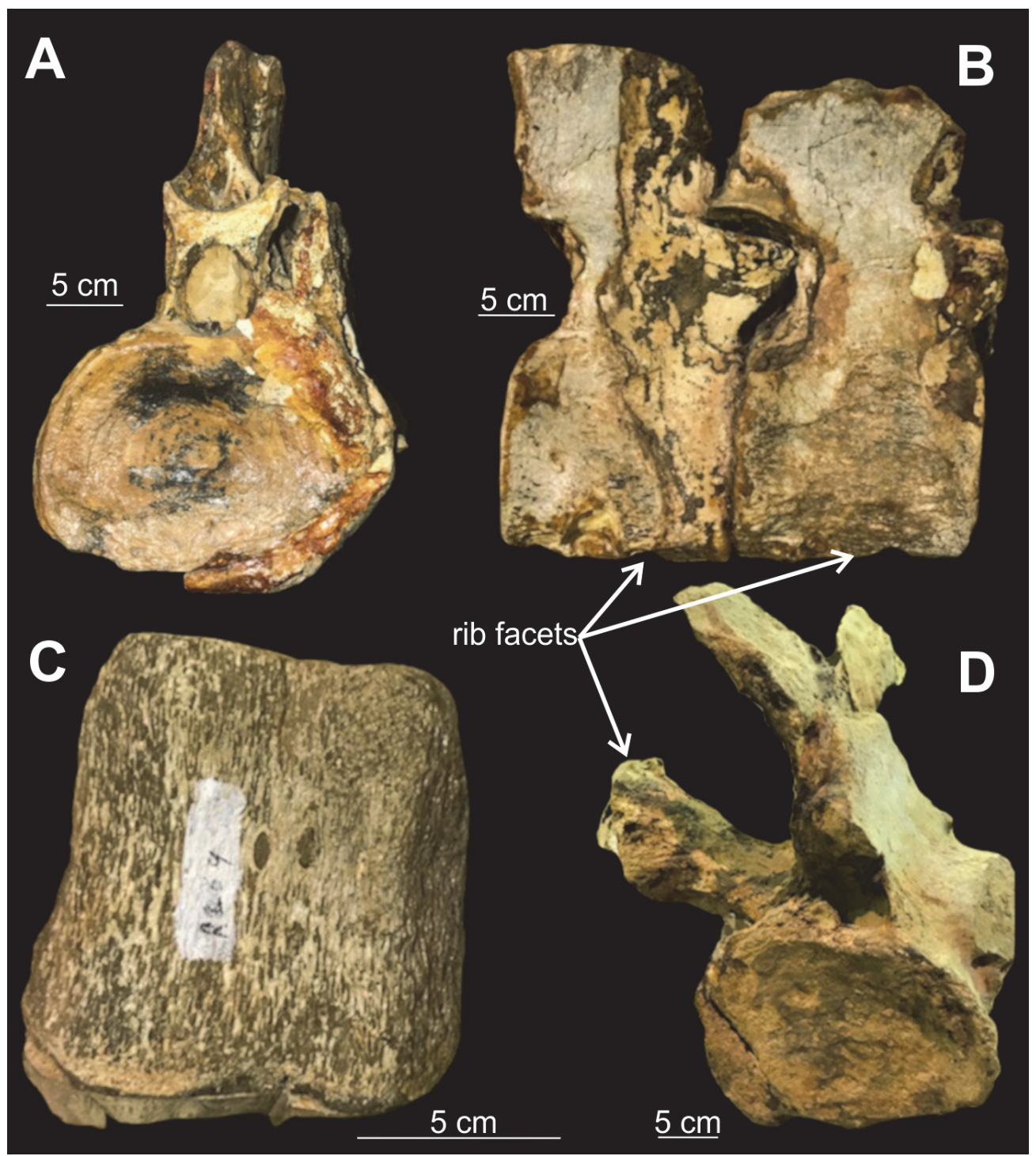

FIGURE 6. Specimen RM FR269. A. Cervical vertebra, anterior view with weakly fused neural arches and neural spine. B. Cervical vertebrae, lateral view with rib facets borne wholly on the centrum. C. Cervical vertebra, ventral view showing paired foramina subcentralia (f.s.). D. Dorsal vertebra, anterior view with rib facets (diapophyses) borne wholly on neural arches. Scales shown on figure.

vertebrae, possessing open neurocentral sutures (Brown, 1981), the specimen appears to be a subadult-adult. Specimen RM FR269 was considered potentially referable to Eromangasaurus australis by museum staff based on the similarity in size, morphology, and preservation of the anterior cervicals with those of the $E$. australis specimen (QM F11050). In the absence of definite shared autapomorphic features, however, this referral should be considered speculative.

Elasmosauridae gen. et sp. indet. (QM F2085) Figure 8
Material. Partial postcranial material; 22 dorsal vertebrae free of matrix of which most are articulated in series of 3 to 4 and one isolated vertebra.

Locality. Flinders River, about $4.8 \mathrm{~km}$ from Richmond.

Stratigraphic horizon. Toolebuc Formation (late Albian).

Description. All vertebrae are dorsals based on the shape of centra and position of rib facets, including 18 dorsal vertebrae with rib facets (diapophyses) borne wholly on the neural arches (CW $=92-116.8 \mathrm{~mm} ; \mathrm{CL}=66.2-95.75 \mathrm{~mm} ; \mathrm{CH}=$ $79.95-106.5 \mathrm{~mm}$ ) (Figure 8E, F); three sacral vertebrae with kidney-shaped rib facets borne partly 


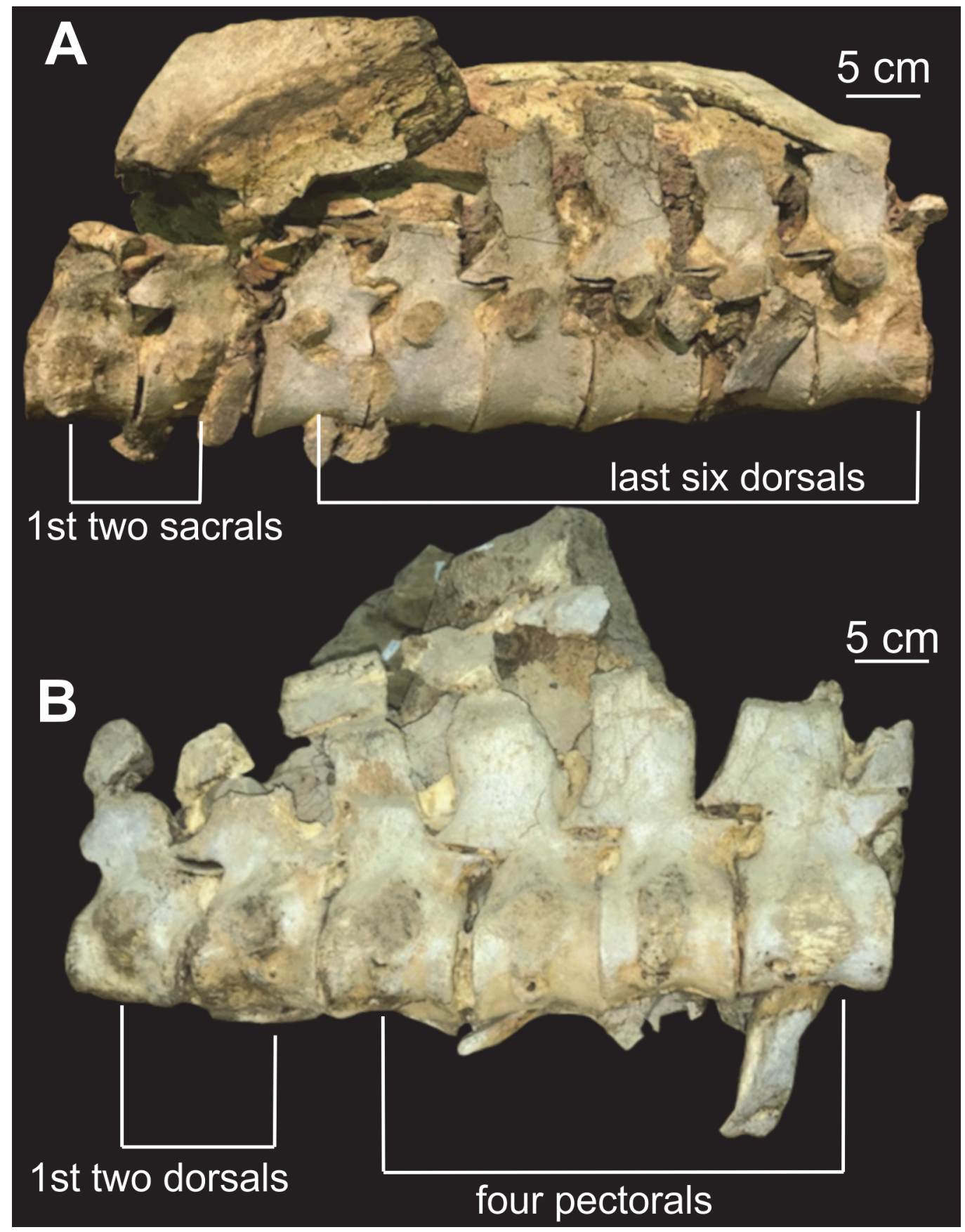

FIGURE 7. Specimen RM FR269. A. Transition from dorsals to sacrals, right lateral view. B. Transition from pectorals to dorsals, right lateral view. Scales shown on figure.

on the centrum and partly on the neural arches $(\mathrm{CW}=102.9-96 \mathrm{~mm} ; \mathrm{CL}=61.25-63.15 \mathrm{~mm} ; \mathrm{CH}$ $=71-75.55 \mathrm{~mm}$ ) (Figure 8C, D) and a single isolated pectoral vertebra, with rib facets borne partly on the centrum and partly on the neural arches $(\mathrm{CW}=116.8 \mathrm{~mm} ; \mathrm{CL}=79.05 \mathrm{~mm} ; \mathrm{CH}=87.2 \mathrm{~mm})$ (Figure 8A, B) also occur. Despite retaining fragments of diapophyses, neural canal, and neural spines, these were primarily useful only in identify- ing the body region of the vertebrae in addition to their shape and position of rib facets (Otero et al., 2014; Sachs and Kear, 2017). However, they mostly were not measurable owing to incompleteness.

Remarks. The original sequence of vertebrae is lost; the current sequence is based on size of centra and position of rib facets utilising the original sequence of cojoined vertebrae where applicable 


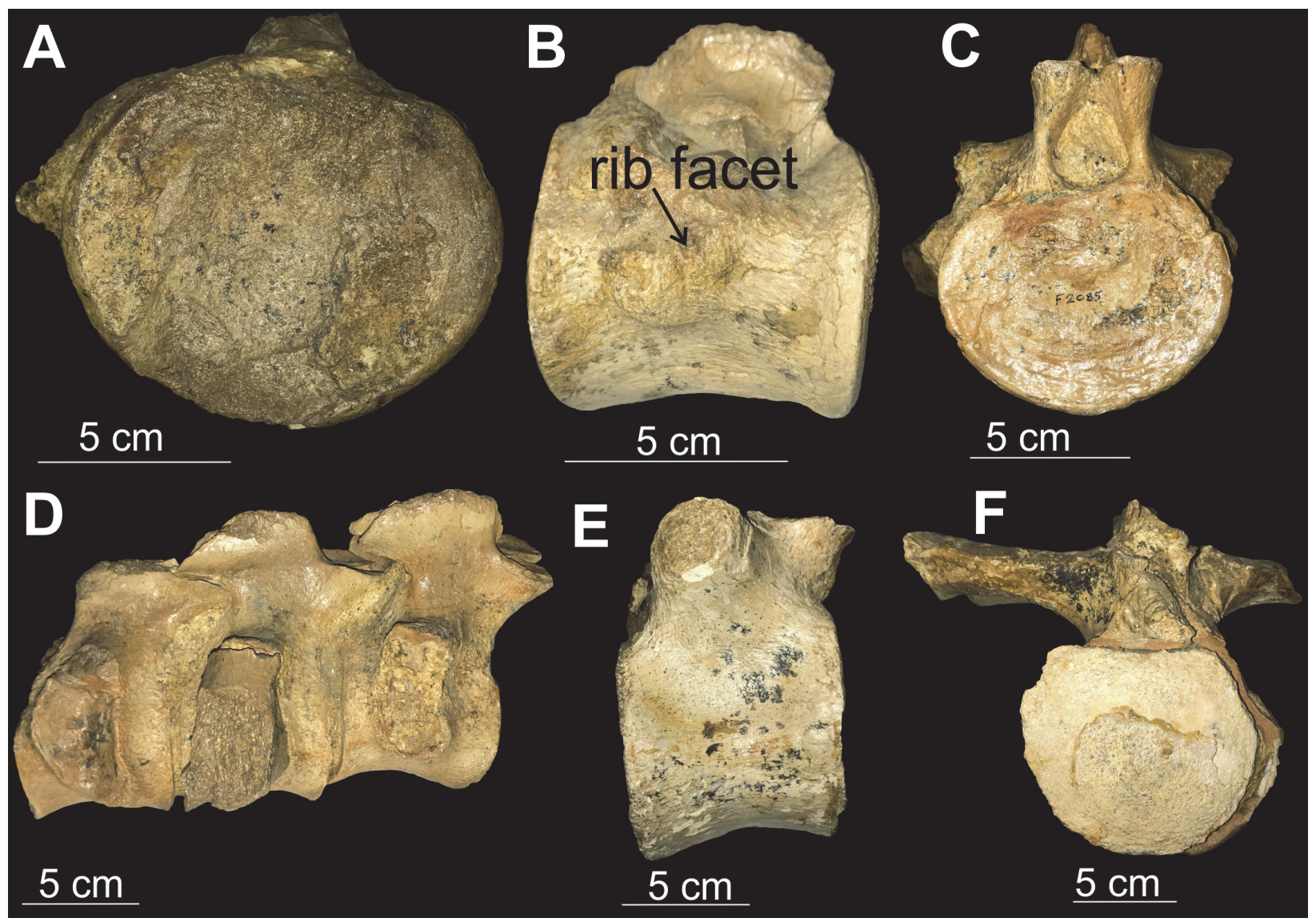

FIGURE 8. Specimen QM F2085. A. Pectoral vertebra, anterior view. B. Pectoral vertebra, lateral view. C. Sacral vertebra, posterior view. D. Sacral vertebrae, lateral view. E. Dorsal vertebra, lateral view. F. Dorsal vertebra, anterior view. Scales shown on figure.

(Figure 8D). Based on the osteological immaturity of the vertebrae with open neurocentral sutures (Brown, 1981), the specimen appears to be a subadult-adult. Specimen QM F2085 was initially described by Longman (1935) as elasmosaurid vertebrae. Persson (1963) mentioned it as well, but neither Longman (1935) nor Persson (1963) carried out morphometric analysis.

Elasmosauridae gen. et sp. indet. (QM L39) Figure 9

Material. Partial postcranial material; six isolated cervical vertebrae, free of matrix.

Locality. Near Bore Drain on 'Lydia Downs' Station, north of Nelia at Julia Creek.

Stratigraphic horizon. Toolebuc Formation (late Albian).

Description. Cervical vertebrae (two anterior, four posterior) occur with distinct foramina subcentralia (Figure 9C, F), parts of neural arches and neural canal (Figure 9B, D), lateral ridges and dumbbellshaped articular facets (Figure 9A) $(\mathrm{CW}=81-$ $122.85 \mathrm{~mm} ; \mathrm{CL}=74.9-90.5 \mathrm{~mm} ; \mathrm{CH}=67-87.6$ $\mathrm{mm}$ ). The change in position of rib facets from being borne almost ventrally on the centrum (Figure 9A) to ventro-laterally on the centrum (Figure $9 \mathrm{E})$ indicates the transition from anterior to posterior cervicals. Parts of the neural spines are retained (Figure 9A, B, D, E), but they are not complete in their dorsal extremity.

Remarks. The original sequence of vertebrae is lost; the current sequence is based on the size and shape of the vertebrae. Vertebrae show elasmosaur characteristics (e.g., lateral ridges and dumbbell-shaped articular facets, obscured by slight distortion) (Otero et al., 2014; Sachs and Kear, 2017). Based on the osteological immaturity of the vertebrae with open neurocentral sutures, the specimen appears to be a subadult-adult.

Elasmosauridae gen. et sp. indet. (RM FR436)

Figure 10

Material. Partial postcranial material with 12 isolated vertebrae.

Locality. Near Richmond, Queensland (exact locality unknown). 


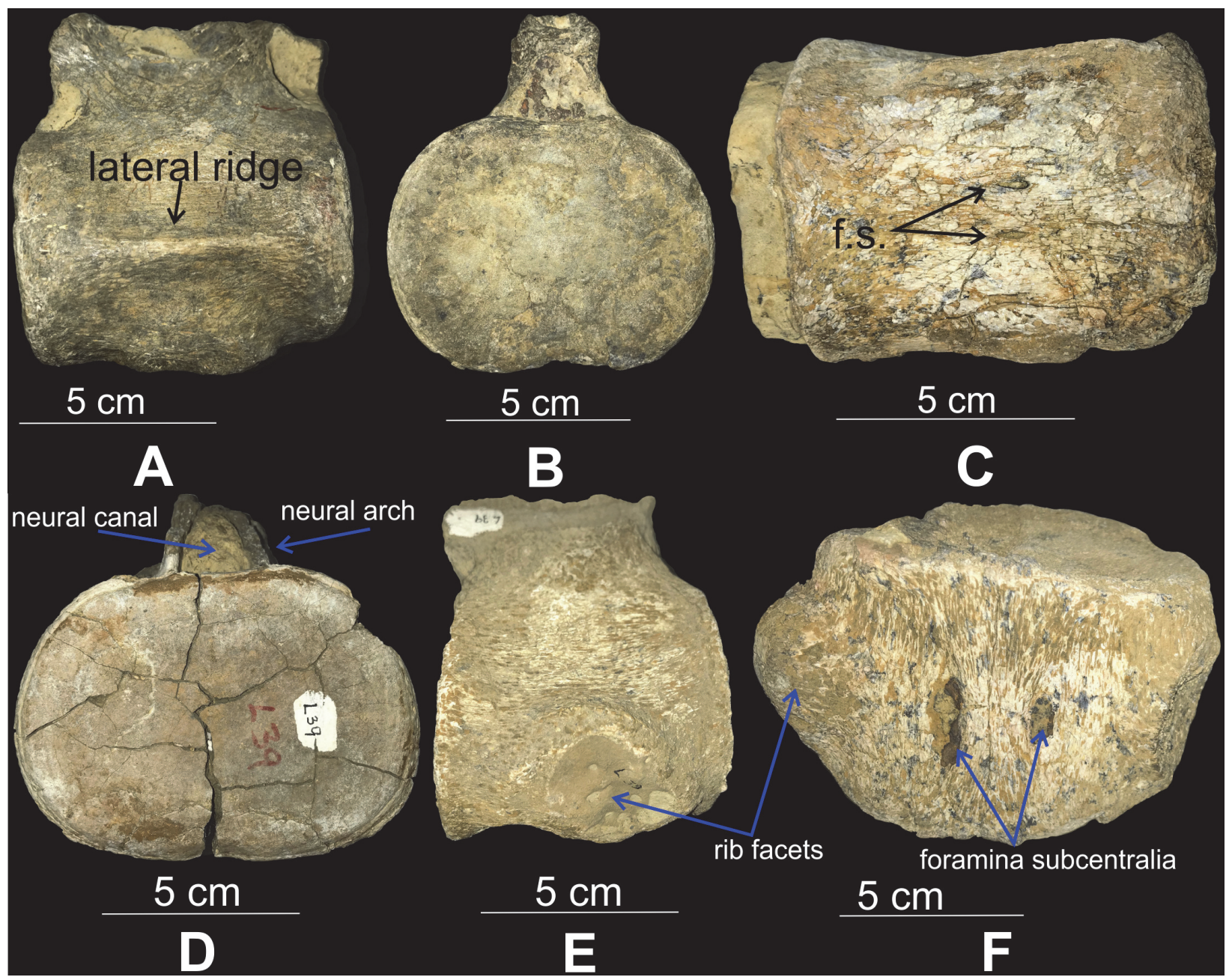

FIGURE 9. Specimen QM L39 - anterior cervicals. A. Lateral view with prominent ridge. B. Anterior view. C. Ventral view with foramina subcentralia. D. Anterior view. E. Lateral view showing rib facet. F. Ventral view showing foramina subcentralia. Scales shown on figure.

Stratigraphic horizon. Toolebuc Formation (late Albian)

Description. Twelve isolated, anterior cervical vertebrae $(\mathrm{CW}=91.2-61.85 \mathrm{~mm} ; \mathrm{CH}=62.65-42.1$ $\mathrm{mm}$; CL could not be measured owing to distortion) are free of matrix (Figure 10A). All centra are complete, but most appear to be dorso-ventrally flattened and sheared, thereby distorting $\mathrm{CL}$ measurements. Vertebrae have faintly visible foramina subcentralia and lack fused elements. All vertebrae bear faint lateral ridges and well-developed dumbbell-shaped articular facets obscured by distortion (Figure 10C) (Otero et al., 2014; Sachs and Kear, 2017).

Remarks. The original sequence of vertebrae is lost and the current sequence is based loosely on vertebra size. The lateral ridges and dumbbellshaped articular facets are consistent with an elasmosaurid identification (Otero et al., 2014). Based on the osteological immaturity of the vertebrae, with open neurocentral sutures, and their size, the specimen appears to be a subadult. It is important to note that all vertebrae have been sheared differentially; some are skewed left dorsally whereas others are skewed right dorsally (Figure 10; Appendix Figure 1). Since shearing was almost certainly caused during compaction, we can infer that the vertebrae were lying on their sides postmortem, but not all were oriented in the same direction. As the original sequence of vertebrae is not preserved, three hypotheses may explain their orientations. If the order reconstructed on the basis of size is correct (Figure 10A; Appendix Figure 1A), individual vertebrae toppled to either side (Appendix Figure 1B), followed by shearing. Alternately, the vertebrae may represent two or more sections of neck that were deposited on different sides (Appendix Figure 1C) and were sheared together 


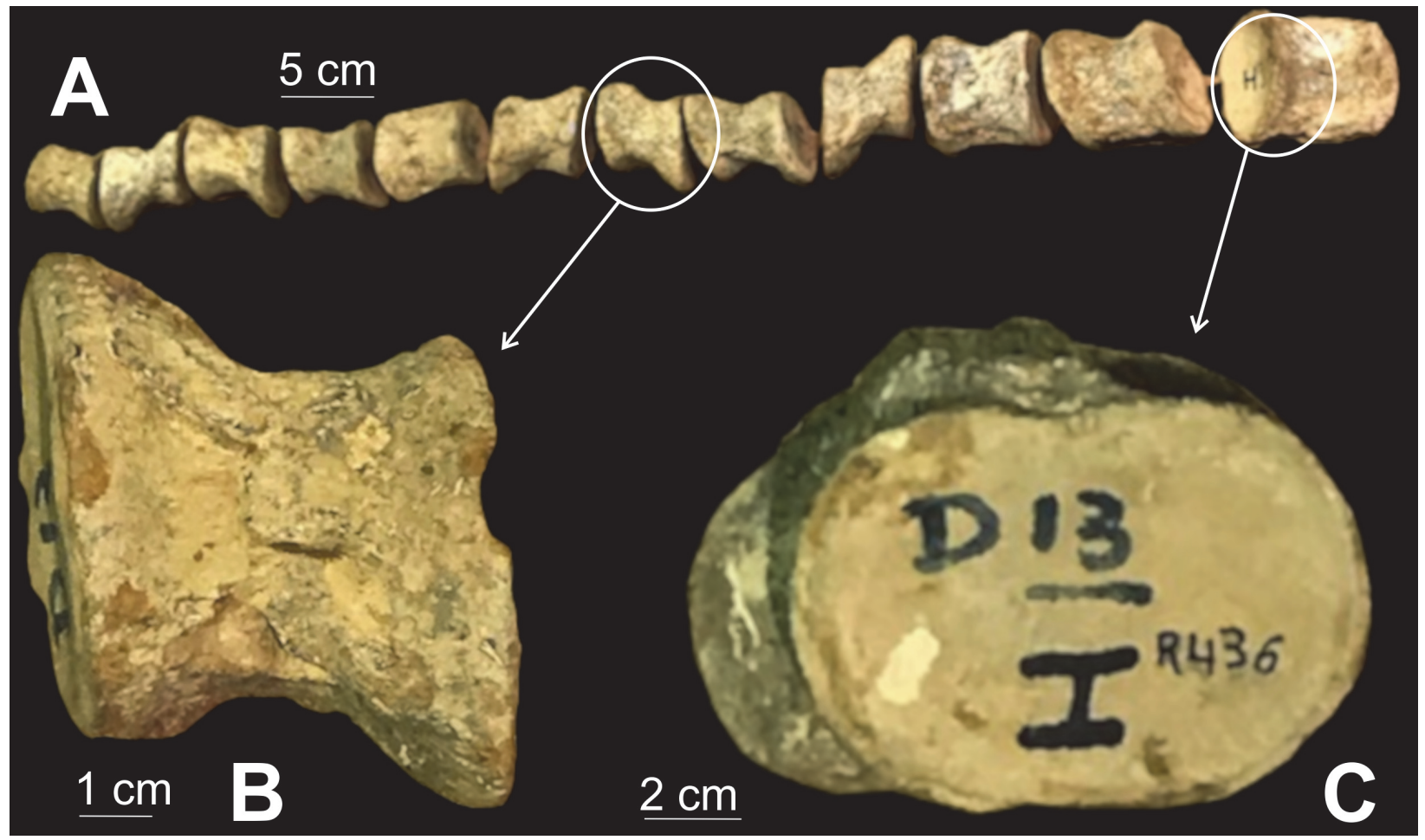

FIGURE 10. Specimen RM FR436. A. 12 anterior cervical vertebrae. B. Ventral view. C. Anterior view. Note the skewed vertebra. Scales shown on figure.

in sections. This would require that the order based on size is incorrect. Finally, the vertebrae may have been disarticulated completely upon deposition, ending up resting in different random orientations prior to compaction (Appendix Figure 1D). This would explain the irregular ordering of the shearing, but would require that none of the vertebrae were deposited on dorsal or ventral surfaces. At this time, the lack of detailed excavation notes makes it impossible to exclude one of the options. Owing to the incomplete data, this specimen was not included in further analyses.

Elasmosauridae gen. et sp. indet. (QM F171282)

Figure $11 \mathrm{~A}-\mathrm{C}$

Material. Single, isolated cervical centrum, free of matrix.

Locality. Flinders River, about $4.8 \mathrm{~km}$ from Richmond.

Stratigraphic horizon. Toolebuc Formation (late Albian).

Description. One anterior cervical with distinct foramina subcentralia separated by a mid-ventral keel (Figure 11C) on the ventral surface and neural arches fused to the centrum (Figure 11B) with lateral ridges and dumbbell-shaped articular facets (Figure 11A) $(\mathrm{CW}=108.4 \mathrm{~mm} ; \mathrm{CL}=98.8 \mathrm{~mm} ; \mathrm{CH}$ $=88.35 \mathrm{~mm}$ ).
Remarks. The vertebra has typical elasmosaurid characteristics (lateral ridges and dumbbell-shaped articular facets) (Otero et al., 2014; Sachs and Kear, 2017). Based on the size and osteological immaturity of the vertebra with open neurocentral sutures (Brown, 1981), the specimen appears to be a subadult-adult. Apparently, no other material was recovered for this individual.

\section{Specimen PL (unregistered Queensland Museum specimen) \\ Figure 11D-F}

Referred material. Two isolated cervical vertebrae (designated as PL1 and PL2).

Locality. Unknown, but Australian and thought to be central Queensland.

Stratigraphic horizon. Unknown.

Description. Two anterior cervicals with distinct foramina subcentralia (Figure 11E) and distinct lateral ridges (Figure 11D); parts of neural arches fused to the centra (Figure 11F) ( $\mathrm{CW}=76.7-78.4$ $\mathrm{mm} ; 77.1-81.1 \mathrm{~mm} ; \mathrm{CH}=66.2-64.2 \mathrm{~mm}$ ).

Remarks. Based on the size and osteological immaturity of the vertebrae, with open neurocentral sutures (Brown, 1981), this specimen appears to be a subadult. No notes accompany these vertebrae and their exact locality and horizon are unknown. Nevertheless, they were included in this 


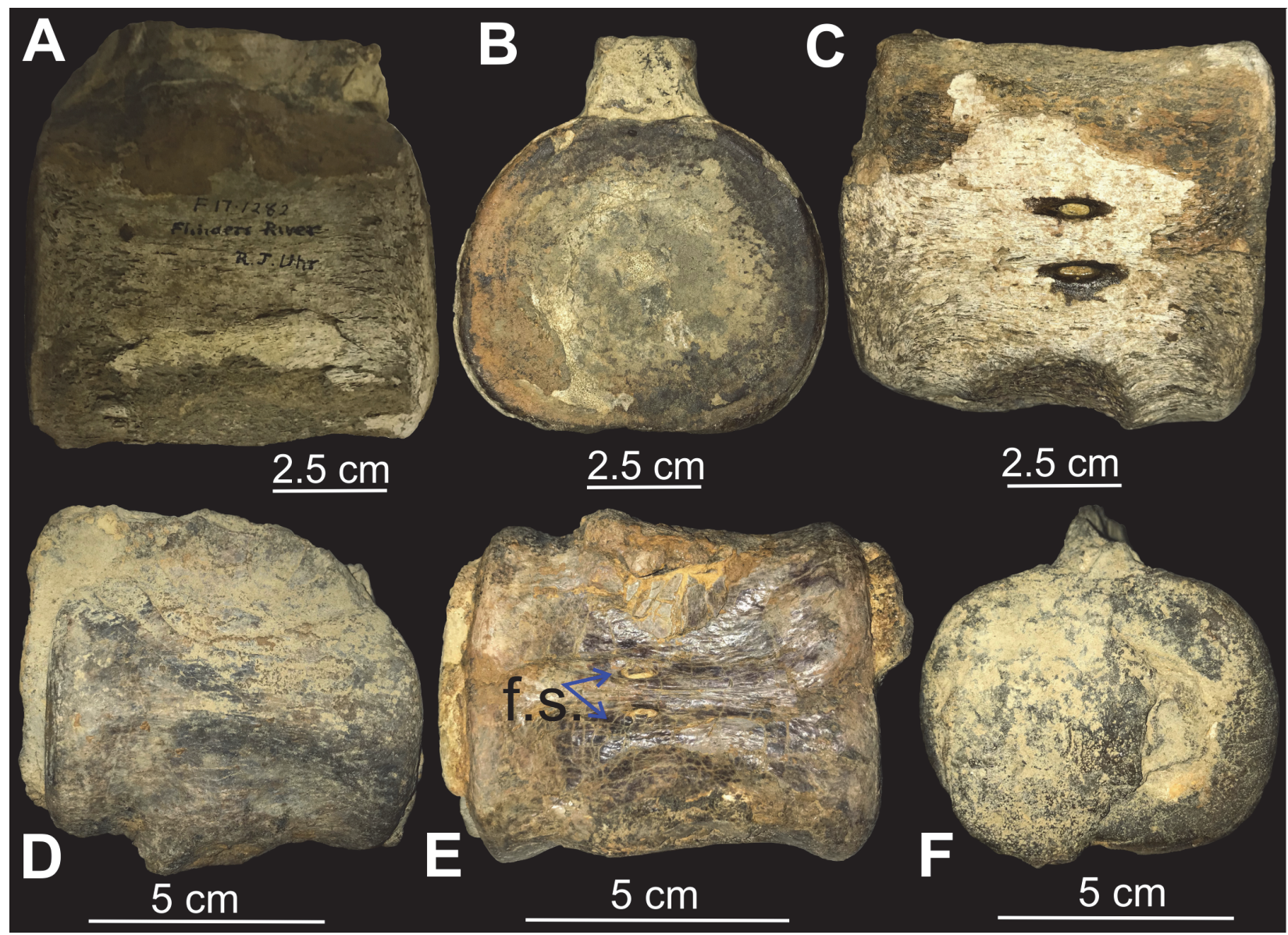

FIGURE 11. A-C. Specimen F171282/QM ISO. A. Lateral view showing lateral ridge. B. Anterior view, showing neural arch fused to the centrum. C. Ventral view showing paired foramina subcentralia. D-F. QM Specimen PL (unregistered). D. Anterior cervical, lateral view showing ridge. E. Anterior cervical, ventral view showing paired foramina subcentralia. F. Anterior cervical, anterior view, showing part of neural arches fused to the centrum. Scales shown on figure.

study as they could be identified as elasmosaur vertebrae (lateral ridges and dumbbell-shaped articular facets) (Otero et al., 2014; Sachs and Kear, 2017).

\section{MORPHOMETRIC ANALYSIS}

\section{Vertebral Length Index Plots}

For the most complete elasmosaurid specimens, VLI was plotted against vertebral position normalised to body region (cervicals, dorsals, and caudals) (Figure 12) to compare general trends along the vertebral column. Specimen RM FR269 (Figure 12) showed an anomalous trend in the cervical region with an apparent dip where other specimens have a peak. This may be the result of the vertebrae being jumbled subsequent to collection, but the anterior cervicals were clearly distinguishable from the posterior, so should be plotted in the correct sector. All specimens (other than the polycotylid QM F12719) appear to represent subadult to adult individuals. However, even for the Australian specimens with well-preserved vertebrae, it is possible that the vertebral sequences may be partly out of order and, hence, further analyses independent of vertebral position were carried out (see below for PCA, HI-BI-VLI, and H/W plots).

Vertebrae from different body regions (cervical, dorsal, and caudal) show somewhat different distributions of VLI with position along the vertebral column. As expected, cervicals show maximum variation in VLI for both Australian and non-Australian specimens (Figure 12). Dorsals have relatively flat distributions and caudals are slightly more variable than dorsals. Even within cervicals, the anterior-mid cervicals ( between normalised $0-0.5$; hereafter referred to as anterior cervicals) (Figures $12,13)$ show maximum disparity compared to the 


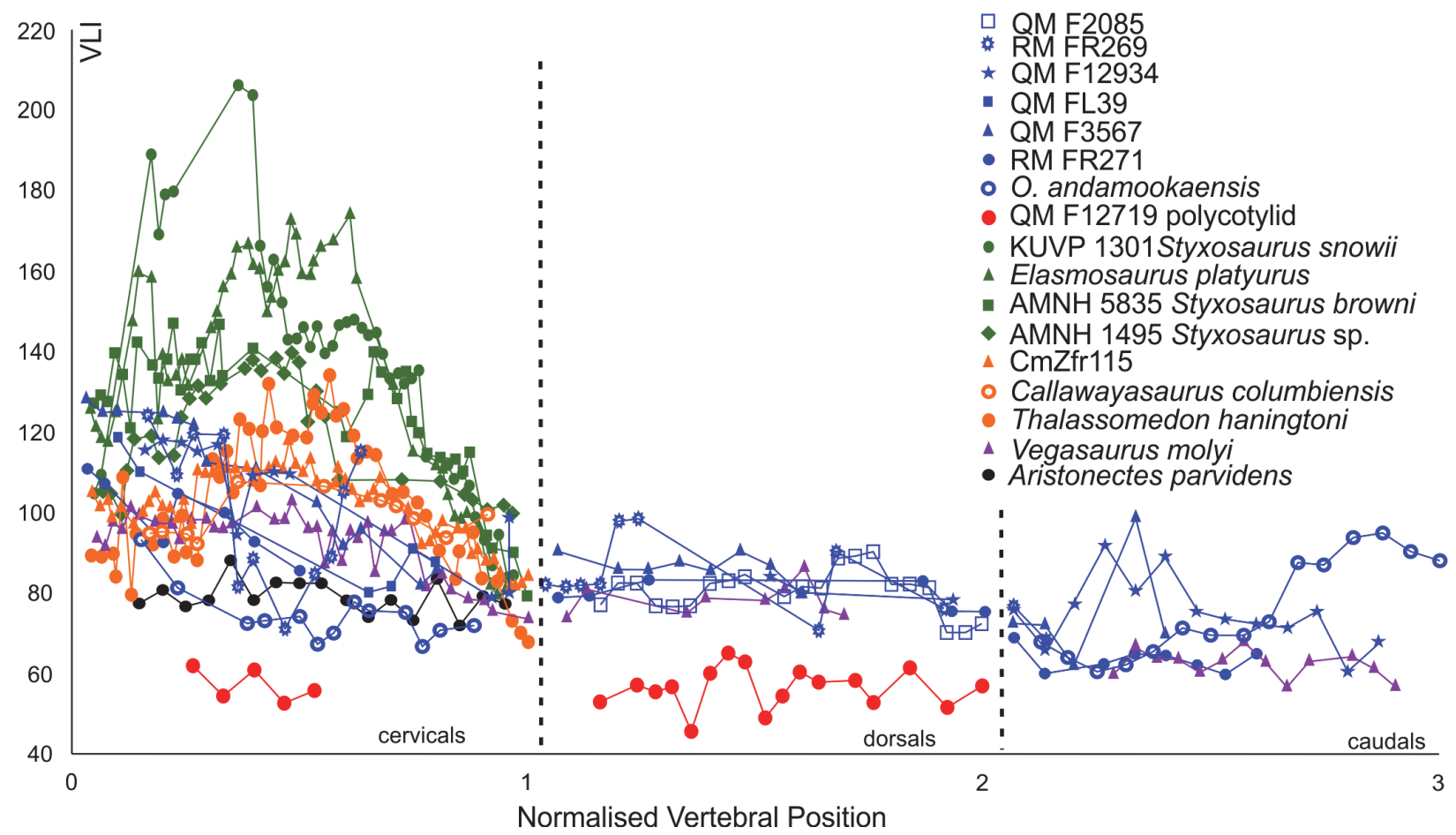

FIGURE 12. Normalised vertebral position (cervicals 0-1; dorsals 1-2; caudals 2-3) plotted against vertebral length index (VLI) for Australian plesiosaurians and non-Australian elasmosaurids. Data for QM F3567 and RM FR271 from Sachs (2004); Opallionectes andamookaensis from Kear (2005a); Elamosaurus platyurus, Thalassomedon haningtoni, Callawayasaurus colombiensis, and Cm Zfr 115 from O'Keefe and Hiller (2006); Vegasaurus molyi from O'Gorman el. (2015); AMNH FARB 1495, AMNH FARB 5835, and AMNH FARB 2554 from Otero (2016); Aristonectes parvidens from O'Gorman (2016a); Kawanectes lafquenianus from O'Gorman (2016b); Lagenanectes richterae from Sachs et al. (2017), and Jucha squalea from Fischer et al. (2020).

remainder of cervicals. Australian elasmosaurid dorsals are relatively flat and consistent in morphology, but with greater VLI than for the polycotylid (QM F12719). Polycotylid dorsals are similar in $\mathrm{VLI}$ to its cervicals. Australian elasmosaur caudals are more variable, but show contrast with the dorsals in a consistent way. As cervicals show more variable trends than dorsals and caudals, they are shown enlarged in Figure 13. For ease of comparison, specimen RM FR269 is excluded in Figure 13 owing to its anomalous, potentially jumbled trend; Styxosaurus snowii (KUVP 1301s) is also excluded because of its very large VLI values.

Cervical vertebrae of the Australian elasmosaurids RM FR271 and QM F12934 show similar trends that decrease in VLI from anterior to posterior, but generally plot within the range of cervicals of specimens possessing 'Cimoliasaurus'-grade cervicals (see Otero, 2016; O'Gorman, 2019a,b basal elasmosaurids like Thalassomedon haningtoni Welles, 1943 and Callawayasaurus colombiensis Welles, 1962, the non-aristonectine weddellonectian elasmosaurid Vegasaurus molyi O'Gorman et al., 2015, and indeterminate elasmo- saurid specimen CM Zfr 115). Specimens possessing this type of cervicals are characterised by VLI values intermediate between the styxosaurines (elasmosaurines) (e.g., Styxosaurus browni Welles, 1952; AMNH FARB 1495; and Elasmosaurus platyurus Cope, 1868), which possess very high VLI values, and aristonectines (e.g., Aristonectes parvidens Cabrera, 1941), which possesses very low VLI values (Figures 12, 13). The Australian elasmosaurid QM F3567 overlaps with the styxosaurines, whereas Opallionectes andamookaensis plots well within the VLI range of $A$. parvidens, consistent with the aristonectine affinity previously suggested by Kear (2006a; i.e., anteroposteriorly shortened cervicals relative to their height with transversely expanded centra with somewhat platycoelous articular surfaces, although the characteristic longitudinal ridge of aristonectines is lacking in $\mathrm{O}$. andamookaensis). Vegasaurus molyi has a distinct trend in the mid cervical region, but is clustered with the 'Cimoliasaurus'-grade cervical morphotypes in the anterior cervical region (Figure 13). Among the 'Cimoliasaurus'-grade morphotypes, Th. haningtoni has 


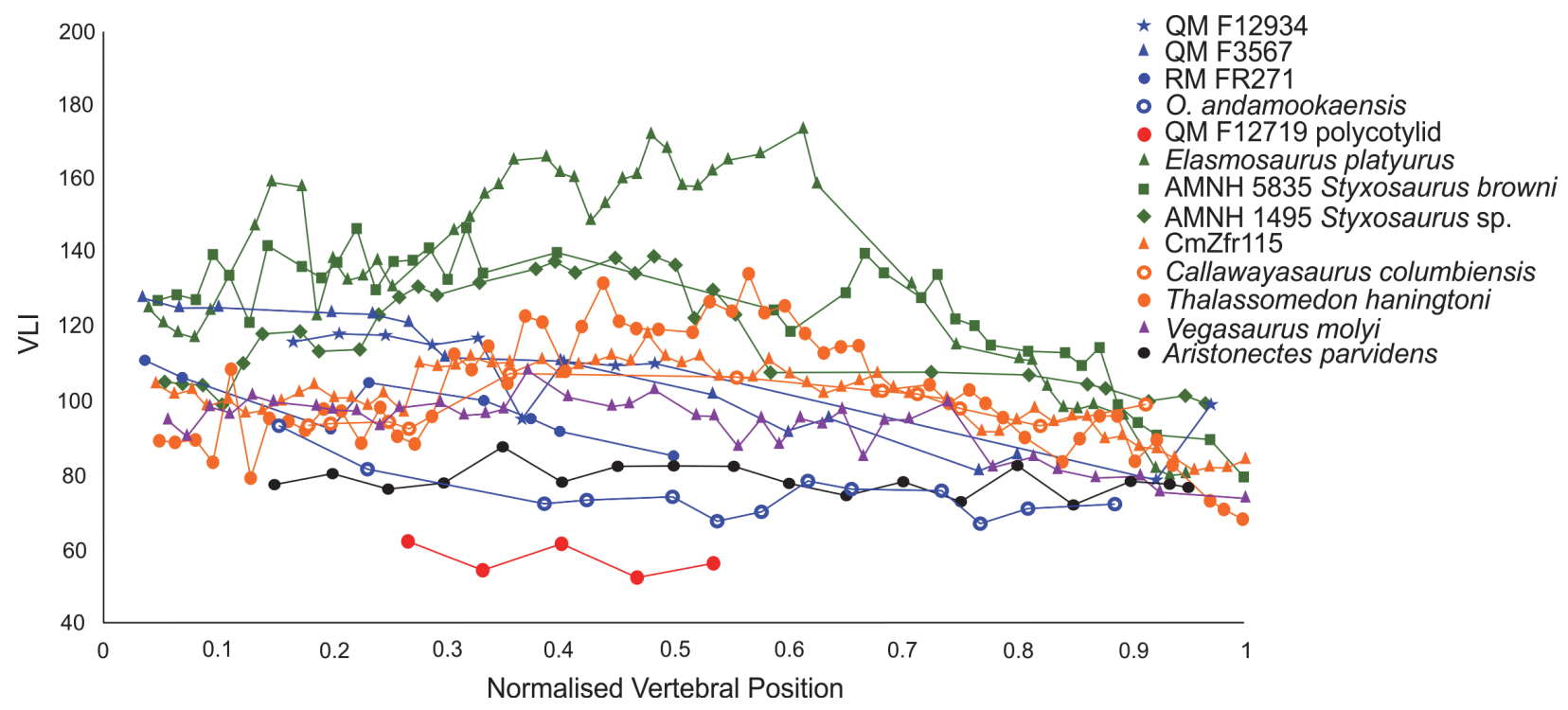

FIGURE 13. Normalised cervical vertebral position plotted against vertebral length index (VLI) for Australian plesiosaurians and non-Australian elasmosaurids. Data for QM F3567 and RM FR271 from Sachs (2004); Opallionectes andamookaensis from Kear (2005a); Elamosaurus platyurus, Thalassomedon haningtoni, Callawayasaurus colombiensis, and Cm Zfr 115 from O'Keefe and Hiller (2006); Vegasaurus molyi from O'Gorman el. (2015); AMNH 1495, AMNH 5835, and AMNH 2554 from Otero (2016); Aristonectes parvidens from O'Gorman (2016a); Kawanectes lafquenianus from O'Gorman (2016b); Lagenanectes richterae from Sachs et al. (2017) and Jucha squalea from Fischer et al. (2020).

relatively high VLI values in the mid-cervical region but still possesses lower VLI values than the styxosaurines (Figure 13). The polycotylid (specimen QM F12719), as expected, plots separately, with lower VLI than all Australian and non-Australian elasmosaurid specimens.

Trends between anterior and posterior cervical VLI in Australian elasmosaurid specimens resemble trends in mid- and posterior cervicals of foreign Late Cretaceous elasmosaurids. However, this trend may be misleading because of the general incompleteness of the Australian specimens and the uncertainty of vertebral position in relatively complete Australian specimens like QM F12934. In order to address this uncertainty, additional morphometric analyses that are independent of vertebral position included the above-mentioned Australian specimens and those with unknown vertebral sequences (Australian specimens RM FR269, QM L39, QM F171282, QM PL) along with non-Australian specimens (Aristonectes quiriquinensis Otero et al., 2014; Tuarangisaurus keyesi Wiffen and Moisley, 1986; Albertonectes vanderveldei Kubo et al., 2012; CM Zfr 115; and AMNH FARB 2554). Ideally, comparisons would have been made comparing precise vertebral positions (e.g., Otero, 2016), but this was not possible for the Australian specimens. Regardless, anterior and posterior cervical vertebrae were separated for analysis to accommodate the greater interspecific variability of anterior cervicals, possibly related to the greater potential for flexibility of that part of the neck (O'Keefe and Hiller, 2006) (Figures 12, 13, see PCA analysis below). Additional analyses concentrate on the anterior cervical vertebrae of Australian and non-Australian specimens.

Plots of VLI against breadth index $(\mathrm{BI})$, height index $(\mathrm{HI})$ versus $\mathrm{BI}$, and $\mathrm{VLI}$ versus breadth height index (BHI) for anterior cervicals (Figure 14, Appendix Figures 2, 3) show different positions for the analysed styxosaurines (characterised by high $\mathrm{VLI}$, low $\mathrm{BI}$, and low $\mathrm{HI}$ values) and aristonectines (characterised by low VLI, high $\mathrm{BI}$, and high $\mathrm{HI}$ values). The present analysis is consistent with that of Otero (2016), where analyses involved precise vertebral positions, with 'Cimoliasaurus'-grade cervicals (Th. haningtoni, V. molyi, Tu. keyesi, CM Zfr 115, and AMNH FARB 2554) and Early Cretaceous non-Australian 'Cimoliasaurus'-grade elasmosaurids (Callawayasaurus colombiensis, Lagenanectes richterae, Jucha squalea) plotting primarily between the styxosaurines and aristonectines. Tuarangisaurus keyesi has a low dispersion point (distance between individual centra within the same individual; sensu Otero, 2016), without disparate elements (i.e., it has a tight cluster) and plots between the 'Cimoliasaurus'-grade morphotype and the elasmosaurines, but relatively closer 


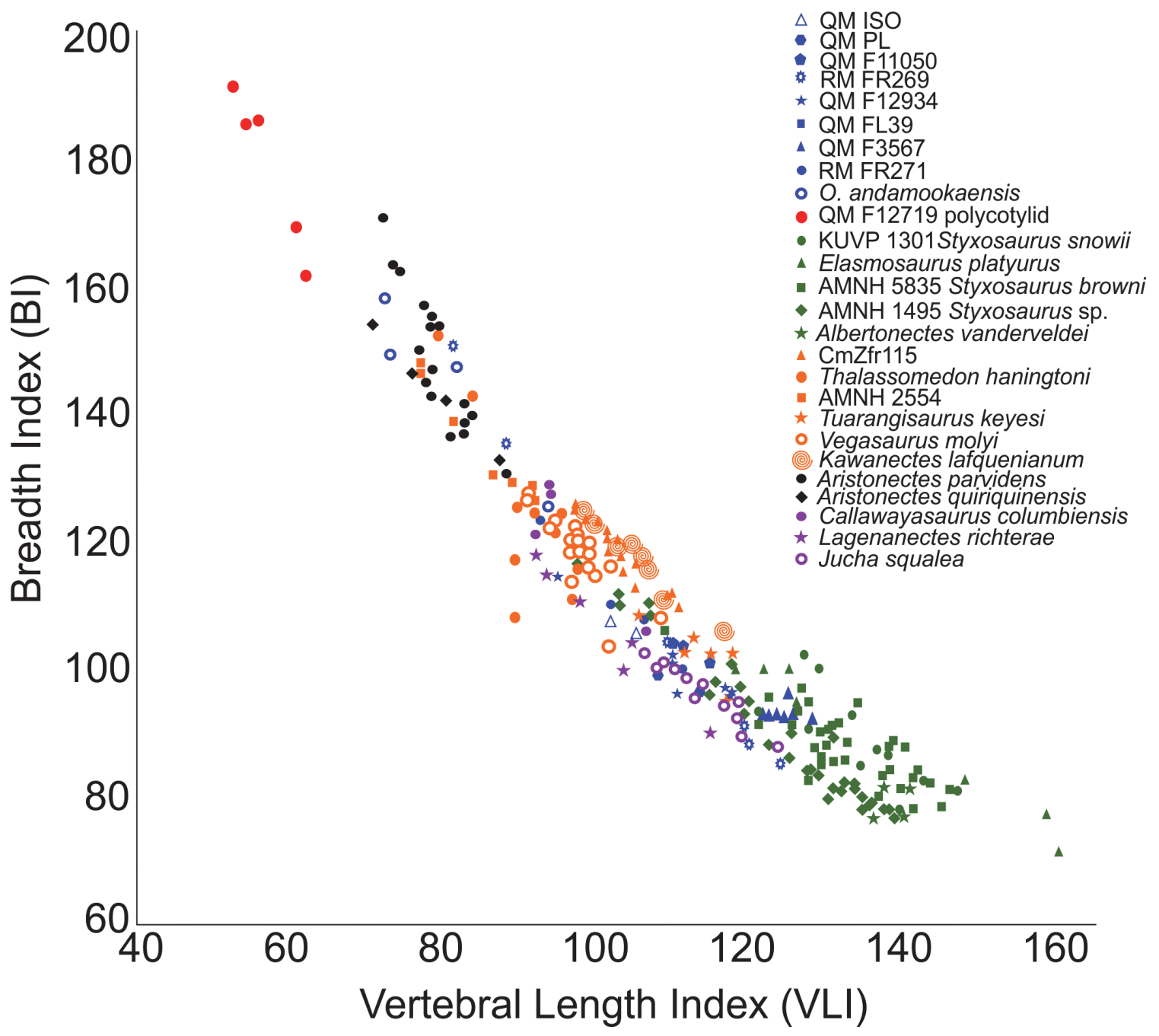

FIGURE 14. Plot for vertebral length index (VLI) against breadth index (BI) for Australian plesiosaurians and nonAustralian elasmosaurids. Data for QM F3567 and RM FR271 from Sachs (2004); Opallionectes andamookaensis from Kear (2005a); Elamosaurus platyurus, Thalassomedon haningtoni, Callawayasaurus colombiensis, and Cm Zfr 115 from O'Keefe and Hiller (2006); Aristonectes quiriquinensis from Otero et al. (2014); Albertonectes vanderveldei from Kubo et al. (2012); Vegasaurus molyi from O'Gorman el. (2015); Tuarangisaurus keyesi from Hiller et al. (2017); AMNH FARB 1495, AMNH FARB 5835, Styxosaurus snowii, and AMNH FARB 2554 from Otero (2016); Aristonectes parvidens from O'Gorman (2016a); Kawanectes lafquenianus from O'Gorman (2016b); Lagenanectes richterae from Sachs et al. (2017) and Jucha squalea from Fischer et al. (2020).

to the latter. On the other hand, $V$. molyi plots well within the 'Cimoliasaurus'-grade morphotype, with a low dispersion point and a relatively complete neck, but distinct from Tu. keyesi. Lagenanectes richterae has a moderate dispersion point, without disparate elements, and plots well within the 'Cimoliasaurus'-grade cervicals but distinct from Australian and non-Australian Early Cretaceous elasmosaurids (e.g., C. colombiensis and $\mathrm{J}$. squalea). Jucha squalea has a low dispersion point, and plots with the Australian elasmosaurids with a few overlapping elements with $C$. colombiensis. Kawanectes lafquenianus (species name necessarily emended from lafquenianum for gender agreement with the masculine -nectes, following ICZN Art. 34.2) has a relatively tight cluster within the 'Cimoliasaurus'-grade cervicals, with low dispersion point, and plots close to indeterminate elasmosaurid specimen CM Zfr 115.

Australian elasmosaurids (QM F3567, RM FR271, RM FR269, QM L39, QM F11050, QM $F 171282$, and QM F12934) generally plot well within the 'Cimoliasaurus'-grade morphotype, but slightly more towards the styxosaurine field. RM FR269 has the highest dispersion point, with some cervicals extending to both ends - a few in the 


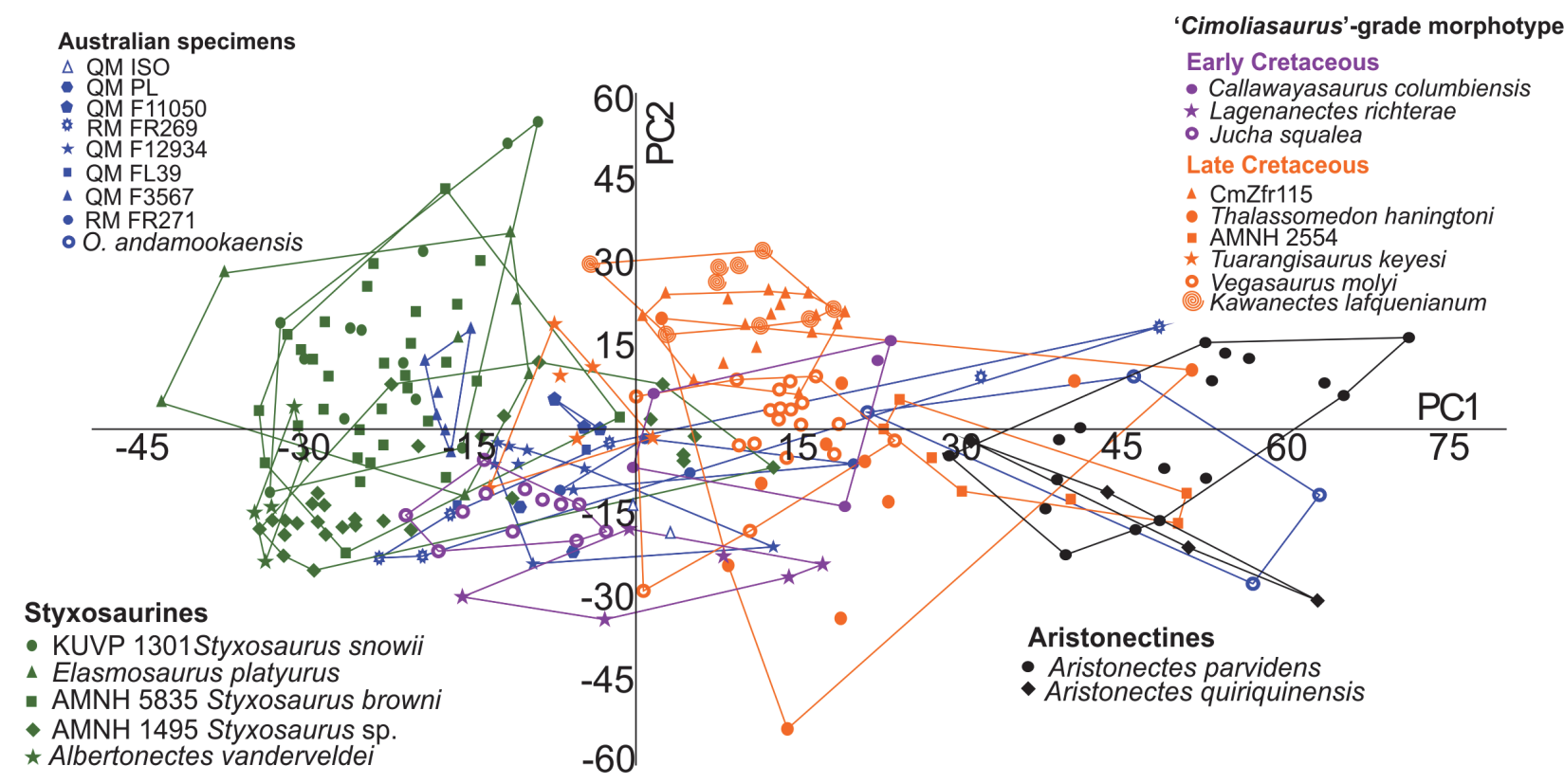

FIGURE 15. Principal Components Analysis for anterior cervicals of Australian xenopsarian specimens (including previously described QM F3567 from Sachs (2004) and Opallionectes andamookaensis from Kear (2006), but excluding polycotylid QM F12719) and non-Australian elasmosaurids using shape variables (HI, BI, BHI). Data for QM F3567 and RM FR271 from Sachs (2004); Opallionectes andamookaensis from Kear (2005a); Elamosaurus platyurus, Thalassomedon haningtoni, Callawayasaurus colombiensis and Cm Zfr 115 from O'Keefe and Hiller (2006); Aristonectes quiriquinensis from Otero et al. (2014); Albertonectes vanderveldei from Kubo et al. (2012); Vegasaurus molyi from O'Gorman el. (2015); Tuarangisaurus keyesi from Hiller et al. (2017); AMNH FARB 1495, AMNH FARB 5835, Styxosaurus snowii, and AMNH FARB 2554 from Otero (2016); Aristonectes parvidens from O'Gorman (2016a); Kawanectes lafquenianus from O'Gorman (2016b); Lagenanectes richterae from Sachs et al. (2017) and Jucha squalea from Fischer et al. (2020).

styxosaurine cluster and a few in the aristonectine cluster - but this could be biased by its more complete neck. Interestingly, QM F3567 plots almost exclusively within the styxosaurine cluster in the $\mathrm{VLI} / \mathrm{BI}, \mathrm{HI} / \mathrm{BI}, \mathrm{VLI} / \mathrm{BHI}$ plots (Figure 14, Appendix Figures 2, 3), similar to the vertebral position plots (Figures 12, 13). In all three plots, $O$. andamookaensis is nested exclusively within the aristonectine cluster, suggesting similar vertebral morphology characterized by shortened vertebrae (see Otero, 2016; O'Gorman, 2020) and consistent with the description by Kear (2006a), although he noted that the anterior cervicals lacked the deep ventral groove seen in Aristonectes. The polycotylid (specimen QM F12719) plots separately from all elasmosaurids based on extremely shortened cervical centra with extremely high $\mathrm{HI}$ and $\mathrm{BI}$ values (Figure 14) and the lowest VLI values (Appendix Figures 2, 3). In the $\mathrm{HI} / \mathrm{BI}$ and $\mathrm{VLI} / \mathrm{BHI}$ plots (Figure 14, Appendix Figure 3), Th. haningtoni has a few disparate elements along $\mathrm{BI}$, despite having a low dispersion point along $\mathrm{HI}$ (see Otero, 2016).

\section{Principal Component Analysis}

PCA loadings and eigenvalues for PCA are shown using the shape variables $(\mathrm{HI}, \mathrm{BI}, \mathrm{BHI})$ in Table 2 for anterior cervicals of Australian and nonAustralian specimens (polycotylid QM F12719 excluded) (Figure 15; see Appendix Figure 4 for inclusion of the outlier polycotylid QM F12719). Similar plots of posterior cervicals of Australian and non-Australian specimens did not differentiate the specimens (Appendix Table 3, Appendix Figure 5). $\mathrm{PC} 1$ accounts for $\sim 69-70 \%$ of variation in $\mathrm{HI}, \mathrm{BI}$, and $\mathrm{BHI}$ for anterior cervicals of Australian and non-Australian specimens (Table 2). Maximum variance along $\mathrm{PC} 1$ reflects differences in shape trends of vertebrae with $\mathrm{HI}, \mathrm{BI}$, and $\mathrm{BHI}$ all having positive loadings, yielding an axis with proportionately long centra and strongly circular cross sections. PC2 accounts for $\sim 30 \%$ variation in $\mathrm{HI}, \mathrm{BI}$, and $\mathrm{BHI}$ (Table 2), also reflecting differences in shape trends. On $\mathrm{PC} 2, \mathrm{BI}$ is slightly positive, $\mathrm{BHI}$ is strongly positive, and $\mathrm{HI}$ is strongly negative, yielding an axis where negative values reflect centra with strongly circular to slightly ellipsoidal cross sections (c.f., Buchholz, 2001; O'Keefe, 2002; 
TABLE 2. PCA scores, percent variance and eigenvalues for shape variables for anterior cervicals of newly described Australian xenopsarian specimens (including previously described QM F3567 from Sachs (2004), but excluding polycotylid QM F12719) and anterior cervicals of non-Australian plesiosauromorph specimens. Data for QM F3567 and RM FR271 from Sachs (2004); Opallionectes andamookaensis from Kear (2005a); Elamosaurus platyurus, Thalassomedon haningtoni, Callawayasaurus colombiensis and $\mathrm{Cm}$ Zfr 115 from O'Keefe and Hiller (2006); Aristonectes quiriquinensis from Otero et al. (2014); Albertonectes vanderveldei from Kubo et al. (2012); Vegasaurus molyi from O'Gorman el. (2015); Tuarangisaurus keyesi from Hiller et al. (2017); AMNH FARB 1495, AMNH FARB 5835, Styxosaurus snowii, and AMNH FARB 2554 from Otero (2016); Aristonectes parvidens from O'Gorman (2016a); Kawanectes lafquenianus from O'Gorman (2016b); Lagenanectes richterae from Sachs et al. (2017) and Jucha squalea from Fischer et al. (2020).

\begin{tabular}{lccc}
\hline Loadings & PC 1 & PC 2 & PC 3 \\
\hline $\mathrm{HI}$ & 0.5269 & -0.4248 & 0.73615 \\
$\mathrm{BI}$ & 0.83701 & 0.10892 & -0.53623 \\
$\mathrm{BHI}$ & 0.14761 & 0.89871 & 0.41295 \\
Eigenvalue & 640.871 & 275.432 & 1.78314 \\
\% variance & 69.805 & 30.001 & 0.19422 \\
\hline
\end{tabular}

O'Keefe and Carrano, 2005; O'Keefe and Hiller, 2006).

PCA plots of anterior cervicals easily discriminate styxosaurines and aristonectines. However, within the styxosaurines, Styxosaurus snowii, S. browni, Elasmosaurus platyurus, and Albertonectes vanderveldei plot exclusively with negative PC1 and positive or negative PC2 values, whereas AMNH FARB 1495 plots with some positive PC1 values. The aristonectine Aristonectes parvidens plots with positive or negative PC2 and exclusively positive PC1 values, whereas $A$. quiriquinensis plots exclusively with positive PC1 and negative PC2 values. 'Cimoliasaurus'-grade cervicals plot between these two groups, but with some overlap with either group. Most Late Cretaceous 'Cimoliasaurus'-grade morphotypes (Thalassomedon haningtoni, Vegasaurus molyi, Kawanectes lafquenianus, and CM Zfr 115) plot primarily with positive PC1 values, but Tuarangisaurus keyesi plots with negative PC1 values. Early Cretaceous non-Australian 'Cimoliasaurus'-grade elasmosaurids plot primarily with negative PC2 values, distinguishing Lagenanectes richterae and Jucha squalea from the Late Cretaceous taxa (Figure 15), but Callawayasaurus colombiensis plots with some PC2 values, thus overlapping styxosau- rines with positive $\mathrm{PC} 1$ values and the Late Cretaceous 'Cimoliasaurus'-grade taxa. Australian elasmosaurids (except QM F3567) plot mostly overlapping the negative PC2 styxosaurines and Early Cretaceous non-Australian 'Cimoliasaurus'grade taxa, although the high dispersion of RM FR269 extends near the styxosaurines. Specimen QM F3567 plots with negative PC1 values completely enveloped within the styxosaurine cluster (Figure 15, Appendix Figures 2, 3). Opallionectes andamookaensis plots positively on the PC1 axis but on both sides of the PC2 axis with the aristonectine cluster. The indeterminate Late Cretaceous elasmosaurid AMNH FARB 2554 plots with the aristonectines and $O$. andamookaensis, and Th. haningtoni has very high dispersion overlapping the 'Cimoliasaurus'-grade and aristonectine clusters. As expected, the polycotylid (QM F12719) is differentiated from all elasmosaurid taxa owing to its very negative PC2 values (Appendix Figure 4).

Comparing posterior cervicals of Australian and non-Australian specimens (Appendix Figure 5; Appendix Table 3), PC1 also is interpreted as a shape factor with strongly positive loadings for all values of $\mathrm{HI}, \mathrm{BI}$, and $\mathrm{BHI}$, yielding an axis with long centra and circular cross sections. PC2 can be inferred as a shape factor with strongly positive loadings for $\mathrm{BHI}$, slightly positive loadings for $\mathrm{BI}$, and negative loadings for $\mathrm{HI}$. It yields an axis with slightly circular to strongly ellipsoidal cross sections (Buchholz, 2001; O'Keefe and Hiller, 2006). The posterior cervicals of almost all Australian and non-Australian specimens plot over a wide range, with significant overlap with each other. Therefore, posterior cervicals are not as useful for distinguishing the elasmosaurid groups.

PCA loadings and eigenvalues are shown for SD-normalized raw measurement data $(\mathrm{CL}, \mathrm{CW}$, $\mathrm{CH}$ ) in Appendix Table 4 for anterior cervicals of Australian and non-Australian specimens (Appendix Figure 6). Log-normalized (In) plots are very similar to SD-normalized plots and both normalisations failed to discriminate Australian and non-Australian specimens based on posterior cervicals. For SD-normalised anterior cervicals, PC1 accounts for $-89-90 \%$ of variation in $\mathrm{CL}, \mathrm{CW}$, and $\mathrm{CH}$ (Appendix Figure 6), while PC2 accounts for $\sim 8-$ $9 \%$. Maximum variance along PC1 primarily reflects differences in size trends of vertebrae despite the attempts to reduce the effect of size by standardizing and centering prior to analysis. Although this analysis (Appendix Figure 6) discriminates Australian and non-Australian elasmosaurid specimens, the considerable size bias prevents 
TABLE 3. MANOVA results with Pillai's Trace values for group pairs of xenopsarian specimens examined (CV: cervicals; alpha value = 0.05). Data for QM F3567 and RM FR271 from Sachs (2004); Opallionectes andamookaensis from Kear (2005a); Elamosaurus platyurus, Thalassomedon haningtoni, Callawayasaurus colombiensis and Cm Zfr 115 from O'Keefe and Hiller (2006); Aristonectes quiriquinensis from Otero et al. (2014); Albertonectes vanderveldei from Kubo et al. (2012); Vegasaurus molyi from O'Gorman el. (2015); Tuarangisaurus keyesi from Hiller et al. (2017); AMNH FARB 1495, AMNH FARB 5835, Styxosaurus snowii, and AMNH FARB 2554 from Otero (2016); Aristonectes parvidens from O'Gorman (2016a); Kawanectes lafquenianus from O'Gorman (2016b); Lagenanectes richterae from Sachs et al. (2017) and Jucha squalea from Fischer et al. (2020).

\begin{tabular}{|c|c|c|c|c|c|c|}
\hline Group 1 & Group 2 & Pillai's & df1 & df2 & $\mathbf{F}$ & p-value \\
\hline Australian elasmosaurs & QM F3567 & 0.5438 & 3 & 30 & 11.92 & $2.61 \mathrm{E}-05$ \\
\hline Elasmosaurines & QM F3567 & 0.04133 & 3 & 92 & 1.322 & 0.272 \\
\hline Elasmosaurines & Aristonectines & 0.8789 & 3 & 107 & 258.9 & $6.87 E-49$ \\
\hline O. andamookaensis & Aristonectines & 0.1005 & 3 & 21 & 0.7819 & 0.5173 \\
\hline O. andamookaensis & Australian elasmosaurs & 0.5664 & 3 & 28 & 12.19 & 2.77E-05 \\
\hline Elasmosaurines & V. molyi & 0.6565 & 3 & 105 & 66.88 & $2.92 \mathrm{E}-24$ \\
\hline Elasmosaurines & T. keysi & 0.147 & 3 & 92 & 5.286 & $2.09 \mathrm{E}-03$ \\
\hline V. molyi & T. keysi & 0.7489 & 3 & 21 & 20.87 & 1.66E-06 \\
\hline V. molyi & Aristonectines & 0.8344 & 3 & 36 & 60.48 & $3.92 \mathrm{E}-14$ \\
\hline T. keysi & Aristonectines & 0.8668 & 3 & 23 & 49.87 & $3.17 \mathrm{E}-10$ \\
\hline C. colombiensis & Australian elasmosaurs & 0.2584 & 3 & 30 & 3.485 & 0.02781 \\
\hline T. haningtoni & Australian elasmosaurs & 0.4669 & 3 & 35 & 10.22 & $5.62 \mathrm{E}-05$ \\
\hline T. haningtoni & C. colombiensis & 0.1759 & 3 & 13 & 0.9252 & 4.56E-01 \\
\hline C. colombiensis & Elasmosaurines & 0.4284 & 3 & 92 & 22.98 & $3.45 \mathrm{E}-11$ \\
\hline CM Zfr 115 & Australian elasmosaurs & 0.771 & 3 & 41 & 46.02 & $3.46 \mathrm{E}-13$ \\
\hline AMNH FARB 2254 & Australian elasmosaurs & 0.5694 & 3 & 33 & 14.55 & 3.31E-06 \\
\hline Elasmosaurines & Australian elasmosaurs & 0.4602 & 3 & 114 & 32.4 & $3.21 \mathrm{E}-15$ \\
\hline Aristonectines & Australian elasmosaurs & 0.8132 & 3 & 45 & 65.3 & $1.99 \mathrm{E}-16$ \\
\hline V. molyi & Australian elasmosaurs & 0.4117 & 3 & 43 & 10.03 & $3.92 \mathrm{E}-05$ \\
\hline C. colombiensis & Aristonectines & 0.7155 & 3 & 23 & 19.28 & 1.79E-06 \\
\hline L. richterae & Australian elasmosaurs & 0.5687 & 3 & 30 & 13.18 & 1.15E-05 \\
\hline L. richterae & Elasmosaurines & 0.7249 & 3 & 92 & 80.83 & $1.08 \mathrm{E}-25$ \\
\hline L. richterae & Aristonectines & 0.7695 & 3 & 23 & 25.6 & $1.64 \mathrm{E}-07$ \\
\hline J. squalea & Australian elasmosaurs & 0.158 & 3 & 36 & 2.252 & 0.09894 \\
\hline J. squalea & Elasmosaurines & 0.4009 & 3 & 98 & 21.86 & $6.39 \mathrm{E}-11$ \\
\hline J. squalea & Aristonectines & 0.9184 & 3 & 29 & 108.8 & $7.01 \mathrm{E}-16$ \\
\hline K. lafquenianus & CmZfr115 & 0.279 & 3 & 22 & 2.838 & $6.14 \mathrm{E}-02$ \\
\hline K. lafquenianus & Australian elasmosaurs & 0.8108 & 3 & 33 & 47.13 & $5.00 \mathrm{E}-12$ \\
\hline K. lafquenianus & Elasmosaurines & 0.6012 & 3 & 95 & 47.75 & $6.61 \mathrm{E}-19$ \\
\hline K. lafquenianus & Aristonectines & 0.9169 & 3 & 26 & 95.67 & $3.60 \mathrm{E}-14$ \\
\hline
\end{tabular}

more meaningful deductions, and these plots are not discussed further.

Shapiro-Wilk's normality test for $\mathrm{HI}, \mathrm{BI}$, and $\mathrm{BHI}$ yielded individual $p$-values of 2.571E-05, 1.834E-07, and 0.03853, respectively. Hence, the variables $\mathrm{HI}, \mathrm{BI}$, and $\mathrm{BHI}$ are not normally distributed, and Box's $M$ test was not performed owing to its sensitivity to violations of normality. MANOVA is robust to violations of normality and is discussed below.

\section{Multivariate Analysis of Variance (MANOVA)}

Complete MANOVA results are shown in Table 3. Only the principal similarities and dissimilarities are discussed here. Since the assumption of Box's $M$ test of equal covariance matrices was violated, Pillai's trace values were calculated. The 
TABLE 4. Non-Australian plesiosauromorph specimens examined for this study.

\begin{tabular}{lll}
\hline \multicolumn{1}{c}{ Taxon } & \multicolumn{1}{c}{ Specimen } & \multicolumn{1}{c}{ Author } \\
\hline Styxosaurus sp. ("Hydralmosaurus serpentinus”) & AMNH FARB 1495 & Cope, 1877 (see Otero, 2016) \\
Styxosaurus snowii & KUVP 1301 & Williston, 1890 \\
Elasmosaurus platyurus & ANSP 10081 & Cope, 1868 \\
Thalassomedon haningtoni & DMNH 1588 & Welles, 1943 \\
Vegasaurus molyi & MLP 93-I-5-1 & O'Gorman et al., 2015 \\
Albertonectes vanderveldei & TMP.2007.011.000 & Kubo et al., 2012 \\
& 1 & \\
Aristonectes quiriquinensis & SGO.PV.957 & Otero et al., 2014 \\
Aristonectes parvidens & MLP 40-XI-14-6 & Cabrera, 1941 \\
Tuarangisaurus keyesi & NZGS CD426 & Wiffen and Moisley, 1986 \\
Callawayasaurus colombiensis & UCMP 38349 & Welles, 1963 \\
"Cimoliasaurus magnus” & AMNH FARB 2554 & Leidy, 1851 \\
Styxosaurus browni & AMNH 5835 & Welles, 1952 \\
Indeterminate elasmosaurid & CM Zfr 115 & \\
Kawanectes lafquenianus & MLP 71-II-13-1 & O'Gorman, 2016 \\
Lagenanectes richterae & BGR Ma 13328 & Sachs et al., 2017 \\
Jucha squalea & UPM 2756/1-53 & Fischer et al., 2020 \\
\hline
\end{tabular}

significance value ( $p$-value) is less than the alpha value $(0.05)$ for most specimen pairs (Table 3 ), indicating that most results are statistically significant and that the MANOVA analysis was generally successful (Pillai 1995). Australian elasmosaurids (RM FR271, RM FR269, QM L39, QM PL, QM F171282, and QM F12934) have insignificant differences between them, but they differ as a group from specimen QM F3567 (Pillai's Trace $=0.5438$ ). They also are significantly different from the nonAustralian styxosaurines (Styxosaurus snowii, $S$. browni, AMNH FARB 1495, Albertonectes vanderveldei, and Elasmosaurus platyurus) (Pillai's Trace $=0.4602$ ). However, that difference is less significant than that between the Australian elasmosaurids and the non-Australian aristonectines (Pillai's Trace $=0.8132$ ). The non-Australian styxosaurines and QM F3567 are not significantly different (Pillai's trace $=0.04133$, $p$-value $=0.272$ ), consistent with all other plots. Similarly, Thalassomedon haningtoni and Callwayasaurus colombiensis are not significantly different (Pillai's Trace $=$ 0.1759 , $p$-value $=0.456$ ). Opallionectes andamookaensis and the non-Australian aristonectines are statistically similar (Pillai's Trace $=0.1005$, $p$-value of 0.5173 ), while $O$. andamookaensis is significantly different from other Australian elasmosaurids (excluding QM F3567) (Pillai's Trace value of $0.5664)$. As a group, the Australian elasmosaurids (excluding QM F3567 and O. andamookaensis) are moderately different from Vegasaurus molyi (Pillai's Trace $=0.4117$ ) and Th. haningtoni (Pillai's Trace $=0.4669$ ); they are similar to C. colombiensis (Pillai's Trace $=0.2584$ ); and significantly different from CM Zfr 115 (Pillai's Trace = 0.771) and AMNH FARB 2554 (Pillai's Trace $=0.5694$ ). The two principal groups, the styxosaurines and aristonectines, are significantly different from each other (Pillai's Trace $=0.8789$ ). Tuarangisaurus keyesi is not significantly different from the styxosaurines (Pillai's Trace $=0.147$ ), but Tu. keyesi and V. molyi differ from each other (Pillai's Trace = 0.7489). Lagenanectes richterae remains distinct from the Australian elasmosaurids (Pillai's Trace = 0.5687), the aristonectines (Pillai's Trace = 0.7695 ), and the styxosaurines (Pillai's Trace $=$ 0.7249 ). Jucha squalea is not significantly different from the Australian elasmosaurids (without QM F3567) (Pillai's Trace $=0.158$, p-value $=0.09894$ ), but is moderately different from the styxosaurines (Pillai's Trace $=0.4009$ ) and significantly different from the aristonectines (Pillai's Trace $=0.9184$ ). Kawanectes lafquenianus remains distinct from the Australian elasmosaurids (Pillai's Trace $=0.8108$ ), styxosaurines (0.6012), and aristonectines (0.9169) but significantly closer to indeterminate elasmosaurid CM Zfr 115 (Pillai's Trace $=0.279$, pvalue $=6.14 \mathrm{E}-02$ ) 


\section{DISCUSSION}

Among plesiosauromorph vertebrae, cervicals are considered to be most useful for systematics (e.g., Welles, 1942; Brown 1981; O'Keefe and Hiller, 2006; O'Gorman et al., 2013; Benson and Druckenmiller, 2014; Otero, 2016) owing to their greater and more variable VLI relative to dorsal and caudal vertebrae. Greater range in VLI distributions within cervicals occurs in both Australian and non-Australian elasmosaurid specimens (Figure 12) and cervical vertebrae, as expected, were able to successfully discriminate the single polycotylid specimen (QM F12719) in every plot. Of the cervicals, the anterior vertebrae were found to be most useful for taxonomic differentiation, owing to their greater morphological variability (compare Figure 15 to Appendix Figure 5). Dorsal and caudal vertebrae of elasmosaurids have lower, more consistent VLI distributions. Of the caudal data, the VLI of Opallionectes andamookaensis alone appears to increase posteriorly (Figure 12), suggesting that some taxonomic utility may exist in the caudals, but data are currently too few for analysis.

\section{Systematic Implications of Australian Elasmosaurid Vertebral Morphology}

As most Australian plesiosauromorph remains from Queensland lack skulls, the only wellaccepted species is Eromangasaurus australis (QM F11050) (Kear, 2007), which provided only five vertebrae for this study. The three sampled cervical vertebrae associated with QM F11050 plot centrally among the Australian specimens. The general trend of cervicals in these Australian elasmosaurids (excluding QM F3567 and Opallionectes andamookaensis), is similar to that of 'Cimoliasaurus'-grade morphotypes (sensu Otero, 2016). 'Cimoliasaurus'-grade vertebrae are, on average, longer than high and wider than long or high (Otero, 2016). These 'can-shaped' vertebrae are somewhat intermediate in morphology between the elongated vertebrae of the styxosaurines and the shortened vertebrae of the aristonectines (Figures 14, 15, Appendix Figures 2-4) (Otero, 2016; O'Gorman, 2019b). The vertebrae for most Australian specimens (except QM F3567 and $O$. andamookaensis), overlap with the non-Australian 'Cimoliasaurus'-grade morphotypes and styxosaurines (Figures 14, 15, Appendix Figures 2-4). This trend (i.e., styxosaurine-like 'Cimoliasaurus'grade morphology) is also apparent on the bivariate plots of PC1 versus $\mathrm{H} / \mathrm{W}$ (Appendix Figure 7A) and PC2 versus VLI (Appendix Figure 8B). The $P C 2$ versus $H / W$ (Appendix Figure $7 B$ ) and PC1 versus VLI (Appendix Figure 8A) plots further discriminate the 'Cimoliasaurus'-grade morphotype from the styxosaurines and aristonectines along a relatively linear trend, indicating that PC2 is a proxy for $\mathrm{H} / \mathrm{W}$ and that PC1 could be a proxy for VLI. However, the PC2 versus H/W plot loses its linear trend for values above 0.7 , as vertebrae become more ellipsoidal in shape (see Appendix Figure 7B).

Thus, most of the analyzed Australian elasmosaurid specimens occupy a 'Cimoliasaurus'grade morphospace between styxosaurines and aristonectines, but overlapping more with the styxosaurines. Specimen QM F3567 is the most styxosaurine-like Australian form, whereas $O$. andamookaensis is isolated and plots with the aristonectines. Otherwise, it is not possible to evaluate the internal diversity of Australian specimens owing to the incompleteness of the data sets, and particularly, the lack of skulls. Regardless, the data suggest the presence of at least three groupings among analyzed Australian elasmosaurs, i.e., the dominant 'Cimoliasaurus'-grade forms and forms that plot either with styxosaurines or aristonectines.

Previously, specimen RM FR269 was considered unofficially likely to be Eromangasaurus australis on the basis of the similar shape and size of its vertebrae, with comparable texture/matrix to those of the E. australis holotype (QM F11050). However, the lack of sufficient vertebrae in the holotype specimen and lack of a skull in RM FR269 precludes direct comparison. In the present analysis, RM FR269 displays an irregular trend of VLI within the cervical vertebrae (Figure 12) that may represent an out of sequence reconstruction. In morphometric analyses, K F0269 plots with the maximum dispersion point, spanning the morphospace between styxosaurines and aristonectines (Figures 14, 15). The lack of excavation records for the specimen compound the problem and the possibility arises that the specimen was reconstructed from the remains of more than one individual. Regardless, vertebrae do not provide support for assignment of RM FR269 to E. australis.

\section{Phylogenetic Implications}

Welles (1943) showed that vertebral remains could distinguish elasmosaurids from other plesiosaurs, and polycotylid vertebral morphology clearly separates them from other plesiosauromorphs (O'Keefe, 2004), as do the morphometric analyses presented above. Our data clearly support the contention that morphometric analyses are useful for distinguishing xenopsarian families (in this case 
Polycotylidae and Elasmosauridae). The present study also separated the elasmosaurids into three primary groups on the basis of vertebral morphology, consistent with the results of Otero (2016). Styxosaurine and aristonectine anterior cervical vertebral morphologies are distinct in all analyses, and between them lie the 'Cimoliasaurus'-grade morphotypes with varying degrees of overlap. While this study is not a phylogenetic analysis, comparison of the more informative anterior cervicals of Australian and non-Australian specimens (Figure 15, Table 4) produced definite clusters providing potential insights into elasmosaurid relationships.

'Cimoliasaurus'-grade cervicals characterize elasmosaurids in the Lower Cretaceous of the southern hemisphere (Kear, 2002; Lazo and Cichowolski, 2003; O'Gorman et al., 2015), and most recent phylogenies (e.g., Otero, 2016; Fischer et al., 2020) suggest basal positions for such taxa (e.g., Callawayasaurus colombiensis, Eromangasaurus australis). The relationship of the $E$. australis holotype cannot be evaluated further here, owing to the sparsity of sampled vertebrae (three). Regardless, E. australis plots with the main cluster of Australian specimens on PCA diagrams (Figure 15, Appendix Figure 4) and near the Early Cretaceous non-Australian 'Cimoliasaurus'-grade forms listed above, which also share overlaps with the styxosaurine cluster.

Australian elasmosaurids from Lower Cretaceous (Aptian-Albian) deposits (Sachs, 2005; Kear, 2007; Kear, 2016; Kear et al., 2017; Otero, 2016; O'Gorman et al, 2019b) share 'Cimoliasaurus'grade cervical morphologies with other early elasmosaurids, and overlap taxa of similar age (e.g., C. colombiensis). Late Cretaceous 'Cimoliasaurus'grade specimens (Kawanectes lafquenianus, CM Zfr 115, AMNH FARB 2554) are generally well discriminated from the Australian elasmosaurids. However, two Late Cretaceous 'Cimoliasaurus'grade taxa, the Maastrichtian Vegasaurus molyi and the Campanian-Maastrichtian Tuarangisaurus keyesi, plot quite close to Australian specimens with low dispersion, and the latter also overlaps styxosaurines and $E$. australis (QM F11050). Thus, some Late Cretaceous forms strongly diverged from analysed Early Cretaceous morphologies, but others appear to retain them. The degree to which this similarity reflects retention of plesiomorphic characters, and thus relationships, or subsequent convergence between Early and Late Cretaceous elasmosaurid cervical vertebrae (due to shared functional morphology) cannot be determined with- out more detailed phylogenetic analysis. The Cenomanian Thalassomedon haningtoni plots with wide dispersion and is the only specimen on PCA plots (e.g., Figure 15) to overlap all identified elasmosaurid clusters (styxosaurines, Australian and non-Australian 'Cimoliasaurus'-grade elasmosaurids, and aristonectines).

The Late Cretaceous styxosaurine and aristonectine clades were consistently separated in all vertebral analyses. Thus, it is tempting to speculate that the general distribution of most 'Cimoliasaurus'-grade morphotypes between the styxosaurines and aristonectines supports a plesiomorphic origin of the 'Cimoliasaurus'-grade cervical morphotype, with subsequent divergence of more derived styxosaurines and aristonectines (Otero, 2016; Fischer et al., 2020). The relatively distinct Late Cretaceous 'Cimoliasaurus' grade $K$. lafquenianus - CM Zfr 115 group also could be considered divergent from the Early Cretaceous forms. However, although such a hypothesis is supported by the available data, it is not possible to exclude convergence. The Early Cretaceous Australian Opallionectes andamookaensis is clearly distinct from contemporary Australian specimens, and Kear (2006a) noted the difficulty of assigning the species to subclade without adequate skull material. The present analysis suggests closer morphological affinities with the latest Cretaceous aristonectines in all plots (e.g., Figures 14-16, Appendix Figures 2-4), but a phylogenetic relationship in that case is not supported by current phylogenies (e.g., O'Gorman et al., 2019a).

Specimen QM F3567 plots well within the styxosaurine distribution (e.g., Figures 14-16, Appendix Figures 2-4), consistent with the previous assignment of QM F3567 to Styxosaurus (Sachs, 2004). Notable also is the recovery of Elasmosaurus platyurus well within the styxosaurine cluster, providing evidence that this taxon falls within that clade (in which case it should be called Elasmosaurinae). The shared 'elongate' nature of the vertebrae of styxosaurines/elasmosaurines, such as Styxosaurus, Elasmosaurus, and Albertonectes, was interpreted as a consequence of endemism within the restricted Western Interior Seaway (WIS) of North America (O'Keefe and Hiller, 2006; Otero, 2016), and elasmosaurids possessing styxosaurine/elasmosaurine cervical centra previously were not known outside the WIS (Otero, 2016). Whether the morphological similarity of QM F3567 reflects relationship (Sachs, 2004) or convergence again will require analysis of additional material, ideally skulls. 


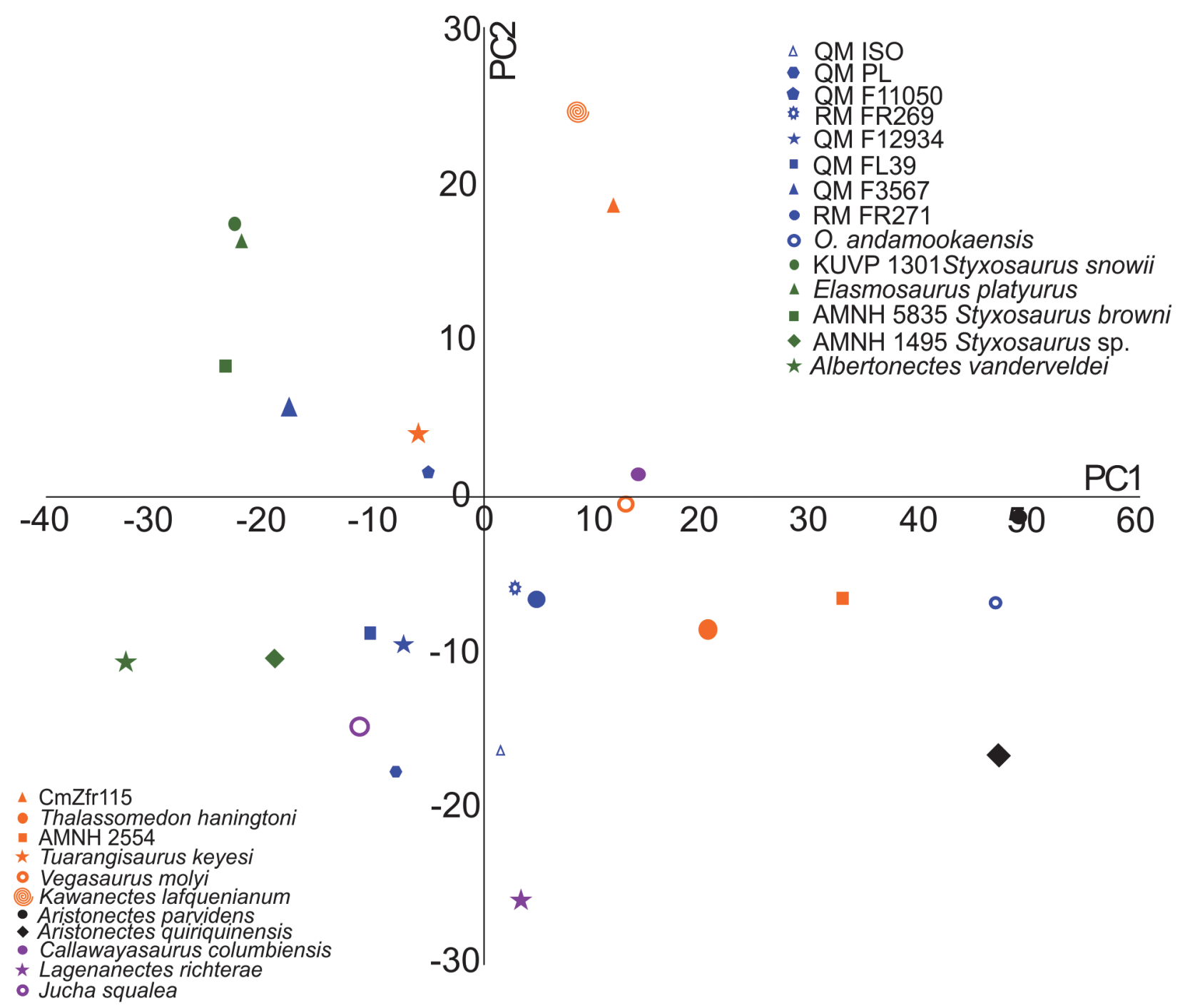

FIGURE 16. Taxon/specimen average plot for anterior cervicals of Australian plesiosauromorph specimens and nonAustralian elasmosaurids. Data for QM F3567 and RM FR271 from Sachs (2004); Opallionectes andamookaensis from Kear (2005a); Elamosaurus platyurus, Thalassomedon haningtoni, Callawayasaurus colombiensis and $\mathrm{Cm} \mathrm{Zfr}$ 115 from O'Keefe and Hiller (2006); Aristonectes quiriquinensis from Otero et al. (2014); Albertonectes vanderveldei from Kubo et al. (2012); Vegasaurus molyi from O'Gorman el. (2015); Tuarangisaurus keyesi from Hiller et al. (2017); AMNH FARB 1495, AMNH FARB 5835, Styxosaurus snowii, and AMNH FARB 2554 from Otero (2016); Aristonectes parvidens from O'Gorman (2016a); Kawanectes lafquenianus from O'Gorman (2016b); Lagenanectes richterae from Sachs et al. (2017) and Jucha squalea from Fischer et al. (2020).

\section{CONCLUSIONS}

On the basis of morphometric analysis of anterior cervical vertebral remains alone, most examined Australian elasmosaurid specimens fall within the 'Cimoliasaurus'-grade morphotype that includes basal elasmosaurids and non-aristonectine weddellonectians (O'Gorman et al., 2019a,b). However, almost all Australian specimens and contemporary (Early Cretaceous) non-Australian 'Cimoliasaurus'-grade morphotypes plot closer to the styxosaurine than to the aristonectine morphol- ogy. Although this could imply a plesiomorphic condition for the 'Cimoliasaurus'-grade cervical morphology, it cannot be distinguished from morphological convergence in the present analysis. Specimens QM F3567 and Opallionectes andamookaensis consistently plot within the elasmosaurine (styxosaurine) and aristonectine morphospaces, respectively, suggesting phylogenetic diversity within the Australian elasmosaurid fauna. Morphometric analysis was more effective at differentiation of specimens at higher taxonomic levels (i.e., family), as is highlighted by the distinct 
separation of the Australian polycotylid (QM F12719) from all elasmosaurid taxa on all plots. The consistent distinction of known styxosaurines/ elasmosaurines and aristonectines in the present analysis provides some confidence in relative positions of the Australian specimens, despite their incompleteness. More complete sequences of Australian elasmosaurid vertebrae, including different ontogenetic stages, would allow more effective comparisons with other taxa, and recovery of such materials should be a priority for fieldwork in the Eromanga Basin. Future iterations of these analyses should also sample plesiosaur taxa more broadly, especially as recent years have witnessed the description of numerous new xenopsarian taxa (e.g., Sato et al., 2006; Berezin, 2011; Otero et al., 2016; Otero and Soto-Acuña, 2021). Regardless, even in this relatively limited study, vertebral remains were found to have substantial higherlevel taxonomic utility in the absence of skulls, and comparative morphometrics offers a powerful tool for incorporating plesiosaur postcranial materials into diversity studies. Although vertebral morphospaces alone may not be sufficient to elucidate lower level taxonomy, more comprehensive plots with more variables, and comparison of individual vertebral positions may be useful for posing or testing phylogenetic hypotheses.

\section{ACKNOWLEDGMENTS}

We wish to thank the journal editors and reviewers, including anonymous reviewers and Drs. V. Fischer and E. Knutsen for their very useful constructive comments on the manuscript. We also thank Dr. B. Kear for comments on a previous version of this work. We thank the museum staff of Queensland Museum (K. Spring) and Kronosaurus Korner Museum (M. Johnston) for their help and access to specimens. VV wishes to thank his parents for financial support throughout the project.

\section{REFERENCES}

Bardet, N., Pascal G., and Sciau, J. 1999. A new elasmosaurid plesiosaur from the Lower Jurassic of southern France. Palaeontology, 42:927-952. https://doi.org/10.1111/1475-4983.00103

Benson, R.B.J. and Bowdler, T. 2014. Anatomy of Colymbosaurus megadeirus (Reptilia, Plesiosauria) from the Kimmeridge Clay Formation of the UK, and high diversity among Late Jurassic plesiosauroids. Journal of Vertebrate Paleontology, 34:1053-1071. https://doi.org/10.1080/02724634.2014.850087

Benson, R.B.J. and Druckenmiller, P.S. 2014. Faunal turnover of marine tetrapods during the Jurassic-Cretaceous transition. Biological Reviews of the Cambridge Philosophical Society, 89:1-23. https://doi.org/10.1111/brv.12038

Berezin, A.Y. 2011. A new plesiosaur of the family Aristonectidae from the Early Cretaceous of the center of the Russian platform. Paleontological Journal, 45:648-660.

Brown, D.S. 1981. The English Upper Jurassic Plesiosauroidea (Reptilia) and a review of the phylogeny and classification of the Plesiosauria. Bulletin of the British Museum (Natural History) Geology Series, 35:253-344.

Burton, G.R. and Mason, A.J. 1998. Controls on opal localisation in the White Cliffs area. Quarternary Notes. Geological Survey NSW, 107:1-11.

Cabrera, A. 1941. Un Plesiosaurio nuevo del Cretáceo del Chubut. Revista del Museo de La Plata, 2:113-130.

Carpenter, K. 1997. Comparative cranial anatomy of two North American Cretaceous plesiosaurs, p. 191-216. In Callaway, J.M. and Nicholls, E.L. (eds.), Ancient Marine Reptiles. Academic Press, San Diego. https://doi.org/10.1016/b978-012155210-7/50011-9

Chatterjee, S. and Small, J.B. 1989. New plesiosaurs from the Upper Cretaceous of Antarctica. Geological Society, London, Special Publications, 47:197-215. https://doi.org/10.1144/gsl.sp.1989.047.01.15

Conybeare, W.D. 1822. Additional notices on the fossil genera Ichthyosaurus and Plesiosaurus. Transactions of the Geological Society of London, 1:103-123. https://doi.org/10.1144/transgslb.1.1.103

Cope, E.D. 1868. Remarks on a new large enaliosaur. Proceedings of the Academy of Natural Sciences of Philadelphia, 20:92-93. 
Cope, E.D. 1869. Synopsis of the extinct Batrachia, Reptilia and Aves of North America. Transactions of the American Philosophical Society, 14:1-252. https://doi.org/10.2307/1005355

Cruickshank, A.R.I. 1997. A Lower Cretaceous pliosauroid from South Africa. Annals of the South African Museum, 105:207-226.

Cruickshank, A.R.I. and Long, J.A. 1997. A new species of pliosaurid reptile from the Early Cretaceous Birdrong Sandstone of Western Australia. Records of the Western Australian Museum, 18:263-276.

Cruickshank, A.R.I., Fordyce, R.E., and Long, J.A. 1999. Recent developments in Australasian sauropterygian palaeontology (Reptilia: Sauropterygia). Records of the Western Australian Museum, 57:201-205.

Day, R.W. 1969. The Early Cretaceous of the Great Artesian Basin, p. 140-173. In Campbell, K.S.W. (ed.), Stratigraphy and palaeontology: essays in honour of Dorothy Hill. Australian University Press, Canberra.

de Blainville, H.D. 1835. Description de quelques espèces de reptiles de la Californie, précédée de l'analyse d'un système général d'Erpétologie et d'Amphibiologie. Nouvelles Annales du Muséum (national) d'Histoire Naturelle de Paris, 4:233-296.

De la Beche, H.T. and Conybeare, W.D. 1821. Notice of the discovery of a new Fossil Animal, forming a link between the Ichthyosaurus and Crocodile, together with general remarks on the Osteology of the Ichthyosaurus. Transactions of the Geological Society of London, S15(1)5:559-594.

Druckenmiller, P.S. 2002. Osteology of a new plesiosaur from the Lower Cretaceous (Albian) Thermopolis Shale of Montana. Journal of Vertebrate Paleontology, 22:29-42. https://doi.org/10.1671/0272-4634(2002)022[0029:ooanpf]2.0.co;2

Druckenmiller, P.S. and Russell, A.P. 2008. A phylogeny of Plesiosauria (Sauropterygia) and its bearing on the systematic status of Leptocleidus Andrews, 1922. Zootaxa, 1863:1-120. https://doi.org/10.11646/zootaxa.1863.1.1

Druckenmiller, P.S. and Knutsen, E.M. 2012. Phylogenetic relationships of Upper Jurassic (Middle Volgian) plesiosaurians (Reptilia: Sauropterygia) from the Agardhfjellet Formation of central Spitsbergen, Norway. Norwegian Journal of Geology, 92:277-284.

Etheridge, R. 1897. An Australian sauropterygian (Cimoliasaurus), converted into precious opal. Records of the Australian Museum, 3:19-29. https://doi.org/10.3853/j.0067-1975.3.1897.1123

Etheridge, R. 1904. A second sauropterygian converted into opal from the Upper Cretaceous of White Cliffs, New South Wales. With indications of ichthyopterygians at the same locality. Records of the Australian Museum, 5:306-316. https://doi.org/10.3853/j.0067-1975.5.1904.1070

Fischer, V., Benson, R.B.J., Druckenmiller, P.S., Ketchum, H.F., and Bardet, N. 2018. The evolutionary history of polycotylid plesiosaurians. Royal Society Open Science, 5:172177. https://doi.org/10.1098/rsos.172177

Fischer, V., Zverkov, N.G., Arkhangelsky, M.S., Stenshin, I.M., Blagovetshensky, I.V., and Uspensky, G.N. 2020. A new elasmosaurid plesiosaurian from the Early Cretaceous of Russia marks an early attempt at neck elongation. Zoological Journal of the Linnean Society, 192:1167-1194.

Gaffney, E.S. 1981. A review of the fossil turtles of Australia. American Museum, 2720:1-38.

Gasparini, Z., Salgado, L., and Casadío, S. 2003. Maastrichtian plesiosaurs from northern Patagonia. Cretaceous Research, 24:157-170. https://doi.org/10.1016/s0195-6671(03)00036-3

Gray, A.R.G., McKillop, M., and McKellar, J.L. 2002. Eromanga Basin stratigraphy, p. 30-56. In Draper, J.J. (ed.), Geology of the Cooper and Eromanga Basins. Department of Natural Resources and Mines, Brisbane.

Gray, J.E. 1825. A synopsis of the genera of reptiles and amphibia, with a description of some new species. Annals of Philosophy, 10:193-217.

Hammer, Ø., Harper, D.A.T., and Ryan, P.D. 2001. PAST: Paleontological statistics software package for education and data analysis. Palaeontologia Electronica, 4.1.4:1-9. http://palaeo-electronica.org/2001_1/past/issue1_01.htm

Henderson, R.A., Crampton, J.S., and Dettmann, M.E. 2000. Biogeographical observations on the Cretaceous biota of Australasia. Memoirs of the Australian Association of Palaeontology, 23:355-404. 
Hiller, N., O'Gorman, J.P., Otero R.A., and Mannering, A.A. 2017. A reappraisal of the Late Cretaceous Weddellian plesiosaur genus Mauisaurus Hector, 1874, New Zealand. Journal of Geology and Geophysics, 60:112-128. https://doi.org/10.1080/00288306.2017.1281317

Johns, R.K. 1968. Geology and mineral resources of the Andamooka Torrens area. Geological Survey South Australia Bulletin, 41:7-103.

Kear, B.P. 2001. Elasmosaur (Reptilia: Plesiosauria) basicranial remains from the Early Cretaceous of Queensland. Records of the South Australian Museum, 34:127-133.

Kear, B.P. 2002. Reassessment of the Early Cretaceous plesiosaur Cimoliasaurus maccoyi Etheridge, 1904 (Reptilia, Sauropterygia) from White Cliffs, New South Wales. Australian Journal of Zoology, 50:671-685. https://doi.org/10.1071/zo01073

Kear, B.P. 2003. Cretaceous marine reptiles of Australia: a review of taxonomy and distribution. Cretaceous Research, 24:277-303. https://doi.org/10.1016/s0195-6671(03)00046-6

Kear, B.P. 2004. Biogeographic and biostratigraphic implications of Australian Mesozoic marine reptiles. Australian Biologist, 17:4-22.

Kear, B.P. 2005a. Marine reptiles from the Lower Cretaceous (Aptian) deposits of White Cliffs, southeastern Australia: implications of a high-latitude, cold water assemblage. Cretaceous Research, 26:769-782. https://doi.org/10.1016/j.cretres.2005.04.006

Kear, B.P. 2005b. A new elasmosaurid plesiosaur from the Lower Cretaceous of Queensland, Australia. Journal of Vertebrate Paleontology, 25:792-805. https://doi.org/10.1671/0272-4634(2005)025[0792:anepft]2.0.co;2

Kear, B.P. 2006a. Marine reptiles from the Lower Cretaceous of South Australia: elements of a high latitude cold-water assemblage. Palaeontology, 49:837-856. https://doi.org/10.1111/j.1475-4983.2006.00569.x

Kear, B.P. 2006b. Plesiosaur remains from Cretaceous high-latitude non-marine deposits in southeastern Australia. Journal of Vertebrate Paleontology, 26:196-199. https://doi.org/10.1671/0272-4634(2006)26[196:prfchn]2.0.co;2

Kear, B.P. 2007. Taxonomic clarification of the Australian elasmosaurid genus Eromangasaurus, with reference to other austral elasmosaur taxa. Journal of Vertebrate Paleontology, 27:241246. https://doi.org/10.1671/0272-4634(2007)27[241:tcotae]2.0.co;2

Kear, B.P. 2016. Cretaceous marine amniotes of Australia: perspectives on a decade of new research. Memoirs of Museum Victoria, 74:17-28. https://doi.org/10.24199/j.mmv.2016.74.03

Kear, B.P., Fordyce, E.R., Hiller, N., and Siversson, M. 2017. A palaeobiogeographical synthesis of Australasian Mesozoic marine tetrapods. Alcheringa, 42:461-486. https://doi.org/10.1080/03115518.2017.1397428

Ketchum, H.F. and Benson, R.B.J. 2010. Global interrelationships of Plesiosauria (Reptilia, Sauropterygia) and the pivotal role of taxon sampling in determining the outcome of phylogenetic analyses. Biological Reviews, 85:361-392. https://doi.org/10.1111/j.1469-185x.2009.00107.x

Knutsen, E.M., Druckenmiller, P.S., and Hurum, J.H. 2012. A new plesiosauroid (Reptilia: Sauropterygia) from the Agardhfjellet Formation (Middle Volgian) of central Spitsbergen, Norway. Norwegian Journal of Geology, 92:213-234.

Krieg, G.W. and Rodgers, P.A. 1995. Stratigraphy - marine succession, p. 112-123. In Drexel, J.F. and Preiss, W.V. (eds.), The Geology of South Australia. Volume 2: the Phanerozoic. Geological Survey of South Australia Bulletin, 54.

Kubo, T., Mitchell, M.T., and Henderson, D.M. 2012. Albertonectes vanderveldei, a new elasmosaur (Reptilia, Sauropterygia) from the Upper Cretaceous of Alberta. Journal of Vertebrate Paleontology, 32:557-572.

Long, J.A. and Cruickshank, A.R.I. 1998. Further records of plesiosaurian reptiles of Jurassic and Cretaceous age from Western Australia. Records of the Western Australian Museum, 19:47-55.

Longman, H.A. 1915. On a giant turtle from the Queensland Lower Cretaceous. Memoirs of the Queensland Museum, 3:24-29.

Longman, H.A. 1922. An ichthyosaurian skull from Queensland. Memoirs of the Queensland Museum, 7:246-256.

Longman, H.A. 1924. A new gigantic marine reptile from the Queensland Cretaceous, Kronosaurus queenslandicus new genus and species. Memoirs of the Queensland Museum, 8:26-28.

Longman, H.A. 1943. Further notes on Australian ichthyosaurs. Memoirs of the Queensland Museum, 12:101-104. 
Ludbrook, N.H. 1966. Cretaceous biostratigraphy of the Great Artesian Basin in South Australia. Geological Survey South Australia Bulletin, 40:7-223.

McKean, R.S. 2012. A new species of polycotylid plesiosaur (Reptilia: Sauropterygia) from the Lower Turonian of Utah: extending the stratigraphic range of Dolichorhynchops. Cretaceous Research, 34:184-199. https://doi.org/10.1016/j.cretres.2011.10.017

Molnar, R.E. 1982a. Australian Mesozoic reptiles, p. 170-220. In Vickers-Rich, P., Monaghan, J.M., and Baird, R.F. (eds.), Vertebrate Palaeontology of Australasia. Pioneer Design Studio, Monash University, Melbourne.

Molnar, R.E. 1982b. A catalogue of fossil amphibians and reptiles in Queensland. Memoirs of the Queensland Museum, 20:613-633.

Molnar, R.E. 1991. Fossil reptiles in Australia, p. 605-702. In Vickers-Rich, P., Monaghan, J.M., and Baird, R.F. (eds.), Vertebrate Palaeontology of Australasia. Pioneer Design Studio, Monash University, Melbourne.

Murray, P.F. 1985. Ichthyosaurs from Cretaceous Mullaman Beds near Darwin, Northern Territory. The Beagle, 2:39-55.

Murray, P.F. 1987. Plesiosaurs from Albian aged Darwin Formation siltstones near Darwin, Northern Territory, Australia. The Beagle, 4:95-102.

Noè, L.F., Taylor, M.A., and Gómez-Pérez, M. 2017. An integrated approach to understanding the role of the long neck in plesiosaurs. Acta Palaeontologica Polonica, 62:137-162. https://doi.org/10.4202/app.00334.2016

O'Gorman J.P. 2016a. New insights on the Aristonectes parvidens (Plesiosauria, Elasmosauridae) holotype: news on an old specimen. Ameghiniana, 53:397-417.

O'Gorman, J.P. 2016b. A small body sized non-aristonectine elasmosaurid (Sauropterygia, Plesiosauria) from the Late Cretaceous of Patagonia with comments on the relationships of the Patagonian and Antarctic elasmosaurids. Ameghiniana, 53:245-268.

O'Gorman J.P. 2020. First record of Kawanectes lafquenianum (Plesiosauria, Elasmosauridae) from the La Colonia Formation of Argentina, with comments on the mandibular morphology of elasmosaurids. Alcheringa, 44:176-193. https://doi.org/10.1080/03115518.2019.1687754

O'Gorman, J.P., Gasparini, Z., and Salgado, L. 2013. Postcranial morphology of Aristonectes (Plesiosauria, Elasmosauridae) from the Upper Cretaceous of Patagonia and Antarctica. Antarctic Science, 25:71-82. https://doi.org/10.1017/s0954102012000673

O'Gorman, J.P., Salgado, L., Olivero, E.B., and Marenssi, S.A. 2015. Vegasaurus molyi, gen. et sp. nov. (Plesiosauria, Elasmosauridae), from the Cape Lamb Member (lower Maastrichtian) of the Snow Hill Island Formation, Vega Island, Antarctica, and remarks on Wedellian Elasmosauridae. Journal of Vertebrate Paleontology, 35:e931285. https://doi.org/10.1080/02724634.2014.931285.

O'Gorman, J.P., Otero, R., Reguero, M., and Gasparini, Z. 2019a. Cretaceous Antarctic plesiosaurs: stratigraphy, systematics and paleobiogeography. Advances in Polar Science, 30:210-227.

O'Gorman, J.P., Santillana, S., Otero, R., and Reguero, M. 2019b. A giant elasmosaurid (Sauropterygia; Plesiosauria) from Antarctica: New information on elasmosaurid body size diversity and aristonectine evolutionary scenarios. Cretaceous Research, 102:37-58. https://doi.org/10.1016/j.cretres.2019.05.004

O'Keefe, F.R. 2001a. A cladistic analysis and taxonomic revision of the Plesiosauria (Reptilia: Sauropterygia). Acta Zoologica Fennica, 213:1-63.

O'Keefe, F.R. 2001b. Ecomorphology of plesiosaur flipper geometry. Journal of Evolutionary Biology, 14:987-991. https://doi.org/10.1046/j.1420-9101.2001.00347.x

O'Keefe, F.R. 2002. The evolution of plesiosaur and pliosaur morphotypes in the Plesiosauria (Reptilia: Sauropterygia). Paleobiology, 28:101-112. https://doi.org/10.1666/0094-8373(2002)028<0101:teopap>2.0.co;2

O'Keefe, F.R. 2004. Preliminary description and phylogenetic position of a new plesiosaur (Reptilia: Sauropterygia) from the Toarcian of Holzmaden, Germany. Journal of Paleontology, 78:973-988. https://doi.org/10.1666/0022-3360(2004)078<0973:pdappo>2.0.co;2

O'Keefe, F.R. and Hiller, N. 2006. Morphologic and ontogenetic patterns in elasmosaur neck length, with comments on the taxonomic utility of neck length variables. Paludicola, 5:206229. 
O'Keefe, F.R. and Wahl, W.W. 2003. Preliminary report on the osteology and relationships of a new aberrant cryptocleidoid plesiosaur from the Sundance Formation, Wyoming. Paludicola, 4:48-68.

Otero, Rodrigo A. 2016. Taxonomic reassessment of Hydralmosaurus as Styxosaurus: new insights on the elasmosaurid neck evolution throughout the Cretaceous. PeerJ, 4:e1777.

Otero, R.A., Soto-Acuna, S., O’Keefe, F.R., O'Gorman, J.P., Stinnesbeck, W., Suarez, M.E., Rubilar-Rogers, D., Salazar, C., and Quinzio-Sinn, L.R. 2014. Aristonectes quiriquinensis, sp. nov., a new highly derived elasmosaurid from the upper Maastrichtian of central Chile. Journal of Vertebrate Paleontology, 34:100-125. https://doi.org/10.1080/02724634.2013.780953

Otero, R.A., and Soto-Acuña, S. 2021. Wunyelfia maulensis gen. et sp. nov., a new basal aristonectine (Plesiosauria, Elasmosauridae) from the Upper Cretaceous of central Chile. Cretaceous Research, 118:104651. https://doi.org/10.1016/j.cretres.2020.104651

Owen, R. 1860. On the Orders of fossil and recent Reptilia, and their distributions in time. Report of the British Association for the Advancement of Science, 29:153-166.

Persson, P.O. 1960. Lower Cretaceous plesiosaurians (Reptilia) from Australia. Lunds Universitets Arsskrift, 56:1-23.

Persson, P.O. 1982. Elasmosaurid skull from the Lower Cretaceous of Queensland (Reptilia, Sauropterygia). Memoirs of the Queensland Museum, 20:647-655.

Pillai, K.C.S. 1995. Some new test criteria in multivariate analysis. Annals of Mathematical Statistics, 26:117-21. https://doi.org/10.1214/aoms/1177728599

Rieppel, O. 1997. Introduction to Sauropterygia, p. 107-119. In Callaway, J.M. and Nicholls, E.L. (eds.), Ancient Marine Reptiles. Academic Press, San Diego, California.

Rieppel, O. 2000. Sauropterygia I: Placodontia, Pachypleurosauria, Nothosauroidea, Pistosauroidea, p. 1-134. In Kuhn, O. and Wellnhofer, P. (eds.), Encyclopedia of Paleoherpetology, Part 12A. Verlag Dr. Friedrich Pfeil, München, Germany.

Roberts, A.J., Druckenmiller, P.S., Delsett, L.L., and Hurum, J.H. 2017. Osteology and relationships of Colymbosaurus Seeley, 1874, based on new material of $C$. svalbardensis from the Slottsmøya Member, Agardhfjellet Formation of central Spitsbergen. Journal of Vertebrate Paleontology, 37:e1278381. https://doi.org/10.7934/p2685

Robertson, R.S. and Scott, D.C. 1990. Geology of the Coober Pedy precious stones field. Results of Investigations, 1981-1986. Geological Survey of South Australia, Report of Investigations, 56:1-55.

Romer, A.S. 1966. Vertebrate Paleontology, Third Edition. University of Chicago Press, Chicago.

Sachs, S. 2004. Redescription of Woolungasaurus glendowerensis (Plesiosauria: Elasmosauridae) from the Lower Cretaceous of Northeast Queensland. Memoirs of the Queensland Museum, 49:713-731.

Sachs, S. 2005. Tuarangisaurus australis sp. nov. (Plesiosauria: Elasmosauridae) from the Lower Cretaceous of northeastern Queensland, with additional notes on the phylogeny of the Elasmosauridae. Memoirs of the Queensland Museum, 50:425-440.

Sachs, S. and Kear, B.P. 2017. Redescription of the elasmosaurid plesiosaurian Libonectes atlasense from the Upper Cretaceous of Morocco. Cretaceous Research, 74:205-222.

Sachs, S., Jahn J.H. and Kear., B.P.2017. A new basal elasmosaurid (Sauropterygia: Plesiosauria) from the Lower Cretaceous of Germany. Journal of Vertebrate Paleontology, 37:e1301945.

Sato, T. 2005. A new polycotylid plesiosaur (Reptilia: Sauropterygia) from the Upper Cretaceous Bearpaw Formation in Saskatchewan, Canada. Journal of Paleontology, 79:969-980. https://doi.org/10.1666/0022-3360(2005)079[0969:anpprs]2.0.co;2

Sato, T. and Storrs, G.W. 2000. An early polycotylid plesiosaur (Reptilia, Sauropterygia) from the Cretaceous of Hokkaido, Japan. Journal of Paleontology, 74:907-914. https://doi.org/10.1666/0022-3360(2000)074<0907:aepprs>2.0.co;2

Seber, G.A.F. 1984. Multivariate Observation. John Wiley \& Sons, New York.

Seeley, H.G. 1874. Note on some of the generic modifications of the plesiosaurian pectoral arch. Quarterly Journal of the Geological Society, London, 30:436-449. https://doi.org/10.1144/gsl.jgs.1874.030.01-04.48

Senior, B.R., Mond, A., and Harrison, P.L. 1978. Geology of the Eromanga Basin. Bulletin of the Bureau of Mineral Resources, Australia, 167:1-102. 
Serratos, D.J., Druckenmiller, P., and Benson, R.B.J. 2017. A new elasmosaurid (Sauropterygia, Plesiosauria) from the Bearpaw Shale (Late Cretaceous, Maastrichtian) of Montana demonstrates multiple evolutionary reductions of neck length within Elasmosauridae. Journal of Vertebrate Paleontology, 37(2):e1278608. https://doi.org/10.1080/02724634.2017.1278608

Sheard, M.J. 1990. Glendonites from the southern Eromanga Basin in South Australia: palaeoclimatic indicators for Cretaceous ice. Geological Survey South Australia Quaternary Geology Notes, 114:17-23.

Storrs, G.W. 1993. Function and phylogeny in sauropterygian (Diapsida) evolution. American Journal of Science, 293:63-90. https://doi.org/10.2475/ajs.293.a.63

Storrs, G.W. 1999. An examination of Plesiosauria (Diapsida: Sauropterygia) from the Niobrara Chalk (Upper Cretaceous) of central North America. University of Kansas Paleontological Contributions, 11:1-15. https://doi.org/10.17161/pcns.1808.3766

Taylor, M.A. and Cruickshank, A.R.I. 1993. Cranial anatomy and functional morphology of Pliosaurus brachyspondylus (Reptilia: Plesiosauria) from the Upper Jurassic of Westbury, Wiltshire. Philosophical Transactions of the Royal Society of London, 341:399-418. https://doi.org/10.1098/rstb.1993.0124

Thulborn, T. and Turner, S. 1993. An elasmosaur bitten by a pliosaur. Modern Geology, 18:489501.

Vakil, V., Webb, G.E., and Cook A.G. 2020. Can vertebral remains differentiate more than one species of Australian Cretaceous ichthyosaur? Alcheringa, 44:537-554. https://doi.org/10.1080/03115518.2020.1853809

Wade, M. 1984. Platypterygius australis, an Australian Cretaceous ichthyosaur. Lethaia, 17:99113. https://doi.org/10.1111/j.1502-3931.1984.tb01713.x

Wade, M. 1990. A review of the Australian Cretaceous longipinnate ichthyosaur, Platypterygius (Ichthyosauria, Ichthyopterygia). Memoirs of the Queensland Museum, 28:15-137.

Welles, S.P. 1943. Elasmosaurid plesiosaurs with description of new material from California and Colorado. Memoir of the University of California, 13:125-215.

Welles, S.P. 1952. A review of the North American Cretaceous elasmosaurs. University of California Publications in Geological Sciences, 29:47-144.

Welles, S.P. 1962. A new species of elasmosaur from the Aptian of Colombia, and a review of the Cretaceous plesiosaurs. University of California, Publications in Geological Sciences, 44:1-96.

White, T.E. 1935. On the skull of Kronosaurus queenslandicus Longman. Occasional Papers of the Boston Society of Natural History, 8:219-228.

White, T.E. 1940. Holotype of Plesiosaurus longirostris Blake and classification of the plesiosaurs. Journal of Paleontology, 14:451-467.

Wiffen, J. and Moisley, W.L. 1986. Late Cretaceous reptiles (Families Elasmosauridae and Pliosauridae) from the Mangahouanga Stream, North Island, New Zealand. New Zealand Journal of Geology and Geophysics, 29:205-252. https://doi.org/10.1080/00288306.1986.10427535

Wilmott, W., Cook, A.G., and Neville, B. 2017. Rocks, Landscapes \& Resources of the Great Artesian Basin: A Handbook for Travellers. Geological Society of Australia Incorporated, Queensland Division.

Williston, S.W. 1908. North American plesiosaurs Trinacromerum. Journal of Geology, 16:715736. https://doi.org/10.1086/621573

Williston, S.W. 1925. The Osteology of the Reptiles. Cambridge, Harvard University Press.

Wintrich, T., Hayashi, S., Houssaye, A., Nakajima, Y., and Sander, P. M. 2017a. A Triassic plesiosaurian skeleton and bone histology inform on evolution of a unique body plan. Science Advances, 3:e1701144. https://doi.org/10.1126/sciadv.1701144

Wintrich, T., Scaal, M., and Sander, P. M. 2017b. Foramina in plesiosaur cervical centra indicate a specialized vascular system. Fossil Record, 20:279-290.

https://doi.org/10.5194/fr-20-279-2017 


\section{APPENDIX TABLE 1.}

All measurements of $\mathrm{CW}, \mathrm{CH}$ and $\mathrm{CL}$ are in $\mathrm{mm}$. Incomplete measurements are represented by $\mathrm{x}$. $\mathrm{VLI}$ and $\mathrm{BI}$ are ratios.

(WoD: width of diapophyses; Ns Ht: neural spine height; $\mathrm{Nc} \mathrm{Ht:} \mathrm{neural} \mathrm{canal} \mathrm{height;} \mathrm{Nc} \mathrm{W}$ : neural canal width; Angle: angle with centre of centrum; Dbfs: distance between foramina subcentralia; CV: cervicals; DV: dorsals; C: caudals).

\begin{tabular}{|c|c|c|c|c|c|c|c|c|c|c|}
\hline Specimen & $\begin{array}{c}\text { Vertebra } \\
\text { Position/ } \\
\text { vertebra no. }\end{array}$ & CW & CL & $\mathrm{CH}$ & WoZ & $\mathrm{Ns} \mathrm{Ht}$ & $\mathrm{Nc} \mathrm{Ht}$ & Nc W & Angle & Dbfs \\
\hline \multirow[t]{27}{*}{ QM F12719 } & CV3 & $x$ & 39.4 & 63.9 & $x$ & $x$ & 21.95 & 18.55 & $x$ & $x$ \\
\hline & CV4 & 59.1 & 36.5 & 58.7 & $x$ & $\mathrm{x}$ & $x$ & $x$ & 40 & 7.7 \\
\hline & CV5 & 63.95 & 34.5 & 62.45 & $x$ & $\mathrm{x}$ & 20.25 & 18.75 & $x$ & 17.15 \\
\hline & CV6 & 60.05 & 35.55 & 56.55 & $x$ & $\mathrm{x}$ & $\mathrm{x}$ & $x$ & 30 & 5.65 \\
\hline & CV7 & 66.1 & 34.55 & 65.25 & $x$ & $x$ & 18.65 & 18.5 & 30 & $x$ \\
\hline & CV8 & 63 & 33.9 & 58.05 & $x$ & $x$ & $x$ & $x$ & $x$ & 10.25 \\
\hline & DV4 & 69.115 & 35.3 & 63.9 & 133.85 & 69.6 & 17.9 & 18.05 & 35 & $x$ \\
\hline & DV6 & 64.1 & 35.85 & 61.4 & $x$ & 53.9 & 21.6 & 18.8 & 45 & $x$ \\
\hline & DV7 & 63.7 & 34.5 & 60.15 & $x$ & $\mathrm{x}$ & $x$ & $x$ & $x$ & $x$ \\
\hline & DV8 & 65.1 & 37.8 & 68.35 & $x$ & $x$ & $x$ & $x$ & $x$ & $x$ \\
\hline & DV9 & 66.8 & 31.1 & 69.65 & $\mathrm{x}$ & $x$ & $x$ & $x$ & $x$ & $x$ \\
\hline & DV10 & 67.4 & 37.55 & 57.35 & $x$ & $x$ & $x$ & $x$ & 35 & $x$ \\
\hline & DV11 & 63.3 & 42.9 & 67.9 & $x$ & 87.1 & 21.85 & 19.3 & 55 & $x$ \\
\hline & DV12 & 63.45 & 40.6 & 64.9 & $x$ & 86.3 & 20.45 & $x$ & 55 & $x$ \\
\hline & DV13 & 63.15 & 32.35 & 68.8 & $x$ & $x$ & $x$ & $x$ & $x$ & $x$ \\
\hline & DV14 & 63.4 & 33.75 & 59.85 & $x$ & $x$ & 19.5 & 17.5 & 55 & $x$ \\
\hline & DV15 & 63.05 & 40.35 & 70.3 & $x$ & $x$ & 22.45 & 18.3 & $x$ & $x$ \\
\hline & DV16 & 71 & 39.9 & 65.8 & $x$ & $x$ & 22.6 & 18.75 & 40 & $x$ \\
\hline & DV18 & 67.95 & 39.7 & 67.75 & $x$ & $x$ & 20 & 17.5 & $x$ & $x$ \\
\hline & DV19 & 66.3 & 34.9 & 65.65 & $x$ & $x$ & 21.45 & 18.3 & $x$ & $x$ \\
\hline & DV21 & 62.45 & 39.65 & 66.4 & $x$ & 76.45 & 19.45 & 15.25 & 45 & $x$ \\
\hline & DV23 & 69.2 & 35 & 66.6 & $x$ & $x$ & 17.95 & 16.55 & 40 & $x$ \\
\hline & DV25 & 64.6 & 36.3 & 62.9 & $x$ & $x$ & $x$ & $x$ & $x$ & $x$ \\
\hline & DV26 & 66.1 & 38.2 & $x$ & 104 & 51.1 & 20.9 & 20.2 & $x$ & $x$ \\
\hline & DV27 & $x$ & 33.65 & 60.95 & $x$ & $x$ & 22.9 & 21.15 & 35 & $x$ \\
\hline & DV28 & $x$ & 43 & 70.3 & $x$ & $x$ & $x$ & $x$ & 35 & $x$ \\
\hline & DV29 & $x$ & 39.35 & 66.85 & $x$ & $x$ & 21.2 & 19.4 & 45 & $x$ \\
\hline \multirow[t]{6}{*}{ QM F11050 } & QM F11216 & 69.1 & 66.1 & 51.3 & $x$ & $\mathrm{x}$ & $x$ & $x$ & $x$ & $x$ \\
\hline & QM F11219a & 66.65 & 64.45 & 49.25 & $x$ & $x$ & $x$ & $x$ & $x$ & $x$ \\
\hline & QM F11218 & $x$ & $x$ & $x$ & $x$ & $\mathrm{x}$ & $x$ & $x$ & $x$ & $x$ \\
\hline & QM F11219b & 72.75 & 71.65 & 52.15 & $\mathrm{x}$ & $x$ & $x$ & $x$ & $x$ & $x$ \\
\hline & QM F11217 & 104.15 & 99.05 & 84.45 & $\mathrm{x}$ & $\mathrm{x}$ & $x$ & $x$ & $x$ & $x$ \\
\hline & QM F11217 & 105.2 & 98.15 & 87.65 & $x$ & $x$ & $x$ & $x$ & $x$ & $x$ \\
\hline \multirow[t]{3}{*}{ QM F12934 } & CV4 & 84.7 & 86.9 & 65.95 & $x$ & $x$ & $x$ & $x$ & $x$ & 4.3 \\
\hline & CV5 & 70.9 & 73.55 & 53.85 & $x$ & $x$ & $x$ & $x$ & $x$ & 7.4 \\
\hline & CV6 & 84.5 & 88.3 & 65.9 & $x$ & $\mathrm{x}$ & $x$ & $x$ & $x$ & 5.1 \\
\hline
\end{tabular}




\begin{tabular}{|c|c|c|c|c|c|c|c|c|c|c|}
\hline Specimen & $\begin{array}{c}\text { Vertebra } \\
\text { Position/ } \\
\text { vertebra no. }\end{array}$ & CW & $C L$ & $\mathrm{CH}$ & WoZ & $\mathrm{Ns} \mathrm{Ht}$ & $\mathrm{Nc} \mathrm{Ht}$ & Nc W & Angle & Dbfs \\
\hline & CV7 & 78.05 & 79.3 & 59.65 & $x$ & $x$ & $x$ & $x$ & $x$ & 6.6 \\
\hline & CV8 & 81.95 & 84.35 & 62.4 & $x$ & $x$ & $x$ & $x$ & $x$ & 5.5 \\
\hline & CV9 & 111.7 & 97.5 & 93.5 & $x$ & $x$ & $x$ & $x$ & $x$ & 6.1 \\
\hline & CV10 & 90.95 & 94.6 & 80.2 & $x$ & $x$ & $x$ & $x$ & $x$ & 7.7 \\
\hline & CV11 & 95.4 & 94.4 & 76.15 & $x$ & $x$ & $x$ & $x$ & $x$ & 7.75 \\
\hline & CV12 & 101 & 98.6 & 78.4 & $x$ & $x$ & $x$ & $x$ & $x$ & 9.35 \\
\hline & CV23 & 123.15 & 83.45 & 89.45 & $x$ & $x$ & $x$ & $x$ & $x$ & 9.5 \\
\hline & CV24 & 103.85 & 97.45 & 93.3 & $x$ & $x$ & $x$ & $x$ & $x$ & 12.25 \\
\hline & DV8 & 97.6 & 77.45 & 86.45 & $x$ & $x$ & $x$ & $x$ & $x$ & $x$ \\
\hline & DV9 & 103.9 & 76.65 & 87.55 & $x$ & $x$ & $x$ & $x$ & $x$ & $x$ \\
\hline & DV14 & 112.3 & 78 & 87.15 & $x$ & $x$ & $x$ & $x$ & $x$ & $x$ \\
\hline & $\mathrm{C} 1$ & 111.6 & 72.8 & 80.6 & $x$ & $x$ & $x$ & $x$ & $x$ & $x$ \\
\hline & $\mathrm{C} 2$ & 106.1 & 61.7 & 80.4 & $x$ & $x$ & $x$ & $x$ & $x$ & $x$ \\
\hline & $\mathrm{C} 3$ & 105.5 & 70.7 & 78.15 & $x$ & $x$ & $x$ & $x$ & $x$ & $x$ \\
\hline & $\mathrm{C} 4$ & 50.5 & 40.35 & 37.3 & $x$ & $x$ & $x$ & $x$ & $x$ & $x$ \\
\hline & C5 & 54.6 & 39.6 & 43.65 & $x$ & $x$ & $x$ & $x$ & $x$ & $x$ \\
\hline & C6 & 60.75 & 50.1 & 52.1 & $x$ & $x$ & $x$ & $x$ & $x$ & $x$ \\
\hline & $\mathrm{C} 7$ & 73.85 & 52.45 & 65.15 & $x$ & $x$ & $x$ & $x$ & $x$ & $x$ \\
\hline & $\mathrm{C} 8$ & 85.05 & 55.25 & 65.7 & $x$ & $x$ & $x$ & $x$ & $x$ & $x$ \\
\hline & $\mathrm{C} 9$ & 81.95 & 56.85 & 75.65 & $x$ & $x$ & $x$ & $x$ & $x$ & $x$ \\
\hline & C10 & 93.6 & 60.4 & 75.65 & $x$ & $x$ & $x$ & $x$ & $x$ & $x$ \\
\hline & C11 & 86.6 & 60.5 & 74.15 & $x$ & $x$ & $x$ & $x$ & $x$ & $x$ \\
\hline & $\mathrm{C} 12$ & 98.15 & 54.6 & 82.05 & $x$ & $x$ & $x$ & $x$ & $x$ & $x$ \\
\hline & C13 & 91.55 & 57.4 & 77.05 & $x$ & $x$ & $x$ & $x$ & $x$ & $x$ \\
\hline & $x$ & 104.1 & 64.6 & $x$ & $x$ & $x$ & $x$ & $x$ & $x$ & $x$ \\
\hline & $x$ & 73.7 & $x$ & 55.05 & $x$ & $x$ & $x$ & $x$ & $x$ & 4.3 \\
\hline & $x$ & $x$ & 87.2 & $x$ & $x$ & $x$ & $x$ & $x$ & $x$ & 22.95 \\
\hline & $x$ & $x$ & 91.15 & $x$ & $x$ & $x$ & $x$ & $x$ & $x$ & 25.2 \\
\hline & $x$ & 115.2 & 85.8 & $x$ & $x$ & $x$ & $x$ & $x$ & $x$ & 25 \\
\hline & $x$ & $x$ & 87.3 & $x$ & $x$ & $x$ & $x$ & $x$ & $x$ & 17.3 \\
\hline & $x$ & $x$ & 82.2 & $x$ & $x$ & $x$ & $x$ & $x$ & $x$ & 36.3 \\
\hline & $x$ & 106.5 & 74.25 & $x$ & $x$ & $x$ & $x$ & $x$ & $x$ & $x$ \\
\hline & $x$ & 110.65 & 81.5 & $x$ & $x$ & $x$ & $x$ & $x$ & $x$ & $x$ \\
\hline \multirow[t]{10}{*}{ RM FR269 } & CV5 & 71.2 & 83.8 & 63.85 & $x$ & $x$ & $x$ & $x$ & $x$ & 8.55 \\
\hline & CV7 & 76.75 & 73.2 & 57.4 & $x$ & $x$ & $x$ & $x$ & $x$ & 9.7 \\
\hline & CV8 & 64.4 & 72.95 & 57.2 & $x$ & $x$ & $x$ & $x$ & $x$ & 4.6 \\
\hline & CV10 & 76.4 & 83.5 & 63.75 & $x$ & $x$ & $x$ & $x$ & $x$ & 7.45 \\
\hline & CV11 & 119.5 & 79.35 & 75.5 & $x$ & $x$ & $x$ & $x$ & $x$ & 16.4 \\
\hline & CV12 & 107.45 & 79.35 & 72.3 & $x$ & $x$ & $x$ & $x$ & $x$ & 12.3 \\
\hline & CV14 & 84 & 53.7 & 66.95 & $x$ & $x$ & $x$ & $x$ & $x$ & $x$ \\
\hline & CV16 & 97 & 72.95 & 75.6 & $x$ & $x$ & $x$ & $x$ & $x$ & $x$ \\
\hline & CV17 & 105 & 80.75 & 76.65 & $x$ & $x$ & $x$ & $x$ & $x$ & 10.2 \\
\hline & CV18 & 94.9 & 87.9 & 71.85 & $x$ & $x$ & $x$ & $x$ & $x$ & 9.6 \\
\hline
\end{tabular}


PALAEO-ELECTRONICA.ORG

\begin{tabular}{|c|c|c|c|c|c|c|c|c|c|c|}
\hline Specimen & $\begin{array}{c}\text { Vertebra } \\
\text { Position/ } \\
\text { vertebra no. }\end{array}$ & $\mathrm{CW}$ & CL & $\mathrm{CH}$ & WoZ & Ns Ht & $\mathrm{Nc} \mathrm{Ht}$ & Nc W & Angle & Dbfs \\
\hline & CV19 & 87.2 & 93.4 & 74.9 & $x$ & $x$ & $x$ & $x$ & $x$ & 9.65 \\
\hline & $\mathrm{P} 1$ & 112.35 & 81.75 & 86.45 & $x$ & $x$ & $x$ & $x$ & $x$ & $x$ \\
\hline & $\mathrm{P} 2$ & 111.5 & 80.95 & 87.1 & $x$ & $x$ & $x$ & $x$ & $x$ & $x$ \\
\hline & P3 & 110.95 & 80.65 & 86.9 & $x$ & $x$ & $x$ & $x$ & $x$ & $x$ \\
\hline & $\mathrm{P} 4$ & 110.9 & 81.2 & 86.5 & $x$ & $x$ & $x$ & $x$ & $x$ & $x$ \\
\hline & DV1 & 109.55 & 91 & 76.55 & $x$ & $x$ & $x$ & $x$ & $x$ & $x$ \\
\hline & DV2 & 109.5 & 91.55 & 76.9 & $x$ & $x$ & $x$ & $x$ & $x$ & $x$ \\
\hline & DV16 & 86.6 & 51.5 & 59.25 & $x$ & $x$ & $x$ & $x$ & $x$ & $x$ \\
\hline & DV17 & 87.85 & 74.6 & 78.55 & $x$ & $x$ & $x$ & $x$ & $x$ & $x$ \\
\hline & DV23 & 94.5 & 60.9 & 65 & $x$ & $x$ & $x$ & $x$ & $x$ & $x$ \\
\hline & $\mathrm{S} 1$ & 94 & 60.95 & 65.2 & $x$ & $x$ & $x$ & $x$ & $x$ & $x$ \\
\hline & $\mathrm{C} 2$ & 84.25 & 51.65 & 68.2 & $x$ & $x$ & $x$ & $x$ & $x$ & 13.55 \\
\hline & $x$ & $x$ & 50.6 & $x$ & $x$ & $x$ & $x$ & $\mathrm{x}$ & $x$ & $x$ \\
\hline & $x$ & $x$ & 82.15 & $x$ & $x$ & $x$ & $x$ & $x$ & $x$ & 9.2 \\
\hline & $x$ & $x$ & 68.8 & 76.5 & $x$ & $x$ & $x$ & $x$ & $x$ & 21 \\
\hline & $x$ & $x$ & 68.5 & 76.5 & $x$ & $x$ & $x$ & $x$ & $x$ & 19.85 \\
\hline & $x$ & $x$ & 68.1 & 76.9 & $x$ & $x$ & $x$ & $x$ & $x$ & 21.1 \\
\hline & $x$ & $x$ & $x$ & 77.35 & $x$ & $x$ & $x$ & $x$ & $x$ & $x$ \\
\hline & $x$ & $x$ & $x$ & 75.7 & $x$ & $x$ & $x$ & $x$ & $x$ & $x$ \\
\hline & $x$ & $x$ & 77.4 & $x$ & $x$ & $x$ & $x$ & $x$ & $x$ & $x$ \\
\hline & $x$ & $x$ & 53.35 & $x$ & $x$ & $x$ & $x$ & $x$ & $x$ & $x$ \\
\hline & $x$ & $x$ & 72.85 & $x$ & $x$ & $x$ & $x$ & $x$ & $x$ & $x$ \\
\hline & $x$ & $x$ & 70.95 & $x$ & $x$ & $x$ & $x$ & $x$ & $x$ & $x$ \\
\hline & $x$ & $x$ & 70.85 & $x$ & $x$ & $x$ & $x$ & $x$ & $x$ & $x$ \\
\hline & $x$ & $x$ & 70.2 & $x$ & $x$ & $x$ & $x$ & $\mathrm{x}$ & $x$ & $x$ \\
\hline & $x$ & $x$ & 70.2 & $x$ & $x$ & $x$ & $x$ & $x$ & $x$ & $x$ \\
\hline \multirow[t]{17}{*}{ QM 20825} & DV4 & 116.8 & 79.05 & 87.2 & $x$ & $x$ & $x$ & $x$ & $x$ & $x$ \\
\hline & DV5 & 101.85 & 78.95 & 88.95 & $x$ & $x$ & $x$ & $x$ & $x$ & $x$ \\
\hline & DV6 & 102.25 & 79.15 & 88.9 & $x$ & $x$ & $x$ & $x$ & $x$ & $x$ \\
\hline & DV7 & 102.9 & 70.3 & 79.95 & $x$ & $x$ & $x$ & $x$ & $x$ & $x$ \\
\hline & DV8 & 92.15 & 66.2 & 80 & $x$ & $x$ & $x$ & $x$ & $x$ & $x$ \\
\hline & DV9 & 92 & 66.45 & 81.65 & $x$ & $x$ & $x$ & $x$ & $x$ & $x$ \\
\hline & DV10 & 103.8 & 83 & 96.45 & $x$ & $x$ & $x$ & $x$ & $x$ & $x$ \\
\hline & DV11 & 101.9 & 79.15 & 87 & $x$ & $x$ & $x$ & $x$ & $x$ & $x$ \\
\hline & DV12 & 101 & 79 & 86.05 & $x$ & $x$ & $x$ & $x$ & $x$ & $x$ \\
\hline & DV13 & 116.8 & 82.7 & 92.25 & $x$ & $x$ & $x$ & $x$ & $x$ & $x$ \\
\hline & DV14 & 116 & 82.95 & 92.05 & $x$ & $x$ & $x$ & $\mathrm{x}$ & $x$ & $x$ \\
\hline & DV15 & 116.1 & 89.8 & 103.2 & $x$ & $x$ & $x$ & $x$ & $x$ & $x$ \\
\hline & DV16 & 116 & 89 & 103 & $x$ & $x$ & $x$ & $x$ & $x$ & $x$ \\
\hline & DV17 & 110.5 & 95.1 & 101.2 & $x$ & $x$ & $x$ & $x$ & $x$ & $x$ \\
\hline & DV18 & 109.95 & 94.05 & 100.5 & $x$ & $x$ & $x$ & $x$ & $x$ & $x$ \\
\hline & DV19 & 109.9 & 95.75 & 102.25 & $x$ & $x$ & $x$ & $x$ & $x$ & $x$ \\
\hline & DV20 & 108.6 & 88.6 & 106.5 & $x$ & $x$ & $x$ & $x$ & $x$ & $x$ \\
\hline
\end{tabular}


VAKIL, Webb, \& CoOK: Plesiosaur Vertebrae

\begin{tabular}{|c|c|c|c|c|c|c|c|c|c|c|}
\hline Specimen & $\begin{array}{c}\text { Vertebra } \\
\text { Position/ } \\
\text { vertebra no. }\end{array}$ & CW & CL & $\mathrm{CH}$ & WoZ & Ns Ht & $\mathrm{Nc} \mathrm{Ht}$ & Nc W & Angle & Dbfs \\
\hline & DV21 & 108.95 & 88.75 & 105.5 & $x$ & $x$ & $x$ & $x$ & $x$ & $x$ \\
\hline & DV22 & 110.5 & 85.45 & 100 & $x$ & $x$ & $x$ & $x$ & $x$ & $x$ \\
\hline & DV23 & 102.9 & 61.25 & 71 & $x$ & $x$ & $x$ & $x$ & $x$ & $x$ \\
\hline & DV24 & 102.9 & 61.35 & 71 & $x$ & $x$ & $x$ & $x$ & $x$ & $x$ \\
\hline & DV25 & 96 & 63.15 & 75.55 & $x$ & $x$ & $x$ & $x$ & $x$ & $x$ \\
\hline \multirow[t]{6}{*}{ QM L39 } & CV2 & 81 & 88 & 67 & $x$ & $x$ & $x$ & $x$ & 45 & 9.55 \\
\hline & CV3 & 93.25 & 90.5 & 70.75 & $x$ & $x$ & $x$ & $x$ & 45 & 8.55 \\
\hline & CV13 & 122.85 & 84.4 & 87.6 & $x$ & $x$ & $x$ & $x$ & 25 & 16.35 \\
\hline & CV14 & 103.2 & 74.9 & 81 & $x$ & $x$ & $x$ & $x$ & 25 & 17.3 \\
\hline & CV15 & 104 & 86.15 & 84.65 & $x$ & $x$ & $x$ & $x$ & 30 & 19.3 \\
\hline & CV16 & 114.1 & 85.5 & 81.15 & $x$ & $x$ & $x$ & $x$ & 15 & 20.75 \\
\hline \multirow[t]{2}{*}{ Isolated PL } & PL1 & 76.65 & 77.05 & 66.15 & $x$ & $x$ & $x$ & $x$ & 45 & 6.9 \\
\hline & PL2 & 78.4 & 81.1 & 64.2 & $x$ & $x$ & $x$ & $x$ & 45 & 6.15 \\
\hline QM F171282 & $\mathrm{x}$ & 108.4 & 98.8 & 88.35 & $\mathrm{x}$ & $\mathrm{x}$ & $\mathrm{x}$ & $\mathrm{x}$ & 35 & 12.05 \\
\hline
\end{tabular}

\section{APPENDIX TABLE 2.}

Queensland Museum Collections sample numbering for the associated vertebrae of specimen QM F11050 (Eromangasaurus australis).

\begin{tabular}{cclc}
\hline Current number & Other number & \multicolumn{1}{c}{ Description } & Trip \\
\hline QM F11050 & GSQ F10552 & Posterior of skull & 1 \\
QM F11050 & AM F60056 & Anterior of skull & 2 \\
QM F12216 & GSQ F10550b & Cervical vertebra & 1 \\
QM F12217 & GSQ F10551 & Two cojoined vertebrae & 1 \\
QM F12218 & GSQ F10550a & Ventral impression of 12216 & 1 \\
QM F12219 & na & Two vertebrae not in contact & 2 \\
\hline
\end{tabular}




\section{APPENDIX FIGURE 1.}

Taphonomic interpretations for RM FR436. A. Specimen RM FR436 showing sequence based on size with uniform shearing direction resulting from toppling to either side before shearing. $\mathbf{B}$. Hypothesis 1, with vertebrae oriented according to size and toppling either direction. C. Hypothesis 2, with two sections of the neck deposited on different sides. D. Hypothesis 3 , with vertebrae oriented randomly, prior to shearing.

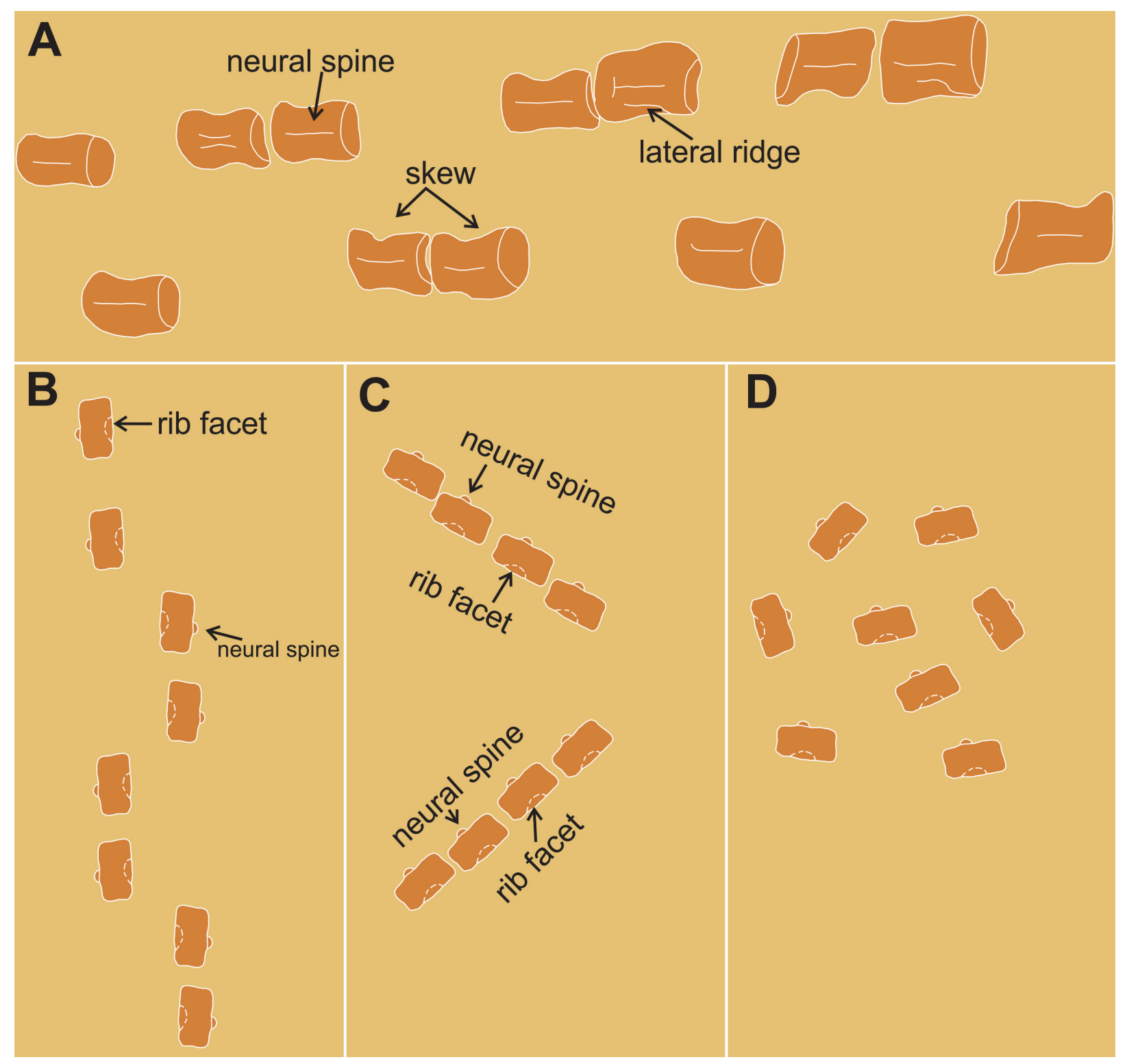




\section{APPENDIX FIGURE 2.}

Plot for height index $(\mathrm{HI})$ against breadth index $(\mathrm{BI})$ for Australian plesiosaurians and non-Australian elasmosaurids. Data for QM F3567 and RM FR271 from Sachs (2004); Opallionectes andamookaensis from Kear (2005a); Elamosaurus platyurus, Thalassomedon haningtoni, Callawayasaurus colombiensis and Cm Zfr 115 from O'Keefe and Hiller (2006); Aristonectes quiriquinensis from Otero et al. (2014); Albertonectes vanderveldei from Kubo et al. (2012); Vegasaurus molyi from O'Gorman el. (2015); Tuarangisaurus keyesi from Hiller et al. (2017); AMNH FARB 1495, AMNH FARB 5835, Styxosaurus snowii, and AMNH FARB 2554 from Otero (2016); Aristonectes parvidens from O'Gorman (2016a); Kawanectes lafquenianus from O'Gorman (2016b); Lagenanectes richterae from Sachs et al. (2017) and Jucha squalea from Fischer et al. (2020).

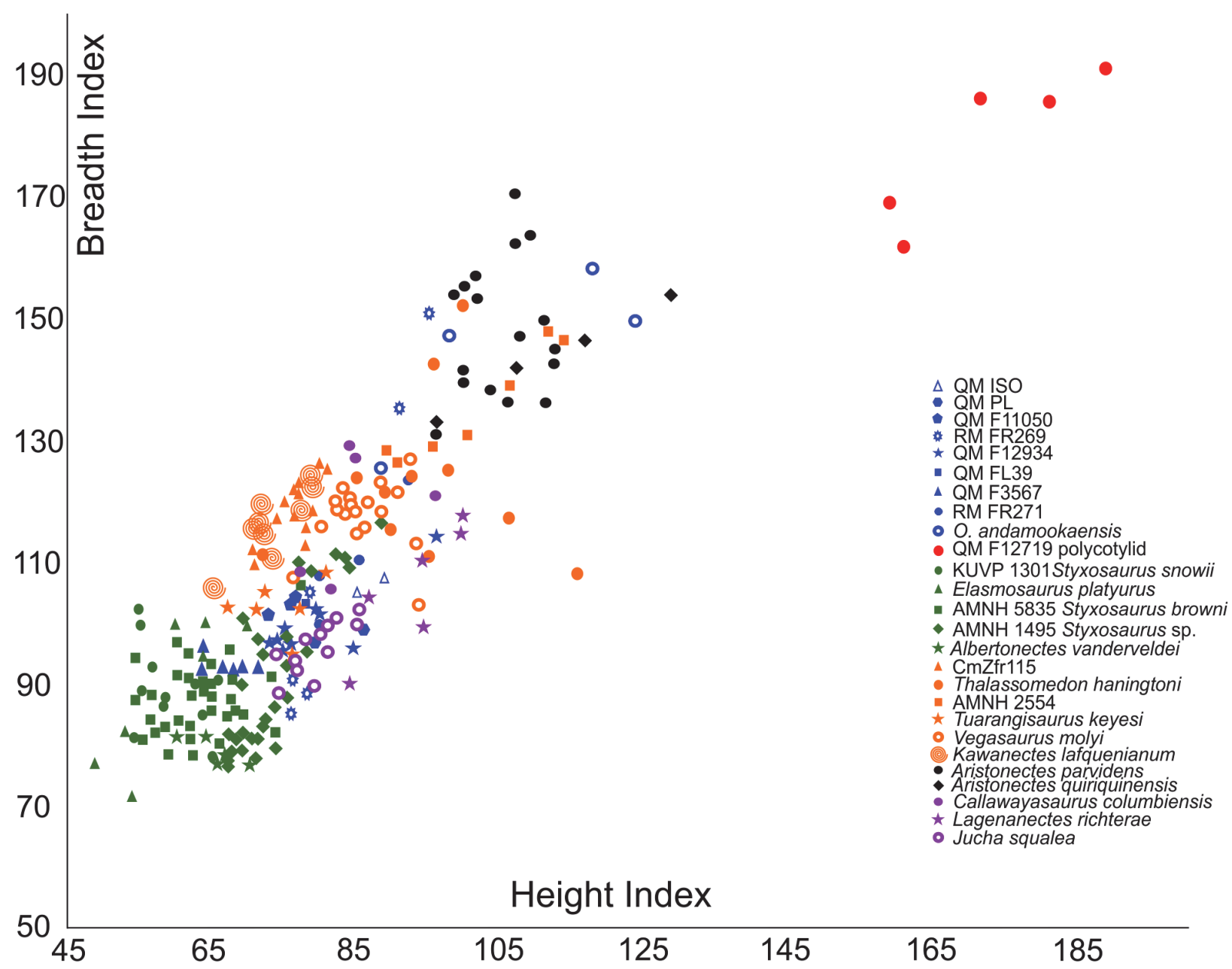




\section{APPENDIX FIGURE 3.}

Plot for vertebral index (VLI) against breadth-height index (BHI) for Australian plesiosaurians and non-Australian elasmosaurids. Data for QM F3567 and RM FR271 from Sachs (2004); Opallionectes andamookaensis from Kear (2005a); Elamosaurus platyurus, Thalassomedon haningtoni, Callawayasaurus colombiensis and Cm Zfr 115 from O'Keefe and Hiller (2006); Aristonectes quiriquinensis from Otero et al. (2014); Albertonectes vanderveldei from Kubo et al. (2012); Vegasaurus molyi from O'Gorman el. (2015); Tuarangisaurus keyesi from Hiller et al. (2017); AMNH FARB 1495, AMNH FARB 5835, Styxosaurus snowii, and AMNH FARB 2554 from Otero (2016); Aristonectes parvidens from O'Gorman (2016a); Kawanectes lafquenianus from O'Gorman (2016b); Lagenanectes richterae from Sachs et al. (2017) and Jucha squalea from Fischer et al. (2020).

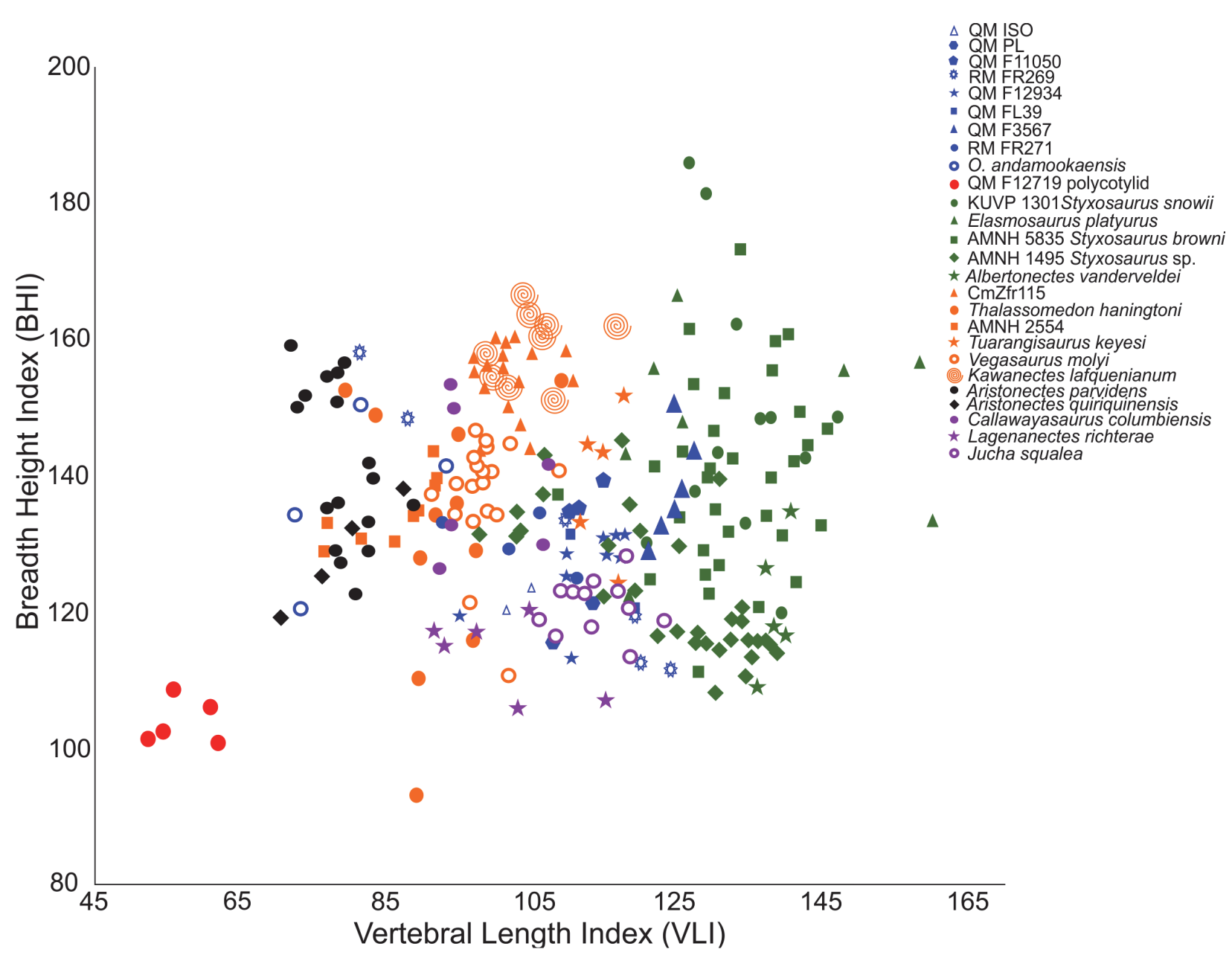




\section{APPENDIX FIGURE 4.}

Principal Components Analysis for anterior cervicals of Australian xenopsarians (including polycotylid QM F12719) and non-Australian elasmosaurids using shape variables. Data for QM F3567 and RM FR271 from Sachs (2004); Opallionectes andamookaensis from Kear (2005a); Elamosaurus platyurus, Thalassomedon haningtoni, Callawayasaurus colombiensis and $\mathrm{Cm}$ Zfr 115 from O'Keefe and Hiller (2006); Aristonectes quiriquinensis from Otero et al. (2014); Albertonectes vanderveldei from Kubo et al. (2012); Vegasaurus molyi from O'Gorman el. (2015); Tuarangisaurus keyesi from Hiller et al. (2017); AMNH FARB 1495, AMNH FARB 5835, Styxosaurus snowii, and AMNH FARB 2554 from Otero (2016); Aristonectes parvidens from O'Gorman (2016a); Kawanectes lafquenianus from O'Gorman (2016b); Lagenanectes richterae from Sachs et al. (2017) and Jucha squalea from Fischer et al. (2020).

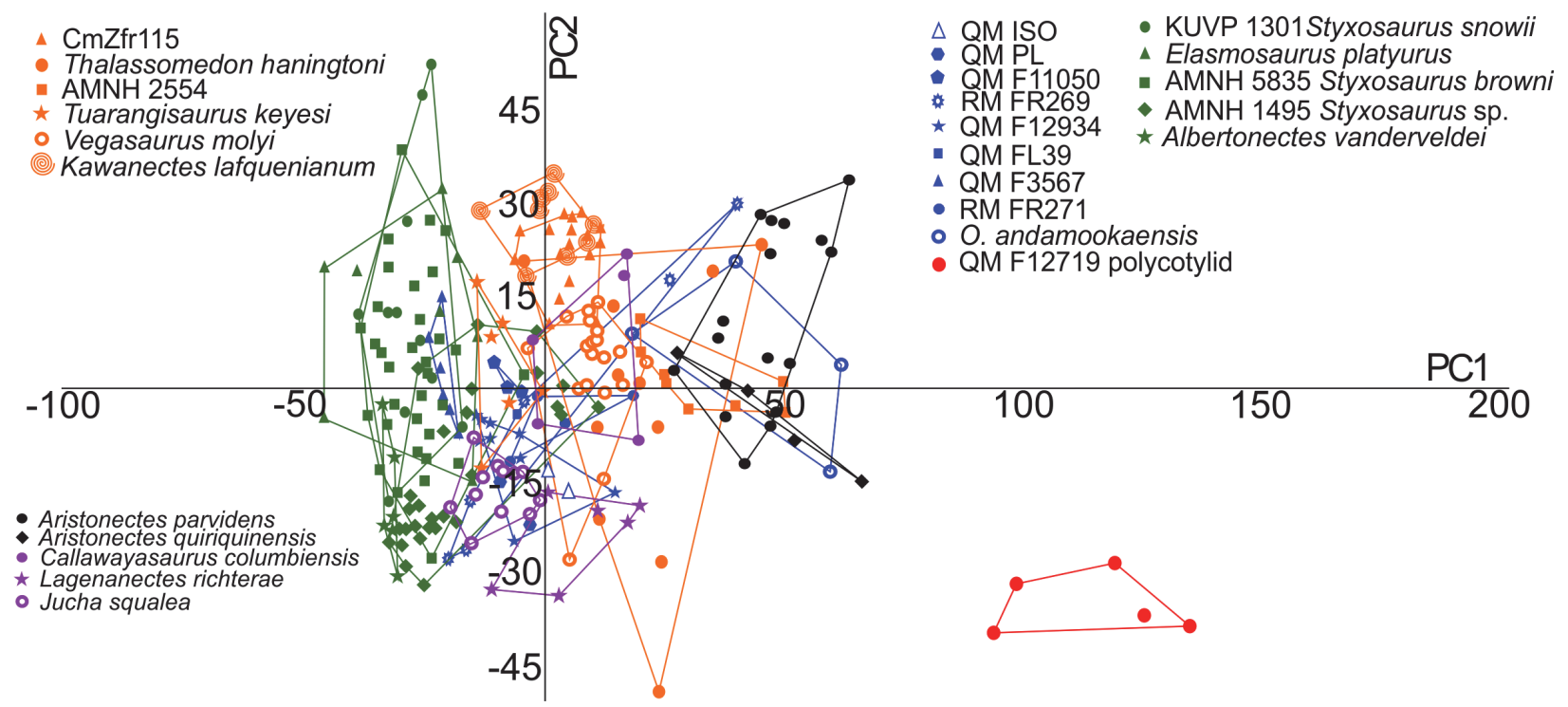




\section{APPENDIX FIGURE 5.}

Principal Components Analysis for posterior cervicals of Australian xenopsarian specimens and non-Australian elasmosaurids using shape variables. Data for QM F3567 and RM FR271 from Sachs (2004); Opallionectes andamookaensis from Kear (2005a); Elamosaurus platyurus, Thalassomedon haningtoni, Callawayasaurus colombiensis and Cm Zfr 115 from O'Keefe and Hiller (2006); Aristonectes quiriquinensis from Otero et al. (2014); Albertonectes vanderveldei from Kubo et al. (2012); Vegasaurus molyi from O'Gorman el. (2015); Tuarangisaurus keyesi from Hiller et al. (2017); AMNH FARB 1495, AMNH FARB 5835, Styxosaurus snowii, and AMNH FARB 2554 from Otero (2016); Aristonectes parvidens from O'Gorman (2016a); Kawanectes lafquenianus from O'Gorman (2016b); Lagenanectes richterae from Sachs et al. (2017) and Jucha squalea from Fischer et al. (2020).

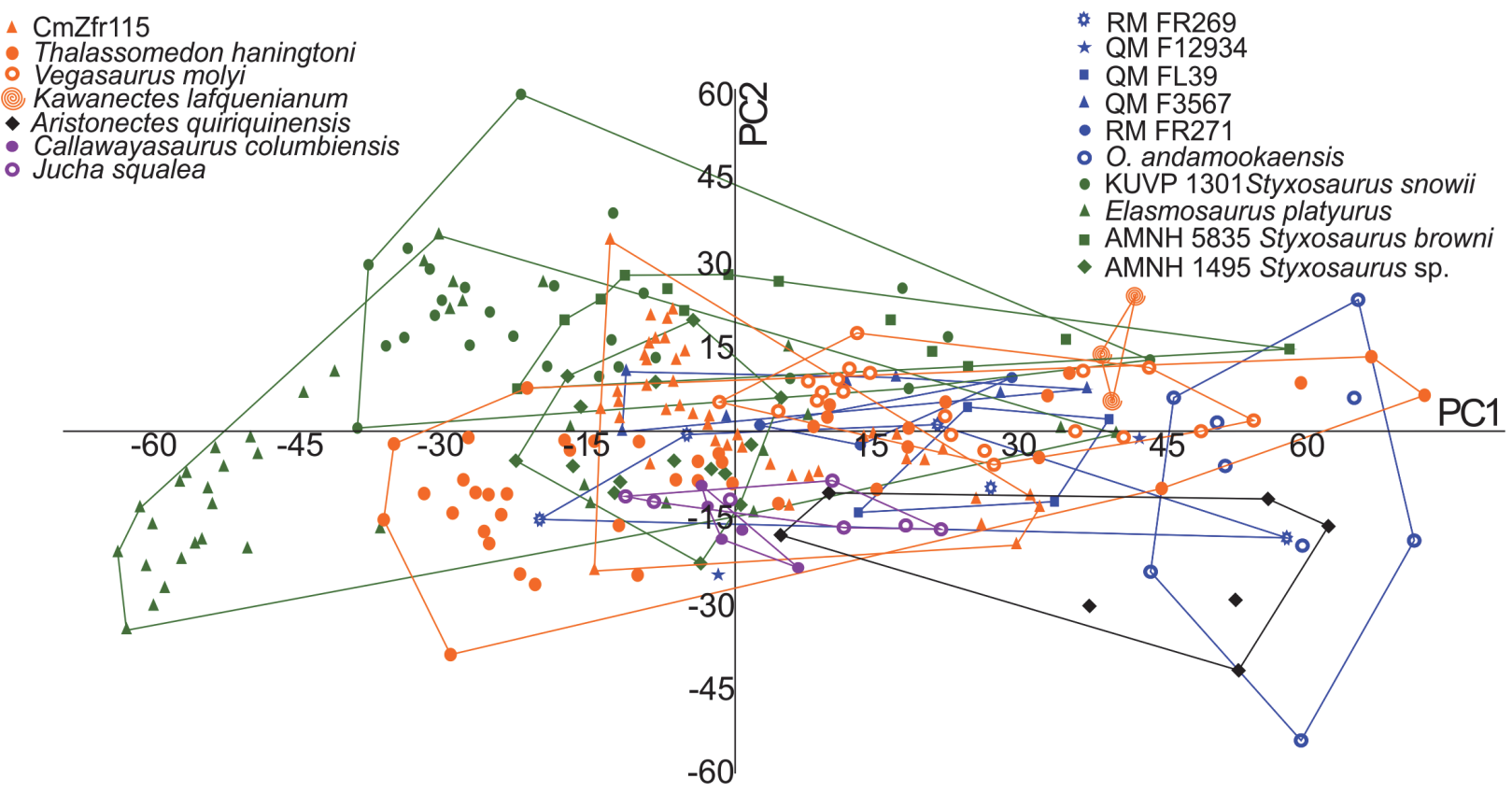

\section{APPENDIX TABLE 3.}

PCA scores, \% variance and eigenvalues for shape variables for posterior cervicals of newly described Australian xenopsarian specimens (including previously described QM F3567 from Sachs, 2004 and including polycotylid QM F12719) and posterior cervicals of non - Australian plesiosauromorph specimens. Data for QM F3567 and RM FR271 from Sachs (2004); Opallionectes andamookaensis from Kear (2005a); Elamosaurus platyurus, Thalassomedon haningtoni, Callawayasaurus colombiensis and Cm Zfr 115 from O'Keefe and Hiller (2006); Aristonectes quiriquinensis from Otero et al. (2014); Albertonectes vanderveldei from Kubo et al. (2012); Vegasaurus molyi from O'Gorman el. (2015); Tuarangisaurus keyesi from Hiller et al. (2017); AMNH FARB 1495, AMNH FARB 5835, Styxosaurus snowii, and AMNH FARB 2554 from Otero (2016); Aristonectes parvidens from O'Gorman (2016a); Kawanectes lafquenianus from O'Gorman (2016b); Lagenanectes richterae from Sachs et al. (2017) and Jucha squalea from Fischer et al. (2020).

\begin{tabular}{lccc}
\hline & PC 1 & PC 2 & PC 3 \\
\hline $\mathrm{HI}$ & 0.54329 & -0.4349 & 0.71812 \\
$\mathrm{BI}$ & 0.82681 & 0.12873 & -0.54756 \\
$\mathrm{BHI}$ & 0.14569 & 0.89123 & 0.42952 \\
Eigenvalue & 870.552 & 245.535 & 2.91016 \\
\% variance & 77.798 & 21.942 & 0.26007 \\
\hline
\end{tabular}




\section{APPENDIX TABLE 4.}

PCA scores, \% variance and eigenvalues for SD-normalised data (cf. Vakil et al., 2020) for anterior cervicals of newly described Australian xenopsarian specimens (including polycotylid QM F12719) and anterior cervicals of non - Australian plesiosauromorph specimens. Data for QM F3567 and RM FR271 from Sachs (2004); Opallionectes andamookaensis from Kear (2005a); Elamosaurus platyurus, Thalassomedon haningtoni, Callawayasaurus colombiensis and $\mathrm{Cm} \mathrm{Zfr}$ 115 from O'Keefe and Hiller (2006); Aristonectes quiriquinensis from Otero et al. (2014); Albertonectes vanderveldei from Kubo et al. (2012); Vegasaurus molyi from O'Gorman el. (2015); Tuarangisaurus keyesi from Hiller et al. (2017); AMNH FARB 1495, AMNH FARB 5835, Styxosaurus snowii, and AMNH FARB 2554 from Otero (2016); Aristonectes parvidens from O'Gorman (2016a); Kawanectes lafquenianus from O'Gorman (2016b); Lagenanectes richterae from Sachs et al. (2017) and Jucha squalea from Fischer et al. (2020).

\begin{tabular}{lccc}
\hline \multicolumn{1}{c}{ Loadings } & PC 1 & PC 2 & PC 3 \\
\hline sdCW & 0.58584 & -0.44901 & 0.67467 \\
sdCL & 0.55382 & 0.82958 & 0.071199 \\
sdCH & 0.59166 & -0.33194 & -0.73468 \\
Eigenvalue & 2.68097 & 0.257741 & 0.06129 \\
\% variance & 89.366 & 8.5914 & 2.043 \\
\hline
\end{tabular}

\section{APPENDIX FIGURE 6.}

Principal Components Analysis for anterior cervicals of Australian xenopsarian specimens (including polycotylid QM F12719) and non-Australian elasmosaurids using SD-normalised data (cf. Vakil et al., 2020). Data for QM F3567 and RM FR271 from Sachs (2004); Opallionectes andamookaensis from Kear (2005a); Elamosaurus platyurus, Thalassomedon haningtoni, Callawayasaurus colombiensis and $\mathrm{Cm}$ Zfr 115 from O'Keefe and Hiller (2006); Aristonectes quiriquinensis from Otero et al. (2014); Albertonectes vanderveldei from Kubo et al. (2012); Vegasaurus molyi from O'Gorman el. (2015); Tuarangisaurus keyesi from Hiller et al. (2017); AMNH FARB 1495, AMNH FARB 5835, Styxosaurus snowii, and AMNH FARB 2554 from Otero (2016); Aristonectes parvidens from O'Gorman (2016a); Kawanectes lafquenianus from O'Gorman (2016b); Lagenanectes richterae from Sachs et al. (2017) and Jucha squalea from Fischer et al. (2020).

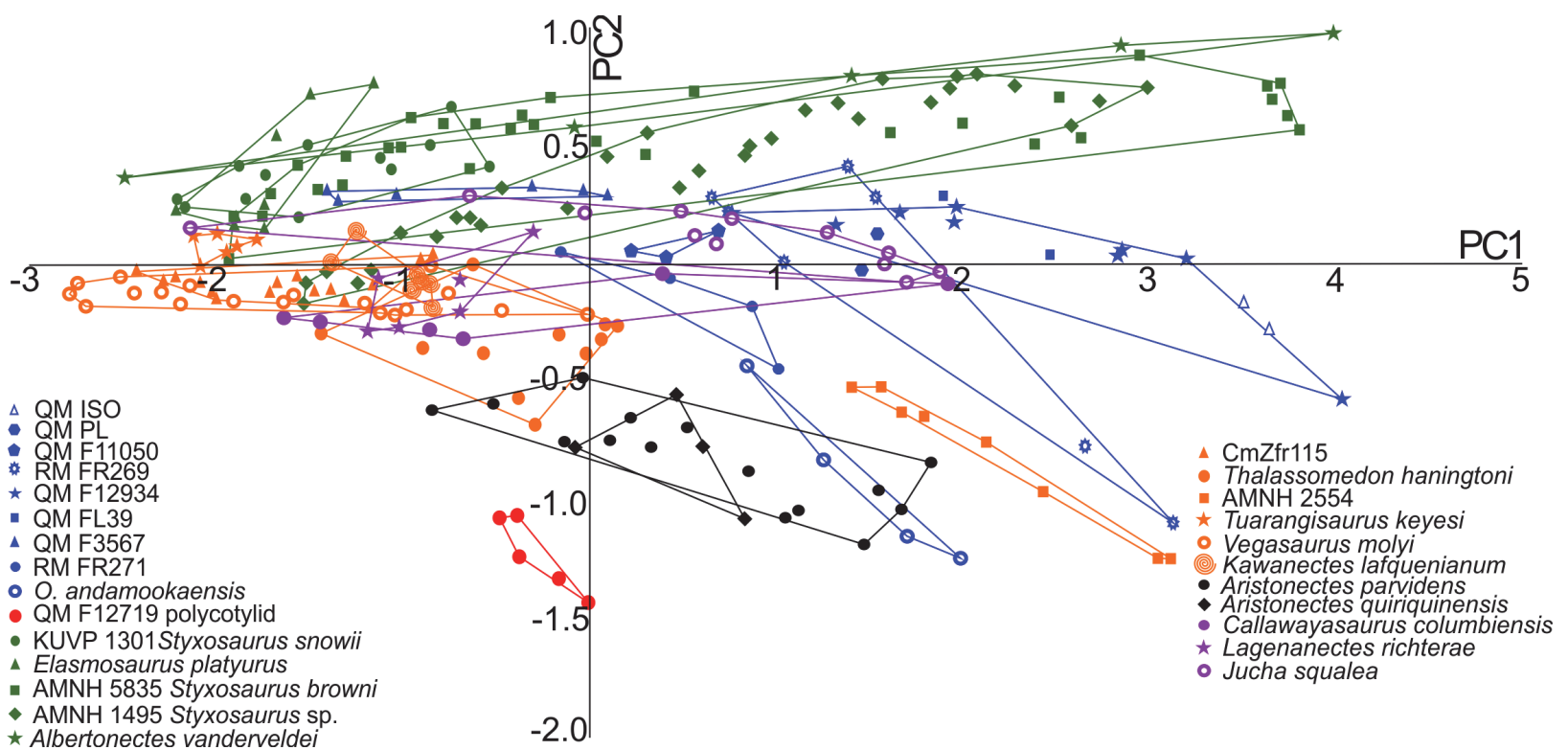




\section{APPENDIX FIGURE 7.}

Plot of PCA versus $\mathrm{CH} / \mathrm{CW}$ for Australian plesiosaurians and non-Australian elasmosaurids. A. $\mathrm{PC} 1$ versus $\mathrm{CH} / \mathrm{CW}$. B. PC2 versus $\mathrm{CH} / \mathrm{CW}$. Data for QM F3567 and RM FR271 from Sachs (2004); Opallionectes andamookaensis from Kear (2005a); Elamosaurus platyurus, Thalassomedon haningtoni, Callawayasaurus colombiensis and Cm Zfr 115 from O'Keefe and Hiller (2006); Aristonectes quiriquinensis from Otero et al. (2014); Albertonectes vanderveldei from Kubo et al. (2012); Vegasaurus molyi from O'Gorman el. (2015); Tuarangisaurus keyesi from Hiller et al. (2017); AMNH FARB 1495, AMNH FARB 5835, Styxosaurus snowii, and AMNH FARB 2554 from Otero (2016); Aristonectes parvidens from O'Gorman (2016a); Kawanectes lafquenianus from O'Gorman (2016b); Lagenanectes richterae from Sachs et al. (2017) and Jucha squalea from Fischer et al. (2020).
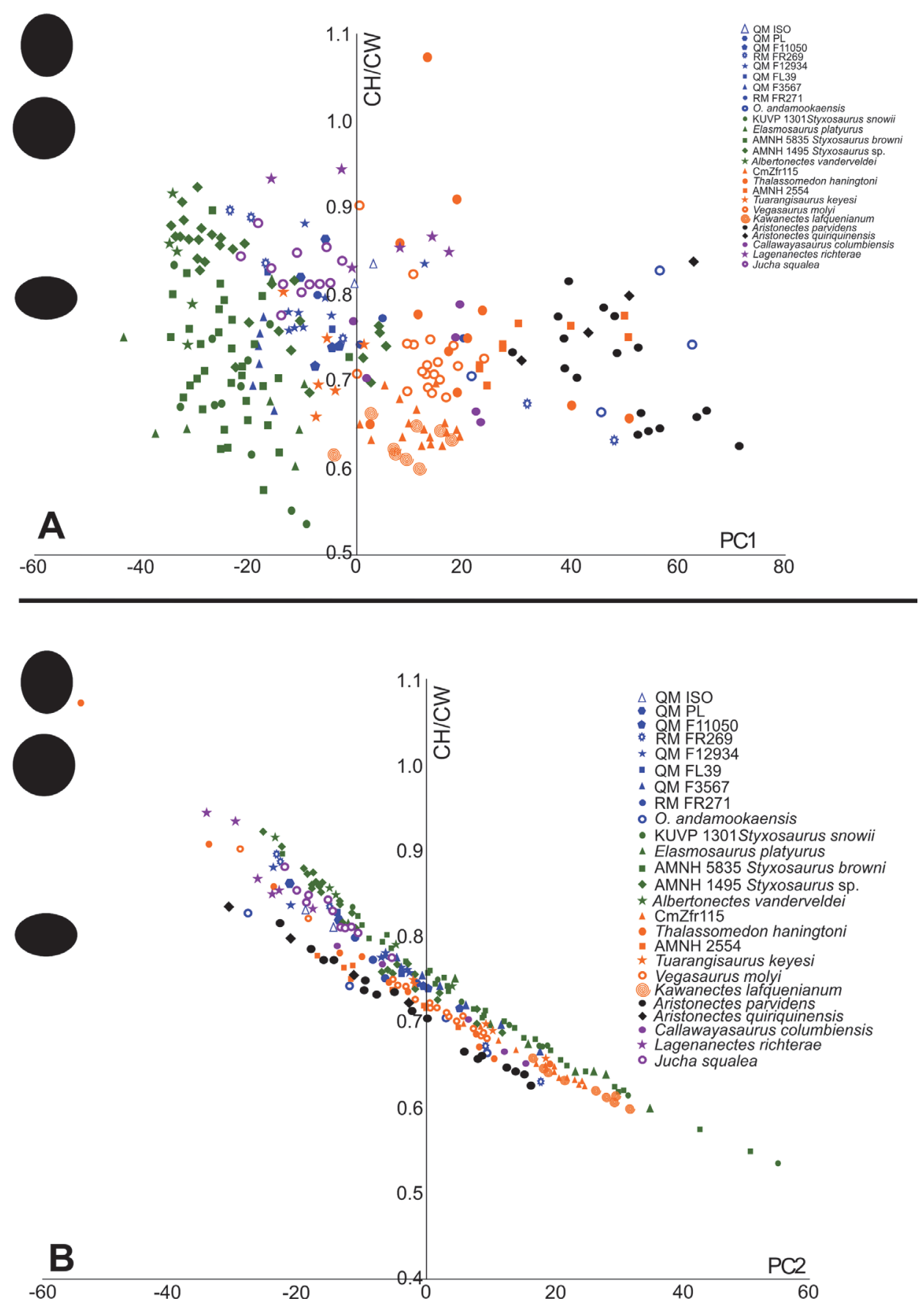


\section{APPENDIX FIGURE 8.}

Principal Components Analysis versus Vertebral Length Index for Australian plesiosaurians and non-Australian elasmosaurids. A. PC1 versus VLI. B. PC2 versus VLI. Data for QM F3567 and RM FR271 from Sachs (2004); Opallionectes andamookaensis from Kear (2005a); Elamosaurus platyurus, Thalassomedon haningtoni, Callawayasaurus colombiensis and Cm Zfr 115 from O'Keefe and Hiller (2006); Aristonectes quiriquinensis from Otero et al. (2014); Albertonectes vanderveldei from Kubo et al. (2012); Vegasaurus molyi from O'Gorman el. (2015); Tuarangisaurus keyesi from Hiller et al. (2017); AMNH FARB 1495, AMNH FARB 5835, Styxosaurus snowii, and AMNH FARB 2554 from Otero (2016); Aristonectes parvidens from O'Gorman (2016a); Kawanectes lafquenianus from O'Gorman (2016b); Lagenanectes richterae from Sachs et al. (2017) and Jucha squalea from Fischer et al. (2020).
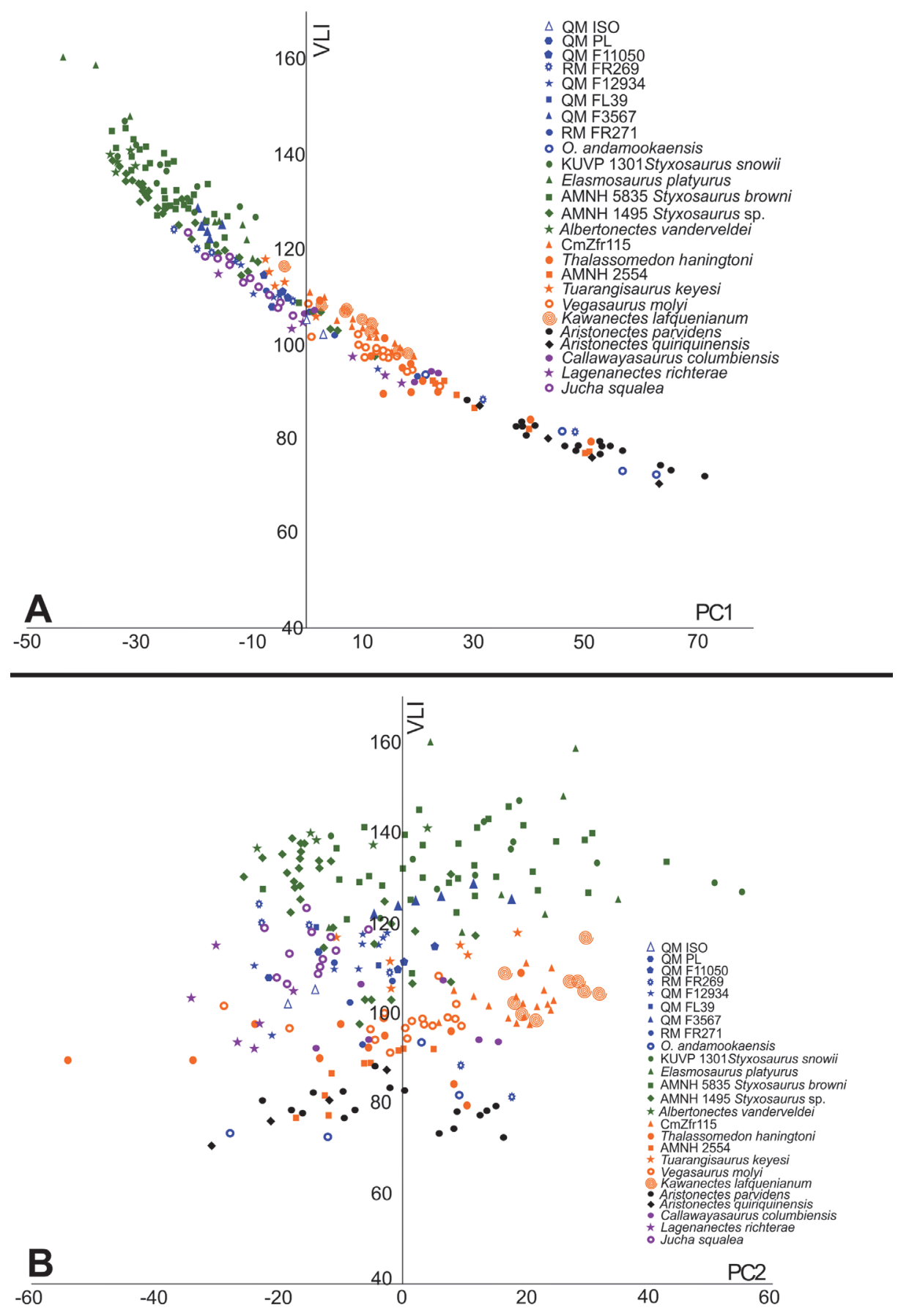